\title{
Osteoarthritis: a rehabilitative approach in general practice
}

Citation for published version (APA):

Heuts, P. H. T. G. (2006). Osteoarthritis: a rehabilitative approach in general practice. [Doctoral Thesis, Maastricht University]. Drukkerij SchrijenLippertzHuntjens. https://doi.org/10.26481/dis.20060210ph

Document status and date:

Published: 01/01/2006

DOI:

10.26481/dis.20060210ph

Document Version:

Publisher's PDF, also known as Version of record

\section{Please check the document version of this publication:}

- A submitted manuscript is the version of the article upon submission and before peer-review. There can be important differences between the submitted version and the official published version of record.

People interested in the research are advised to contact the author for the final version of the publication, or visit the DOI to the publisher's website.

- The final author version and the galley proof are versions of the publication after peer review.

- The final published version features the final layout of the paper including the volume, issue and page numbers.

Link to publication

\footnotetext{
General rights rights.

- You may freely distribute the URL identifying the publication in the public portal. please follow below link for the End User Agreement:

www.umlib.nl/taverne-license

Take down policy

If you believe that this document breaches copyright please contact us at:

repository@maastrichtuniversity.nl

providing details and we will investigate your claim.
}

Copyright and moral rights for the publications made accessible in the public portal are retained by the authors and/or other copyright owners and it is a condition of accessing publications that users recognise and abide by the legal requirements associated with these

- Users may download and print one copy of any publication from the public portal for the purpose of private study or research.

- You may not further distribute the material or use it for any profit-making activity or commercial gain

If the publication is distributed under the terms of Article $25 \mathrm{fa}$ of the Dutch Copyright Act, indicated by the "Taverne" license above, 


\title{
OSTEOARTHRITIS:
}

A REHABILITATIVE APPROACH IN GENERAL PRACTICE

\author{
Peter H.T.G. Heuts
}


Illustration: Joop Noordkamp and Beernd Noordkamp

Cover design and layout: lingrid Schreibers, SRL, Hoensbroek.

Printed by: Drukkerij SchrijenLippertzHuntjens, Voerendaal

The printing of this thesis is financially supported by the Dutch Arthritis Association (Nationaal Reumafonds) and the Rehabilitation Foundation Limburg (Stichting Revalidatie Limburg).

All rights are reserved. No part of this publication may be reproduced or transmirted in any form or by any means, without permission in writing form of the copyright owner.

Osteoardhritis: a rehabiliative approach in general practice/Peter H.T.G. Heuts - Thesis University Maastricht - With references - With summary in Dutch

ISBN: 90-9020339-7

ISBN-13: 978-90-9020339-3

(C) 2006 Peter H.T.G. Heuts, Maastricht, The Nerherlands 


\title{
OSTEOARTHRITIS:
}

\section{A REHABILITATIVE APPROACH IN GENERAL PRACTICE}

\author{
PROEFSCHRIFT \\ ter verkrijging van de graad van doctor \\ aan de Universireit Maastricht, \\ op gezag van de Rector Magnificus, \\ Prof. mr. G.P.M.F. Mols \\ volgens het besluit van het College van Decanen, \\ in het openbaar te verdedigen \\ op vrijdag 10 februari 2006 om 14.00 uur \\ door
}

Petrus Hubertus Theodorus Gerardus Hetuts 


\section{Promatores}

Prof. dr. C.P. van Schayck

Prof. dr. R.A. de Bie

Prof. dr. C. van Weel (UMC, St. Radboud)

\section{Beoordelingscommissie}

Prof. dr. S. van der Linden (voorzitter)

Prof. dr. J.A. Knotmerus

Prof. dr. J. Dekker (Vrije Universiteit Amsterdam)

Prof. dr. D.T. Wade (Oxford Centre for Enablement, Oxford, UK; Universiteir

Maastricht)

The studies in this thesis are supported by grants from the Dutch Arthritis Association (Nationaal Reumafonds) and the Rehabilitation Foundation Limburg (Stichting Revalidarie Limburg). 
WE MUST CONTINUE TO MAKE BOLD ATTEMPTS TO MEET THE CHALLENGE OF PREVENTING CHRONIC MUSCULOSKELETAL PAIN.

KNOWLEDGE TO DATE has LAID A GOOD FOUNDATION, BUT THE HOUSE IS YET TO BE BUILT.

$$
\text { Stevern J. Lintort }
$$

"The challenge of prewenting chronic musculoskeletal pain", 1994. 


\section{CONTENTS}

PAGE

CHAPTER ONE

General introduction.

Osteoarthritis, a rehabilitative approach in general practice.

CHAPTER TWO

Self-management in osteoarthritis of hip or knee:

A randomized, controlled trial in a primary health care setting.

CHAPTER THREE

Is a self-management program in general practice cost-effective in patients with osteoarthritis?

CHAPTER FOUR

Assessment of readiness to change in patients

with osteoarthritis. Development and application of a new questionnaire.

CHAPTER FIVE

Pain-related fear and daily functioning in patients with osteoarthritis. Novel investigations with the Tampa Scale for Kinesiophobia.

CHAPTER SIX

General discussion 
PAGE

SUMMARY

SAMENVATTING

143

APPENDIX A:

153

The European Definition of General Practicel

Family Medicine (WONCA)

DANKWOORD

159

Curriculum Vitae

LIST OF PUBLICATIONS 
Outline 10

The author's point of view 11

Osteoarthritis: its main characteristics and consequences

Specific issues in general care for osteoarthritis patients

A rehabilitative approach offers opportunities in managing osteoarthritis

What is a "stepped-care approach" and how is it related to primary care?

A brief description of the content of the thesis 


\section{CHAPTER ONE}

GENERAL INTRODUCTION

OSTEOARTHRITIS,

A REHABILITATIVE APPROACH IN GENERAL PRACTICE 


\subsection{OUTLINE}

This doctoral thesis is entitled: Osteoarthritis, a rehabilitative approach in general practice. The backbone of the work is a study on the effectiveness of a self-management programme for osteoarthritis patients, based on up-to-date understandings of osteoarthritis (1) and self-management (2), and performed in a primary health care serring $(3,4)$. Along with the results of a randomized controlled trial several adjacent studies are presented, for example about diagnostic issues, about the influence of painrelated fear on daily functioning in osteoarthritis parients, about some aspects of costbenefit and a stepped-care approach for the enormous group of patients with osteoarthritis.

In this chapter the main topics of the current thesis will be introduced. We will start with a short personal note. Thereafter, the following questions will be addressed:

1. What are the main characteristics of osteoarthritis and its consequences?

2. What are specific issues in general care for osteoarthritis patients?

3. Why do we refer to the current approach as a rehabilitative approach?

4. What is the use and usefulness of self-management in osteoarthritis patients?

5. What is meant with "a stepped care approach" and why is it considered to be helpful in the care for osteoarthritis patients?

After the introductory explanations, the main research questions will be described, followed by an overview of the chapters in the current dissertation.

Because the results of the present studies are (or are to be) separately published as articles in international peer reviewed journals considerable overlap between the chapters is inevitable. We deliberately did not choose to rewrite most of the chapters based on these arricles in order to provide readers the opportunity to read them separately. The general introduction as well as the general discussion offers an overview providing the links between the different studies and in the end the overall conclusions of the whole study project. 


\subsection{THE AUTHOR'S POINT OF VIEW}

To begin, some personal remarks are given here to illustrate the author's point of view, explaining his choice of the studies presented in this thesis.

In 1993 I started working as a consultant in rebabilitation medicine in Hoensbroeck Rehabilitation Centre at the Deparment for Patients with Rhewmatic Diseases andor Chronic Pain Conditions. I was impressed by the diffowlties and the problems in daily life of patients with chronic pain problems. At the same time, I also expevionced the promising opportunities of cognitiv-bebavional interventions in this group. I became involved in several randomized controlled trials on cognitive-bebavional interventions for chronic pain patients (5-7) and learned a lot in applying this in daily practice working with our team at Hoensbroeck Rehabilitation Centre. Attending the 7th World Congress on Patn (Paris, august 1993; organized by the LASP, Intemational Organization for the Study of Pain) was another inspiring and infuential experience (8). Knowledge acquined from that congress still steer part of my work. For instance, at least three plenary lectures presented at that congress were of influence in the choice and elaboration of studies in this theis (Keefe (9), Linton (10), VonKorf (11)). Keefe offered a state-af-the-art presentation on the bohavional perspective, tackling controversies and underscoring its importance (9). Linton presented a convincing plea for the prevention of chronic pain prablems. He described two main challenges in this freld: first, the need to develop screening procedures that would belp ws efficiently identifying persons at risk: and second, the challenge to implement early interventions preventing chronic problems: (10). VonKorf described the promise and the problems of pain management in primary care settings, thus enabling the development of an agenda for cinical and research work (11). These wnderstandings were very belpful for me in focusing efforts in the vast area of chronic pain and the research bere presented is to an important extent influenced due to this. 


\subsection{OSTEOARTHRITIS: ITS MAIN CHARACTERISTICS AND CONSEQUENCES}

Osteoarthritis $(O A)$ is a clinical syndrome characterised by joint pain and stiffness, usually described in parhological terms as a condition of cartilage degeneration, subchondral bone stiffening, and active new bone formation (1). In the patient, $O A$ is mainly perceived as joint pain, (morning) stiffness and loss of function $(12,13)$. On physical examination patients with $\mathrm{OA}$ often have tenderness on palpation, bony enlargement, crepitus on motion, and/or limitation of joint mocion (14). OA is a chronic musculoskeletal disorder, which can affect multiple joints in the human body. The condition of the joint cartilage can degenerate progressively, while simultaneously active new bone formation (i.e. osteophytes) can develop as well as loosening of ligaments and joint capsulae. Moreover, loss of muscle strength can occur, which is shown to be of importance in the development and maintenance of pain and disability in patients with OA (15).

$\mathrm{OA}$ is a disorder with a high prevalence $(16,17)$. From data collected in a nationwide three-month study in Dutch general practices, prevalence was estimated to be 14/1000 subjects for $\mathrm{OA}$ of the hip and $23 / 1000$ for the knee (18). In a recent nationwide survey ( $\mathrm{n}=3664$ ) Picavet and co-workers investigated health related quality of life in multiple musculoskeletal diseases (19). The worst quality of life parrerns were found for OA of the hip and knee, osteoporosis, rheumatoid arthritis and fibromyalgia (19). Since the incidence of $O A$ increases with age, it is evident that in an ageing western population like the Dutch, OA is a growing health care burden.

The goals of contemporary management of the patient with OA consist of control of pain and improvement in function and health-related quality of life, with avoidance, if possible, of adverse effects of therapy (14). In current evidence based reviews on treatment in OA pharmacologic, nonpharmacologic and surgical trearment modalities are described $(1,14,20)$. 
In a recent report -available on internet (www.medisin.ntnu.no/wonca) - the discipline of general practice/family medicine is described, as well as the professionals tasks and the core competencies required of general practitioners (21). (See for a summary Appendix A). The characteristics that define the discipline relate to several abilities that every specialist family doctor should master. These key abilities are clustered into six core competencies:

1. Primary care management,

2. Person-centered care,

3. Specific problem solving skills,

4. Comprehensive approach,

5. Community orientation,

6. Holistic modeling.

Looking at these definitions, professional tasks and core competencies, it can easily be concluded that the care for people with OA fits nicely in general practice. However, several challenges concerning managing $O A$ in a general care setting still are to be met. First, when a person with joint complaints visits a general practitioner the main complaint is for instance "stiffness", "pain", "limited motion" or "hampered function". In the early stages it is often difficult to establish a clear diagnosis and prognosis. Furthermore, even when the diagnosis $\mathrm{OA}$ is beyond doubt, several questions remain, for example concerning severity of the disorder $(20,22-30)$, level of funcrional impairment (31-33), and its impact on participation $(13,34)$.

Second, person-oriented care not only requires somatic diagnostics and adequate pain relief, but also self-care enhancing measures. In order to be able to know what personcentered measures are required, the diagnostic procedures need to be to a certain degree "broad" enough, i.e. comprehensive and holistic. For this purpose biopsychosocial analyses are very helpful (35). Figure 1 shows the biopsychosocial model of arthritis pain and disability developed by Keefe et al (35). This model shows the opportunities and links with the characteristics of general care/family medicine, such as personcentered care by applying a comprehensive approach and holistic modeling in a community context. 
Third, what comprehensive treatment modalities are available that really meet the questions and problems of $O A$ patients and are evidence based and tested for application in general care? For this purpose a rehabilitative approach and selfmanagement is explored and researched (see below). The current thesis adopts a biopsychosocial approach.

Biomedical Interventions

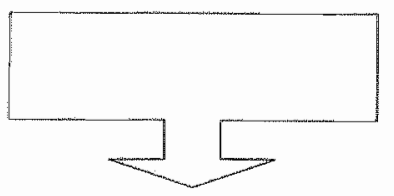

Biological Hactors:

- carrilage dtumage

- joint diegenerarion

- inflammation

- surelling

- decondirionairge

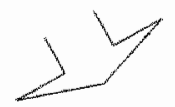

Pspchological Factors:

- helplessness

- depression

- coping

- self-efficacy

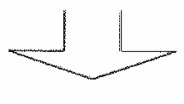

Arthritis Pain

and

\section{Psychospcial Interventions}

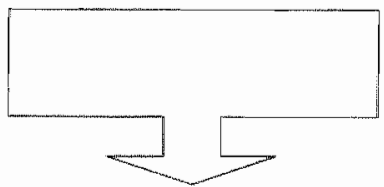

Social Factors:

- social support

- socio-economic status

- spouse/cariegiver responses.

\section{Disability}

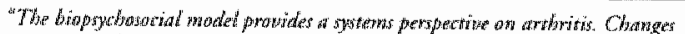

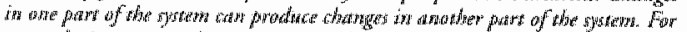

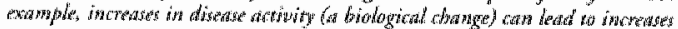

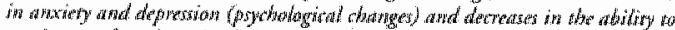

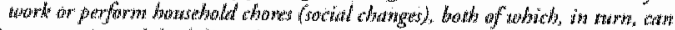

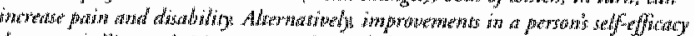

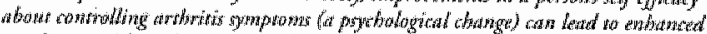

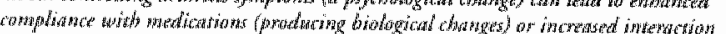

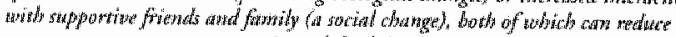
pain and aliberiling

Figure 1: Biopochosacial model of arthrivis pain (Keefe et al (35)) 
$\mathrm{OA}$ is considered to be an incurable chronic disorder. Since no successful treatments for OA exist that resolve all signs and symptoms of the disease, the person with this condition (36) has to manage both the consequences of pain and stiffness and the consequences of treatment procedures (e.g. medications, exercises, operations, changes in lifestyle, etcetera). A number of OA symptoms as well as several of the prescribed treatments influence daily activiries like work, family life and leisure time, which may hamper quality of life considerably $(19,33,36)$. Therefore, people with OA are not only -as is the case in many orher chronic conditions- confronted with changed bodily functions but frequently also need to change activity-patterns. This may require a rehabilitative approach.

The aim of rehabilitation has been described (37) as to mobilize the resources of individuals with impairment(s) so that, by having realistic goals, they may achieve optimal life satisfacrion.

A certain number of OA-patients are successful in adapting to the constraints of the disease (36). However, very often this is not the case and several problems remain, such as restricted mobility, chronic pain, fatigue, anxiety and depression, as well as restrictions in participation (employment, household duties, leisure activities, et cetera) $(13,38)$. If adaptation to the consequences of $O A$ is not successful or incomplete, patients may need and seek professional help and assistance. In this context rehabilitative strategies can be used to enhance adaptation (39).

The core features of rehabilitation are described by Wade as follows (40):

- co-ordinated, multidisciplinary team-work, by

- a team with expertise and an interest in disability, who

- actively involve the parient and family in the process, which is set within

- an explicitly recognized framework encompassing all aspects of illness.

An important example of such a recognized framework is the International Classification of Functioning, Disability and Health (ICF) (34). ICF belongs to the "family of international classifications" developed by the World Health Organization (WHO) for application relating various aspects of health. The ICF is complementary to the International Classification of Diseases (ICD), the latter providing an etiological framework and classification of diseases, while the ICF focuses on components of functioning and disability. ICF provides a description of situations with regard to 
human functioning and its restrictions and serves as a framework to organize this information (34). In ICF bodily functions and structures are recognised as well as environmental and personal factors that influence activities and participation of a person.

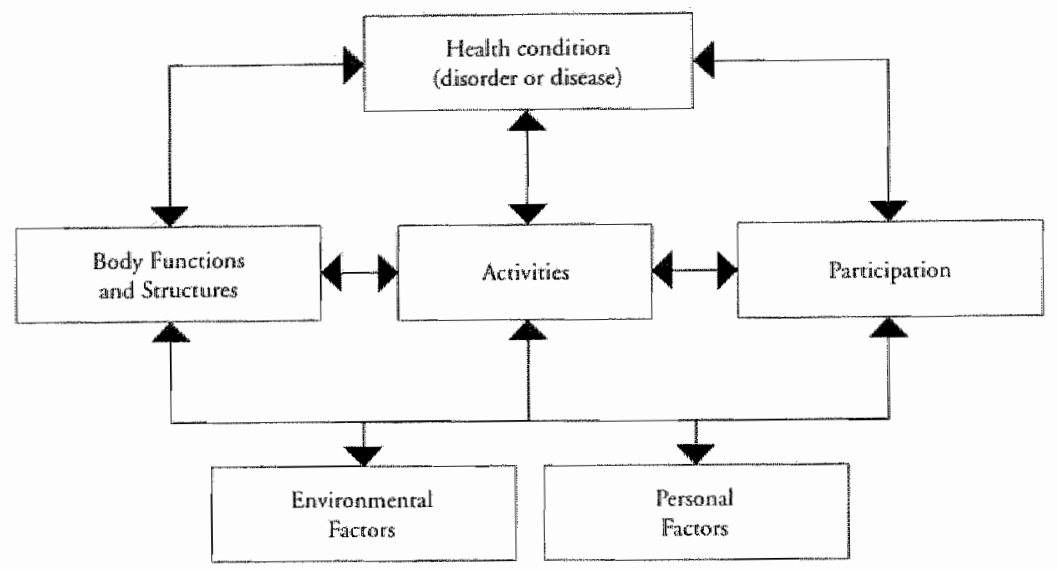

Figure 2: Interactions berween components of $\mathrm{ICF}$

As has been briefly pointed out above, the management of OA is partly pharmacological and surgical, but also educational and non-pharmacological (for example in applying exercise programs, assistive devices, bracing, joint protection and energy conservation) (14). A recent guideline emphasizes that improved communication and education are important factors in decreasing pain and improving function in patients with OA (14). A rehabilitative approach, therefore, is helpful in integrating the various treatment modalities in the care of $O A$ patients.

Managing OA requires -as in many other chronic conditions- the acquaintance and training of skills to enhance and maintain functioning with growing physical impairments. Therefore, the mainstay in management should be a rehabilitative approach. This presupposes for example the development of self-regulative compensatory techniques ("how to perform when it is not anymore possible in the usual, accustomed manner?"). It also requires appropriate pain amelioration through for example medication and other modalities like relaxation or physical modalities. A way to achieve this may be a self-management programme as part of a rehabilitative approach. 
For arthritic conditions the prototype of a self-management program has been developed, introduced and widely tested by Lorig and co-workers (41-44). In a recent editorial Lorig summarizes the main characteristics of self-management programmes and the results of three decades of studies on the subject (45). Two major differences between mere education and evidence-based self-management are intervention content and process. First, self-management starts with the idea of partnership between patients and health professionals. The beliefs and problems of people with chronic conditions are central. Health professionals are asked what knowledge patients must have and what behaviours they must change to manage their condition (45). These two points of view are then combined into the content of a self-management program. Second, self-management programs are built on self-efficacy theory $(2,44,46,47)$. They are designed to enhance patients' confidence to manage their lives while living with chronic disease. Lorig (45) summarizes: "In simple terns, this theory states that if people think they can do something, they probably can. "This has important consequences for the process of the intervention, which must contain skills mastery, modelling, (re-) interpretation of symptoms and enhancement of social persuasion.

In a self-management program people are taught how to take greater initiative for their health and their personal functioning. In short, these kind of programs can be described as including the following issues: proximal goal setting combined with selfincentives as motivators to increase level of activity, pain control techniques and managing medication programs, self-relaxation, problem-solving and self-diagnostic skills for monitoring and interpreting changes in one's health status, as well as skills in locating community resources (2). 


\subsection{WHAT IS A "STEPPED-CARE APPROACH" AND HOW IS IT RELATED TO PRIMARY CARE?}

General care is where most patients seeking medical care for painful joint conditions are seen. Since $O A$ is such a high prevalent joint disorder, it is of utmost importance to organize general care service in a cost-effective and evidence based manner. Von Korff has proposed an individualized stepped-care approach for this purpose (48). Stepped care is a framework for organizing services based on the intensity of patients' needs. It has been described as a useful strategy for organizing general care services for health problems such as hypertension, hypercholesterolemia, nicotine dependence, depression, alcohol dependence, behaviorally based problems and low back pain (49, $50)$.

In general, a stepped approach initially provides the least intensive, and often least expensive, intervention as a first step in improving outcomes. If patients do not experience a favorable result, services are intensified -sometimes called "stepped-up"to the next level of intervention that typically is more complex and probably more expensive (51). The obvious benefit of a stepped-care approach is that services are better matched to patients' needs, and excessive, expensive or unnecessary services are minimized resulting in greater efficiency and cost savings (49).

Although Von Korff and coileagues have highlighted back pain as an example for using a stepped-care approach (49-55), the general model for services and the conceptual framework for the delivery of care apply to other ongoing pain problems (e.g., neck pain, rension type headache, and osteoarthritis) (49).

Von Korff discerns three significant challenges in the general care setting for the managenent of chronic pain management (48):

1. The time avatilable for assessment and management of patients in any one contact is brief.

2. General practitioners see patients varying widely in severity and chronicity of their pain condition.

3. At the time of the initial visit it cannot be reliably determined whether a particular patient is likely to have a favorable outcome requiring only acute palliative care or a less favorable long-term outcome that might benefit from subsequent interventions to support effective self-catre. 
This also applies to OA. Given the high prevalence of $O A$ it is very important to develop strategies to meet these challenges. Core fearure of a stepped-care approach is that care is modified based on the patient's outcome. Von Korff proposes the steppedcare approach as a form of care which is personalized to each patient's specific concerns, activity limitations, preferences, and the level of readiness. Also, the level of care is guided by the severity and duration of activity limitations of the patient and the possible concurrent comorbidity, specific fears and worries.

In the general discussion of this thesis the usefulness of this model for the $O A$ population will be discussed further.

\subsection{RESEARCH QUESTIONS}

The aim of this study project was to find out whether self-management of OA of the hip and/or knee in primary care consisting of health-education and training-group sessions administered in general care, followed by maintenance counselling by telephone contacts is effective in terms of relevant outcomes in middle-aged patients (40-60 years). This study was not only set up and analyzed from the individual point of view but also from a societal perspective, meaning that special interest was to be placed on the (early) secondary preventive effects self-management may have in middle-aged OA patients.

The specific research questions formulated for this study were threefold:

1. What are the effects of self-management on pain, functional limitations, selfreported acrivities, quality-of-life and self-efficacy in middle-aged OA patients?

2. Which individual patient-characteristics determine the effectiveness of reaching self-management in middle-aged OA patients in a general health care setting?

3. What are the effects of self-management on health-behavior, health-care consumption, and indirect costs related to $\mathrm{OA}$ in the middle-aged group of $\mathrm{OA}$ patients? 
In chapter 2 a randomized controlled trial on self-management in middle-aged patients with $O A$ is presented (56). This study is performed in general care and 273 patients were involved $(3,4)$. Until now, it represents the second published, randomized controlled trial on self-management in $\mathrm{OA}$ parients in a primary care setting $(57,58)$.

Chapter 3 is about health care urilization, effecriveness of self-management and costs related to OA. In several international publications, self-management programs are presented as having the potential of improving health benefits while reducing health care costs $(42,59)$. Here we present data on health utilization and related costs as well as indirect costs related to $\mathrm{OA}$, which were sampled from the randomized controlled trial described in chapter $2(60)$.

Chapter $\mathbf{4}$ is on the development of a self-report measure for the assessment of the Stages of Change in patients with $\mathrm{OA}$, in order to identify those patients who will benefit most from participating in a self-management program. The Stages of Change model is investigated because it recently received considerable attention in the literature on health promotion and it appears to be potentially helpful in the process of selecting and preparing patients for self-management strategies. However, several critical issues on this model and its use need to be solved.

Chapter 5 describes studies concerning pain-related fear in OA. First, the factorstructure of a widely used questionnaire on pain related fear (the TSK; Tampa Scale on Kinesophobia) is investigated in a sample of OA patients. Second, the role of painrelated fear in OA compared with other factors, such as radiological findings and level of pain intensity, is studied.

The general discussion in chapter $\mathbf{6}$ provides several links between the findings of the separate studies and offers some thoughts and conclusions for both clinical application and further research. 


\subsection{REFERENCES}

1. Brandt K.D., Doherty M., Lohmander L.S.. Osteoarthritis. Oxford: Oxford University Press; 2003.

2. Bandura A. Self-efficacy: the exercise of control. New York: Freeman and Company; 1997.

3. Bosch van den W., Weel van C.. Journaal 2000: Netwerk Academische Huisartspraktijken Nijmegen CMR/NMP. Nijmegen: Universitair Medisch Centrum St.Radboud Nijmegen; 2000.

4. Akker van den M., Metsemakers J.F, Limonard C.B., Knottnerus J.A.. General practice: a gold mine for research. Data and scientific use of the Registration Network Family Practices. Maastricht: Unigraphic, Universiteit Maastricht; 2004.

5. Vlaeyen J.W.S., Teeken Gruben N.J., Goossens M.E.J.B., Rutten van Molken M.P.M.H., Pelt R.A.G.B., van Eek H., et al. Cognitive-educational treatment of fibromyalgia: a randomized clinical trial. I. Clinical effects. J Rheumatol $1996 ; 23(7): 1237-45$.

6. Kole Snijders A.M.J., Vlaeyen J.W.S., Goossens M.E.J.B., Rutten van Molken M.P.M.H., Heurs P.H.T.G., van Breukelen G., et al. Chronic low-back pain: what does cognitive coping skills training add to operant behavioral treatment? Results of a randomized clinical trial. J Consult Clin Psychol 1999;67(6):931-44.

7. Hout van den J.H.C., Vlaeyen J.W.S., Heuts P.H.T.G., Zijlema J.H., Wijnen J.A.. Secondary Prevention of Work-Related Disability in Nonspecific Low Back Pain: Does Problem-Solving Therapy Help? A Randomized Clinical Trial. The Clinical Journal of Pain 2003:19:87-96.

8. Gebhart G.F., Hammond D.L., Jensen T.S., editors. Proceedings of the 7th World Congress on Pain. Seattle: IASP Press; 1994.

9. Keefe EJ., Lefebvre J.. Pain Behavior Concepts: Controversies, Current Status, and Future Directions. In: Gebhart G.F., Hammond D.L., Jensen T.S., editors. Proceedings of the 7 th World Congress on. Pain. Seattle: IASP Press; 1994. p. 127147.

10. Linton S.J.. The Challenge of Preventing Chronic Musculoskeletal Pain. In: Gebhart GF, Hammond DL, Jensen TS, editors. Proceedings of the 7th World Congress on Pain. Seattle: IASP Press; 1994. p. 149-166.

11. VonKorff M.. Perspectives on Management of Back Pain in Primary Care. In: Jensen T.S., editor. Proceedings of the 7 th World Congress on Pain. Seattle: IASP Press; 1994. p. 97-110. 
12. Bock de G.. Peripheral osteoarthritis in general practice. Leiden: Leiden University; 1994.

13. Hopman-Rock M., Kraaimaar F.W., Bijlsma J.W.J.. Quality of life in elderly subjects with pain in the hip or knee. Quality of life research 1997;6:67-76.

14. Altman R.D., Hochberg M.C., Moskowitz R.W., Schnitzer T.J.. Recommendations for the medical management of osteoarthritis of the hip and knee; 2000 update. Arthritis \& Rheumarism 2000;43(9):1905-1915.

15. Steulrjens M.P., Dekker J., van Baar M.E., Oostendorp R.A., Bijlsma J.W.. Muscle strength, pain and disability in patients with osteoarthritis. Clinical Rehabilitation $2001 ; 15(3): 331-341$.

16. Felson D., Zhang Y.. An updare on the epidemiology of knee and hip osteoarthritis with a view to prevention. Arthr Rheum 1998;41:1343-1355.

17. Felson D.T.. Epidemiology of osteoarthritis. In: Brandt K.D., Doherty M., Lohmander L.S., editors. Osteoarthritis. Oxford: Oxford University Press; 2003. p. $8-16$.

18. Ruwaard D., Kramers P., editors.1997: de Som der Delen. Volksgezondheid Toekomst Verkenning. Bilthoven: Rijksinstituut voor Volksgezondheid en Milieu; 1997.

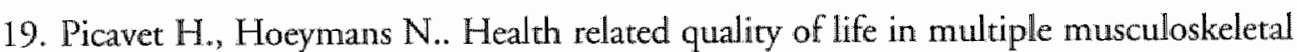
diseases: SF-36 and EQ-5D in the DMC3 study. Ann Rheum Dis 2004;63:723-729.

20. Pendleton A., Arden N., Dougados M., Doherty M., Bannwarth B., Bijlsma J., et al. EULAR recommendations for the management of knee osteoarthritis: report of a task force of the Standing Committee for International Clinical Studies Including Therapeutic Trials (ESCISIT). Annals of the Rheumatic Diseases 2000;59(12):936-944.

21. Allen J., Gay B., Crebolder H., Heyman J., Svab I., Ram P., et al. The European Definitions of the Key Features of the Discipline of General Practice, the Role of the General Practitioner, and a Description of the Core Competencies of the General Practitioner/Family Physician.: WONCA EUROPE (The European Sociery of General Practice/Family Medicine); 2002.

22. Ravaud P., Giraudeau B., Aulely G-R, Drape J-L, Rousselin B., Paolozzi L., et al. Variability in knee radiographing: implication for definition of radiological progression in medial knee osteoarthritis. Ann Rheum Dis 1998;57:624-629.

23. Watt I., Doherty M... Plain radiographic features of osteoarthritis. In: Brandt K.D., Doherty M., Lohmander L.S., editors. Osteoarthritis. Oxford: Oxford University Press; 2003. 
24. Altman R.D., Hochberg M.C., Murphy W.A., Wolfe E., Lequesne M.. Atlas of individual radiographic features in osteoarchritis. Osteoarthritis and Cartilage 1995;3(Supplement A):3-70.

25. Bierma-Zeinstra S., Oster D., Bernsen R., Verhaar J., Ginai A., Bohnen A. Joint space narrowing and relationship with symptoms and signs in adults consulting for hip pain in primary care. The Journal of Rheumatology 2002;29:1713-8.

26. Dennison E., Doherry M. The natural history and prognosis of osteoarthritis. In: Brandt K.D., Doherty M., Lohmander L.S., editors. Osteoarthritis. Oxford: Oxford University Press; 2003. p. 227-233.

27. Hochberg M.C., Altman R.D., Brandt K.D., Clark B.M., Dieppe B.A., Griffin M.R., et al. Guidelines for the medical management of osteoarthritis. Part $\mathbb{1}$. Osteoarthritis of the hip. Arthritis \& Rheumatism 1995;38(11):1535-1540.

28. Hochberg M.C., Altman R.D., Brandt K.D., Clark B.M., Dieppe P.A., Griffn M.R., et al. Guidelines for the medical management of osteoarthritis. Part II: Osteoarthritis of the knee. Arthritis \& Rheumatism 1995;38(11):1541-1546.

29. Lanyon P., O'Reilly S., Jones A., Doherty M.. Radiographic assessment of symptomatic knee osteoarthritis in the community: definitions and normal joint space. Ann Rheum Dis 1998;57:595-601.

30. Ledingham J., Dawson S., Preston B., Milligan G., Doherty M.. Radiographic progression of hospital referred osteoarthritis of the hip. Annals of the rheumatic diseases 1993;52:263-267.

31. Cushnaghan J., Cooper C., Dieppe P., Kirwan J., McAlindon T., McCrae F.. Clinical assessment of osteoarthritis of the knee. Annals of Rheumatic Diseases 1990;49:768-770.

32. Dekker I., Boot B., Woude L.vd, Bijlsma J.W... Pain and disability in osteoarthitis: a review of biobehavioral mechanisms. I Behav Med 1992;15:189-214.

33. Sharma L., Cahue S., Song J., Hayes K., Pai Y-C, Dunlop D.. Physical functioning over three years in knee osteoarthritis. Role of psychosocial, local mechanical, and neuromuscular factors. Arthritis \& Rheumatism 2003:48(12):3359-3370.

34. WHO, Organisation WH. International Classification of Functioning, Disability and Health. Geneva; 2001.

35. Keefe F.J., Smith S.J., Buffington A.L., Gibson J., Studts J.L., Caldwell D.S.. Recent advances and future directions in the biopsychosocial assessment and treatment of arthritis. J Consult Clin Psychol 2002;70(3):640-55. 
36. Hopman-Rock M.. Living with arthritic pain in the hip or knee: disability, health status, physical activity, coping with pain, quality of life, and health care urilization of community-leving elderly people. Utrecht; 1997.

37. Fugl-Meyer A., Branholm I., Fugl-Meyer K.. Happiness and domain-specific life satisfaction in adult northern Swedes. Clinical Rehabilitation 1991;5:25-33.

38. Hopman-Rock M., Kraaimaat F., Bijlsma J.. Physical activity, physical disability and osteoarthritic pain in older adults. Journal of Aging and Physical Activicy 1996:4:324-337.

39. Dijk van A.J.. On Rehabilitation Medicine. A theory-oriented contribution to assessment of functioning and individual experience. Delft: Eburon Publishers; 2001.

40. Wade D.T. Research into rehabilitation. What is the priority? Clinical Rehabilitation 2001;15(3):229-232.

41. Lorig K., Holman H.. Arthritis self-management studies: a twelve-year review. Health Education Quaterly 1993;20(1):17-28.

42. Lorig K.R., Mazonson P.D., Holman H.R. Evidence suggesting that health education for self-management in patients with chronic arthritis has sustained health benefirs while reducing health care costs. Arthritis and Rheumatism 1993;36(4):439-446.

43. Lorig K., Sobel D., Ritter P., al e. Effect of a self-management program on patients with chronic disease. Eff Clin Practice 2001;4:256-262.

44. Lorig K., Bodenheimer T., Holman H., al e. Patient self-management of chronic disease in primary care. JAMA 2002;288:2469-2475.

45. Lorig K.. Self-Management Education. More than a nice extra. Medical care 2003;41(6):699-701.

46. Kanfer $\mathbb{E}$.H., Reinecker H., Schmelzer D.. Selbst-management Therapie: Ein Lehrbuch fur die klinische Praxis. Berlin Heidelberg New York: Springer-Verlag; 2000.

47. Barlow J., Wright C., Sheasby J., Turner A., Hainsworth J.. Self-management approaches for people with chronic conditions: a review. Patient Education and Counseling 2002; 48:177-187.

48. Von Korff M.. Pain management in primary care: an individualized stepped-care approach. In: Turk R.G.D.C., editor. Psychosocial factors in pain: critical perspectives. New York London: The Guilford Press; 1999. p. 360-373. 
49. Pruitt S.D., Von Korff M. Improving the Management of Low Back Pain: a Paradigm Shift for Primary Care. In: Turk D.C., Gatchel R.J., editors. Psychological Approaches to Pain Management. Second ed. New York London: The Guilford Press; 2002.

50. Von Korff M., Gruman J., Schaefer J., Curry S., Wagner E. Collaborative management of chronic illness. Annals of Internal Medicine 1997;127:1097-1102.

51. Von Korff M.. Pain management in primary care: an individualized stepped-care approach. In: Turk R.J.G.D.C., editor. Psychosocial factors in pain: critical perspectives. New York London: The Guilford Press; 1999. p. 360-373.

52. Balderson B.H., Lin E.H., Von Korff M.. The management of pain-related fear in primary care. In: Asmundson G.J., Vlaeyen J.W.S., Crombez G., editors. Understanding an treating fear of pain. Oxford: Oxford University Press; 2004.

53. Balderson B.H., Von Korff M.. The stepped care approach to chronic back pain. In: Linton S, editor. New Avenues for the Prevention of Chronic Musculosskeletal Pain and Disability. Amsterdam: Elsevier; 2002. p. 238-243.

54. Von Korff M.. Perspectives on Management of Back Pain in Primary Care. In: Gebhart G.F., Hammond D.L., Jensen T.S., editors. Proceedings of the 7th World Congress on Pain. Seattle: IASP Press; 1994. p. 97-110.

55. Von Korff M., Tiemens B.. Individualized stepped care of chronic illness. West J Med 2000;134:133-137.

56. Heuts P.H.T.G., Bie de R.A., Drietelaar M., Aretz K., Hopman-Rock M., Bastiaenen CH, et al. Self-Management in Osteoarthritis of Hip or Knee: A Randomized Clinical Trial in a Primary Healthcare Setting. The Journal of Rheumatology 2005;32:543-49.

57. Solomon D.H., Warsi A., Brown-Stevenson T., Farrell M., Gauthier S., Mikels D., et al. Does self-management education benefit all populations with arthritis? A randomized controlled trial in primary care physician network. Journal of Rheumatology 2002;29:362-8.

58. Fries J.F., Lorig K., Holman H.R.. Patient Self-Management in Arthritis? Yes! The Journal of Rheumatology 2003.

59. Wheeler J.R.. Can a disease self-management program reduce health care costs? The case of older women with heart disease. Medical care 2003;41(6):706-15.

60. Goossens M.E.J.B., Rutten-van Mölken M.P.M.H., Vlaeyen J.W.S., Linden van der S.M.J.P.. The cost diary: a method to measure direct and indirect costs in costeffectiveness research. Journal of Clinical Epidemiology 2000;53:688-695. 
Abstract 28

Introduction 29

Methods 30

Measurements 31

Results 37

Discussion $\quad 40$

Acknowledgements

References 44 


\section{CHAPTER TWO}

SELF-MANAGEMENT IN OSTEOARTHRITIS OF HIP OR KNEE: A RANDOMIZED CLINICAL TRIAL IN A PRIMARY HEALTH CARE SETTING

Peter H.T.G. Heuts, ${ }^{1}$, Rob de Bie $^{3}$, Marion Drietelaar ${ }^{2}$, Karin Aretz, Marijke Hopman-Rock ${ }^{4}$, Caroline H.G. Bastiaenen ${ }^{3}$, Job F.M. Metsemakers', Chris van Weel', Onno C.P. van Schayck².

1. Rehabilitation Foundation Limburg, Zandbergsweg 111, 6432 CC Hoensbrock, The Netherlands

2. Department of General Practice, Research Institute CAPHRI, Maastricht Uniwersity, PO. Box 616, $6200 \mathrm{MD}$ Maastricht, The Netherlands

3. Department of Epidemiology, Maastriche University, P.O. Box 616,6200 MD Masstricht, The Nertherlands

4. Department Physical Activity and Health, TNO Prevention and Health, $\mathbb{P} . \mathrm{O}$. Box 2215,2301 CE Leiden, "The Nerherlands

5. Departmenc of Family Medicine, University Medical Cenre St Radboud, Nijmegen, The Netherlands

Keywords: osteoarchritis, self-management, tandomized controlled trial, primary health care.

Published in: The Joumal of Rheumatology 2005;32:543-49. 


\subsection{A BSTRACT}

\section{Objective}

To assess in a primary health care serting the efficacy of a self-management programme in middle-aged patients with osteoarthritis.

\section{Desïgn}

Two-group randomized controlled trial. The experimental intervention was compared with care-as-usual. Durarion of follow-up was 21 months after start of the intervention.

\section{Setting}

Recruiment of participants, treatments and follow-up measurement all were performed in a general health care setring and was done by $\mathrm{GP}_{\mathrm{s}}$ and via advertisements. Self-management was instructed by physiotherapists.

\section{Participants}

Two-hundred-and-seventy-three patients (age between 40 and 60 years) with osteoarthriris in hip(s) and/or knee(s).

\section{Main outcome measures}

Pain severity in hip(s) and/or knee(s), the main other complaints and functional limitations.

\section{Results}

After written informed consent the 297 patients were randomized: 149 selfmanagement and 148 controls. Before start of the intervention 24 participants withdrew for practical reasons (17 in self-management and 7 in control group). At 3 months follow-up the intervention group significantly improved on VAS pain knee (0.67; SD 2.10) and WOMAC (2.46; SD 9.49), while the control group showed stable VAS knee pain (0.01; SD 2.00) and deterioration on WOMAC (0.53; SD 9.47). At 21 months follow-up the differences between the intervention and control group increased in favour of the intervention group (VAS pain knee: $\mathrm{p}$ values from 0.023 at 3 months to 0.004 at 21 months; WOMAC $p$-values from 0.030 to 0.022 ).

\section{Conclusions}

The self-management programme positively influenced knee pain and self-reported funcrional level in this sample of osteoarthritis patients. Interestingly, the differences between the groups increased during follow-up in favour of the intervention group. 


\subsection{INTRODUCTION}

General practitioners are frequently consulted by patients with osteoarthritis of the hip or knee. From data collected in a nationwide three-month study in Dutch general practices, prevalence was estimated to be $14 / 1000$ subjects for osteoarthritis of the hip and 23/1000 for the knee (1). Thus, in the Netherlands (total population about 16 million) approximately 775,000 patients of all ages with this chronic joint disorder are currently registered with the general practitioner, of whom approximately $17 \%$ are aged between 40-60 years and can be considered relatively young (2). The average consultation frequency of osteoarthritis patients is about 2.8 per year, adding up to a toral of over 6 million consultations in general practice each year. For the patient osteoarthritis is mainly characterised by joint pain, (morning) stiffness and loss of function $(3,4)$. Every year abour half of all prevalent cases are referred for radiographic examination, a quarter is referred to a physiotherapist for symptomatic treatment and 15,000 hip and 7,000 knee operations are performed as a result of osteoarthritis. Consequently, the total costs of health-care for osteoarthritis are substantial and increasing as the Durch population is ageing. In order to reduce the burden of hip and knee osteoarthritis on the national health-care budget in the furure, it is important to find out whar the secondary preventive effects of teaching self-management are in relatively young patients with osteoarthritis. This sub-population is of particular interest since $a$ ) information on the effecriveness of self-management in this group is sparse $(5,6)$ and $b$ ) from a societal point of view, the gains of self-management may be enormous considering the fact that many osteoarthritis patients within the specific agegroup involved are still active on the labour-market and probably will be for several years to come.

Over 50\% of incident osteoarthritis cases are being treated by the general practitioner alone, usually by means of (pain-) pharmacotherapy and referral to physiorherapy. Among general practitioners there is currently no consensus about the optimal treatment of osteoarthritis in primary care (3) although there is a need for unambiguous, practical self-management programs, both from the side of health-care professionals as from patients themselwes (7). Recent international guidelines stress the importance of self-management for osteoarthritis patients $(8,9)$.

Several studies show evidence concerning the efficacy of self-management (10-12) and/or irs separate components (exercise $(13,14)$, education $(15,16)$, counselling (17)) 
in osteoarthritis of the hip and knee in patients over 55. One study also indicated a significant reduction of health care costs in the long term (11). Recently, the results of a Dutch trial demonstrated the efficacy and feasibility of the program developed within the framework of this particular study $(4,18,19)$. Significant effects were observed on the outcome measures of pain, muscle-function, self-efficacy and knowledge of osteoarthritis. However, all the studies mentioned above have focussed on elderly patients with osteoarthritis ( $>55 \mathrm{yrs}$ ), and although the self-management approach is scientifically well grounded for these older patients, there is a complete lack of information on the possible secondary preventive effects of self-management in younger osteoarthritis patients ( $<55 \mathrm{yrs}$ ). Ir is of great relevance to investigate whether it is possible to beneficially influence prognosis in this younger age-group with a method with proven efficacy in the older age group.

The present paper presents the results of a randomized controlled trial on selfmanagement in a primary health care setting with middle-aged osteoarthritis patients.

\subsection{METHODS}

\section{Participants}

Participants of this study were recruited both from academic registration networks of primary care practices $(20,21)$ and by local advertisements (see figure 1). Two morbidity registration networks in the Netherlands, representing approximately 77 general practitioners were collaborating in this study $(2,20)$. Additionally, letters were sent to 309 other general practices in Limburg (The Netherlands), which resulted in 15 more general practitioners willing to refer patients to this study.

The study population consisted of patients with osteoarthritis age 40 to 60 years. For inclusion in the study the following criteria were used:

1. Characteristic radiological appearance;

2. Heberden's nodes;

3. Joint disorder of at least 3 monchs' duration, with no constitutional symptoms and at least three of the following:

a. Irregular swelling;

b. Crepitation;

c. Stiffness or limitation of movement; 
d. Normal ESR, rheumatoid tests and uric acid;

e. Patient over age of 40 .

In the current study the ICHPP-2 Criteria were administered, because these were used in previous studies in general health care settings (22) while the ACR-criteria were recently (23) described not to be validated in general health care. In the group participants that entered the study via advertisements $(n=124)$ both ACR and ICHPPC criteria were checked showing full agreement in this subpopulation.

Patients with rheumatoid arthritis, ankylosing spondylitis and gout were excluded.

\subsection{MEASUREMENTS}

\section{At baseline:}

The following baseline characteristics of the participants (table 1) were described before the start of the treatment: age, gender, radiological findings hips and knees, socioeconomic status and the way of entering the trial (referred by general practitioner or advertisement).

\section{Radiographs}

A rating score was obtained according to the scoring system proposed by Kellgren (24). In the current study, radiographs were taken at baseline from the hips and the knees. All radiographs were scored by an independent, experienced radiologist who was blinded for treatment. The Kellgren score obtained in each of the four joints (two knees and hips) ranged from 0 to 5 and presented in table 2 .

\section{Socioeconomic status}

In this report level of education and job participation are described (table 1).

\section{Ontcome:}

There was a patient follow-up with measurements at 3 months and 21 months. Primary outcome measures were pain severity and self-reported functional status.

\section{Pain severity}

Pain intensity in the hips and knees was measured with visual analogue scales (VAS). Since the signs and symptoms of OA vary over time, three VAS-measurements were 


\section{Patient characteristics (n)}

Number of participanis

Age in years (mean/SD)

Giender:

- male

- Cemale

BMI

Recruitment:

- general practice

- advertisement

SES

- education low

- educarion middle

- edacation ligh

- paying job: yes/no

Primary outcone measures (mean/SD)

WOMAC

PSFS

VAS knee pain

VAS hip pain

Stcondary ontcome naeasures (mean/SD)

$\mathrm{TSK}$

ASES

$\$ 636$

- Heald change

- Mrysical functioning

- General heidn perceprion

Walle 1. Bartine hamacristing (total $x=273$ )
132

$51.0(5.0)$ 


\begin{tabular}{|c|c|c|c|c|c|c|}
\hline Score & Description & Criteria & Knee left & Knee right & Hip lefti & Hip right \\
\hline & & & $N=259$ & $\mathrm{n}=259$ & $\mathrm{n}=259$ & $n=259$ \\
\hline 0 & None & No signs of $\mathrm{OA}$ & 55.1 & 49.6 & 37.0 & 35.4 \\
\hline 1 & Doubrful & $\begin{array}{l}\text { Doubrful narrowing of joint space } \\
\text { and possible osteophytic lipping. }\end{array}$ & 20.3 & 23.0 & 28.8 & 30.4 \\
\hline 2 & Minimal & $\begin{array}{l}\text { Definite osteophytes and possible } \\
\text { narrowuing of joint space. }\end{array}$ & 10.5 & 10.9 & 17.1 & 19.8 \\
\hline 3 & Moderate & $\begin{array}{l}\text { Moderate mulciple asteophytes, } \\
\text { definite narnowing of joint space } \\
\text { and some sclerosis and possible } \\
\text { deformity of bone ends. }\end{array}$ & 9.8 & 14.1 & 11.7 & 10.1 \\
\hline 4 & Severe & $\begin{array}{l}\text { Large osteophytes, marked narrowing } \\
\text { of joint space, severe sclerosis and } \\
\text { definite deformity of bone ends. }\end{array}$ & 4.3 & 2.3 & 1.6 & 3.5 \\
\hline 5 & Prosthesis & Joint replaced by prosthesis. & 0 & 0 & 3.9 & 0.8 \\
\hline
\end{tabular}

Table 2" Radiological crizeria for osteoarthritis in percentages (OA) (24)

registered: intensity of pain today, intensity of pain last week, and intensity of pain last month. These three VAS scores strongly correlated (Pearson $\mathrm{r}$ ranged from .806 to .956; all significant at a .01 level). To obtain a reliable and reproducible indication of pain severity, mean VAS scores on these scales were entered in the analyses as a composite score. Anchors of the VAS scales were 'no pain at all' to 'the worst imaginable pain'. Mean scores of the measures are shown in table 1.

\section{Functional status questionnaire}

The WOMAC (Western Ontario and McMaster Universities Osteoarthritis Index) has been developed by Bellany and colleagues aimed to assess outcome in OA trials (2527). This measure is a three-dimensional (i.e., pain, stiffness, physical function), disease-specific (OA), self-administered health status questionnaire, available in Likertand VAS-versions. In this study the Likert version was used. 
Patient Speciftc Functional Status (PSFS)(28)

Every participant was asked to choose the two most salient problems in daily functioning. This is a way of detecting the specific problems of a particular patient. On a visual analogue scale the participant scored the importance of the particular activity from his point of view (from "not important" to "very important"). Thereafter they had to score on a visual analogue scale from the difficulty in performing these two activities: "How difficult was it last week for you to perform this activity?" ("no difficulry" to "impossible to perform"). All visual analogue scores were measured on $10 \mathrm{~cm}$ lines.

The following secondary outcome measures were used:

Health related quality of life

General health status was measured with a general health-related quallity of life questionnaire (SF36) (29). For the purpose of cost-effectiveness analyses a second generic quality of life measure was used in the study, the EuroQol (EQ5D), which is further clescribed in chapter 3 of the current thesis $(30,31)$.

\section{Self-efficacy}

Self-efficacy was measured with a questionnaire ASES developed by Lorig et al (32) and in a Dutch-language version was administered by Taal et al (33). A total score is the sum of the scores on the 9 items divided by 9 .

\section{Pain-related fear}

The Dutch version of the Tampa Scale for Kinesiophobia (TSK) was used to assess pain-related fear. The TSK $(34,35)$ is a 17 -item questionnaire that is aimed at the assessment of fear of (re-)injury due to movement. Each item is provided with a 4-point Likert scale with scoring alternatives ranging from "strongly agree" to "strongly disagree". Psychometric properties of the Dutch version of the TSK have found to be good (36).

\section{Stages of Change}

Participants in the study were categorized along the Stages of Change using a questionnaire recently designed (37). During follow these measurements were repeated. 


\section{Procedure}

The study was approved by the Medical Ethical Committee of Maastricht University and the Maastricht University Hospital. Approval was also received from the Review Committee of the Review Committee of the Registration Network Family Practices (RegistratieNet Huisartspraktijken, RNH)(20).

In a randomized controlled clinical trial the effects of a group-wise self-management programme were compared with the effects of care-as-usual in middle-aged (40-60 year) parients with osteoarthritis. Recruitment of participants was done in a general population via family physicians and via advertisements. For the self-management intervention physiotherapists were recruited working in a primary health care setting. Prerequisites for physiotherapists participating in the trial were: fulfilment of the training for the intervention study (3 sessions of each 4 hours) and having the opportunity to work with groups of 6 to 12 patients (instruction room, facilities for exercises, relaxation and reception of partners of the participants). Several meetings for discussion and description of "care-as-usual" were organised with experienced physiotherapists prior to the start of the patient enrolment.

The baseline and outcome measurements were performed by an independent research assistant (with a physiotherapy background) who was blinded for treatment assignment and nor involved in the treatment of participants.

\section{Randomization}

After admission for the study via general practitioner or via advertisement the in- and exclusion criteria were checked. Participants signed an informed consent and were invited for baseline assessment. A computer-generated randomization scheme was prepared and kept by a secretary, who was not involved in patient selection, treatment, and data-gathering and analysis. A patient was included in the study when fulfilling the following: meeting the inclusion criteria, signed informed consent, able to participate (time and place) in the self-management groups if randomised so and complete baseline-measurements.

\section{Intervention: self-management or care-as-usual.}

The self-management programme was based on earlier studies and publications $(4,11$, $17,19,38,39)$ and rewritten and redesigned especially for this study (PH and CB). The self-management intervention consisted of 6 sessions of each 2 hours and was lead by two physiotherapists. These meetings were highly strucrured. Appendix A offers an 


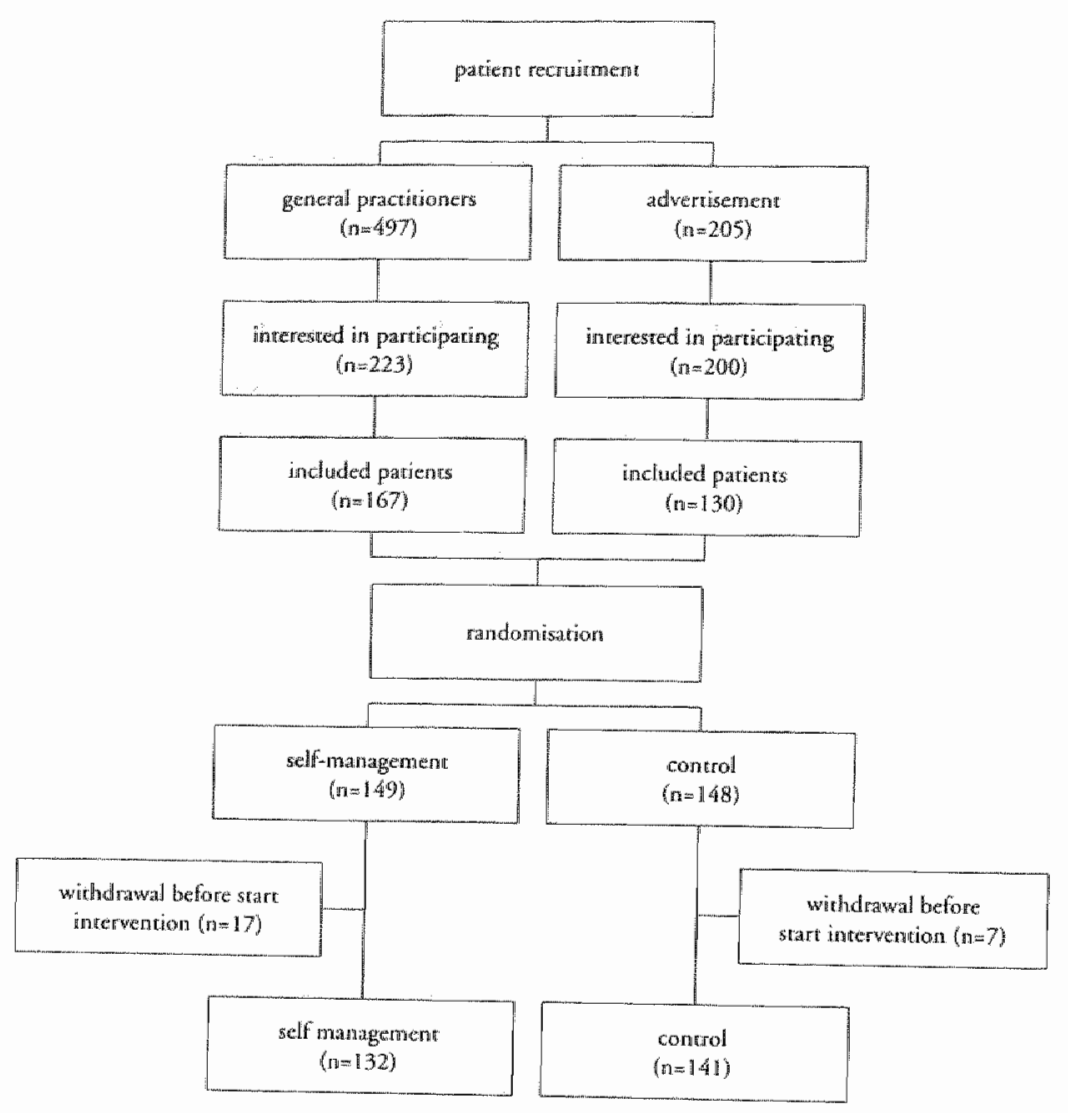

Figure 1: Patient recruitment

overview of the topics per session. Standardized training materials were developed and administered: for example, sheets and audiovisual material used by physiotherapists during the sessions and booklets for participants, as well as a short handbook on osteoarthritis and self-management with an overview of all relevant information. In the self-management programme participants were taught how to take initiative in their personal health and functioning. The programme included the following: Participants learned to use adequate goal setting in combination with self-incentives as motivators to optimize level of activity. A rational adherence to prescribed medication and other treatments was discussed. Self-relaxation was trained both for pain control as well as for improvement of overall well-being. Problem-solving was part of the self-management programme for empowering the participant in handling daily hassles. Self-diagnostic skills were taught for monitoring and interpreting changes in one's health status. 
Participants also received information about community resources and skills were trained to optimize use of health care services. For the intervention applied here the term "self-management" was chosen, because the 6-session intervention resembles the ASMP (Arthritis Self Management Programme) developed by Kate Lorig. It should be mentioned however that the intervention is an example of a cognitive behavioral intervention (CBT) since it includes several techniques such as problem solving and goal setting which are typical CBT interventions (40-50).

Care-as-usual was described as prescribed by family physician or consulted specialist and not influenced.

\section{Data analysis}

All data analyses were done with SPSS statistical sofrware. At baseline mean scores on patient characteristics and outcome measures of both interventions were compared. The baseline status of the study groups was compared with respect to thel distribution of all independent prognostic variables and the baseline values of the outcome variables. Statistical analyses were carried out according to the "intention-to-treat" approach (51). For each individual the differences between baseline and post-treatment scores of the outcome measures were calculated at 3 months and 21 months follow-up. These difference-scores were calculated in such a way that a positive score represents an improvement (e.g. T4 minus T0 of SF36, because a higher score on SF36 represents improvement and T0 minus T4 on VAS of pain, because a lower score represents an improvement), and a negative score represents a deterioration. ANOVA was calculated for the mean difference scores of the both intervention groups.

\subsection{Results}

\section{Study sample}

After written informed consent the 297 patients were randomized: 149 selfmanagement and 148 controls. Before start of the intervention 24 participants withdrew for practical reasons (17 in self-management and 7 in control group). This resulted in a number of 273 participaring osteoarthritis patients (110 male, 163 female). Participants reported moderate pain intensity in the hips (mean score on VAS 3.36; SD 2.77) and knees (mean VAS 4.06; SD 2.66). An evident level of discomfort and disability (mean score on WOMAC: 34; SD 16.13) was noted. Radiological 
changes were reported in $78.4 \%(n=214)$ of the patients, while physical examination showed Heberden's nodes in $15.4 \%(\mathrm{n}=41)$ and crepitation in knees in $66.3 \%$ $(\mathrm{n}=181)$. Stiffness was reported by $88.6 \%(\mathrm{n}=242)$ of participants. In $48.8 \%(\mathrm{n}=135)$ of the patients procedures were performed, e.g. diagnostic arthroscopy $(9.2 \%, n=25)$, menisectomies ( $19.9 \%, \mathrm{n}=57$ ), endoprostheses (hip $4.7 \%, \mathrm{n}=12)$, osteotomy ( $1.4 \%$, $\mathrm{n}=4$ ) and cartilage remodeling (nettoyages $3.2 \%, \mathrm{n}=9$ and "patella shaving" .4 \%, $n=1)$. Table 2 shows the severity of radiological findings assessed with the Kellgren scoring method (24).

\section{Comparability of treatment groups}

Mean scores at baseline characteristics (table 1) were compared between the intervention and control group ( $t$-test for mean group scores) and showed no relevant differences. Before start of the interventions 24 participants withdrew, 17 in the selfmanagement and 7 in the care-as-usual group. This was mostly due ro practical reasons (not able to participate on the planned data of the interventions and somerimes due to disappointment about the result and consequences of the randomization).

Five participants withdrew during the intervention from the self-management programme for several reasons. Three persons were not satisfied by the programme, one stopped because of knee pain and another couldn't attend because of the situation at home.

\section{Data analysis}

Results of the data analyses are shown in table 3. Data were analyzed following the intention-to-treat-principle; referring to the fact that all participants were analyzed in the intervention group they entered by tandomization. Table 3 describes the data set and results as well as the number of missing questionnaires, because for missing questionnaires no imputarion methods was administered. Mean change scores on the primary outcome measures were all in the same direction. At 3 months follow-up the intervention group significantly improved on VAS pain knee (0.67; SD 2.10) and WOMAC (2.46; SD 9.49), while the control group showed stable VAS knee pain $(0.01 ;$ SD 2.00) and deterioration on WOMAC (-0.53; SD 9.47). At 21 months follow-up the differences between the intervention and control group increased in favour of the intervention group (VAS pain knee: p-values from 0.023 at 3 months to 0.004 at 21 months; WOMAC p-values from 0.030 to 0.022 ). So, the effects on knee pain and self-reported daily functioning were better in the self-management group than in the control group. 


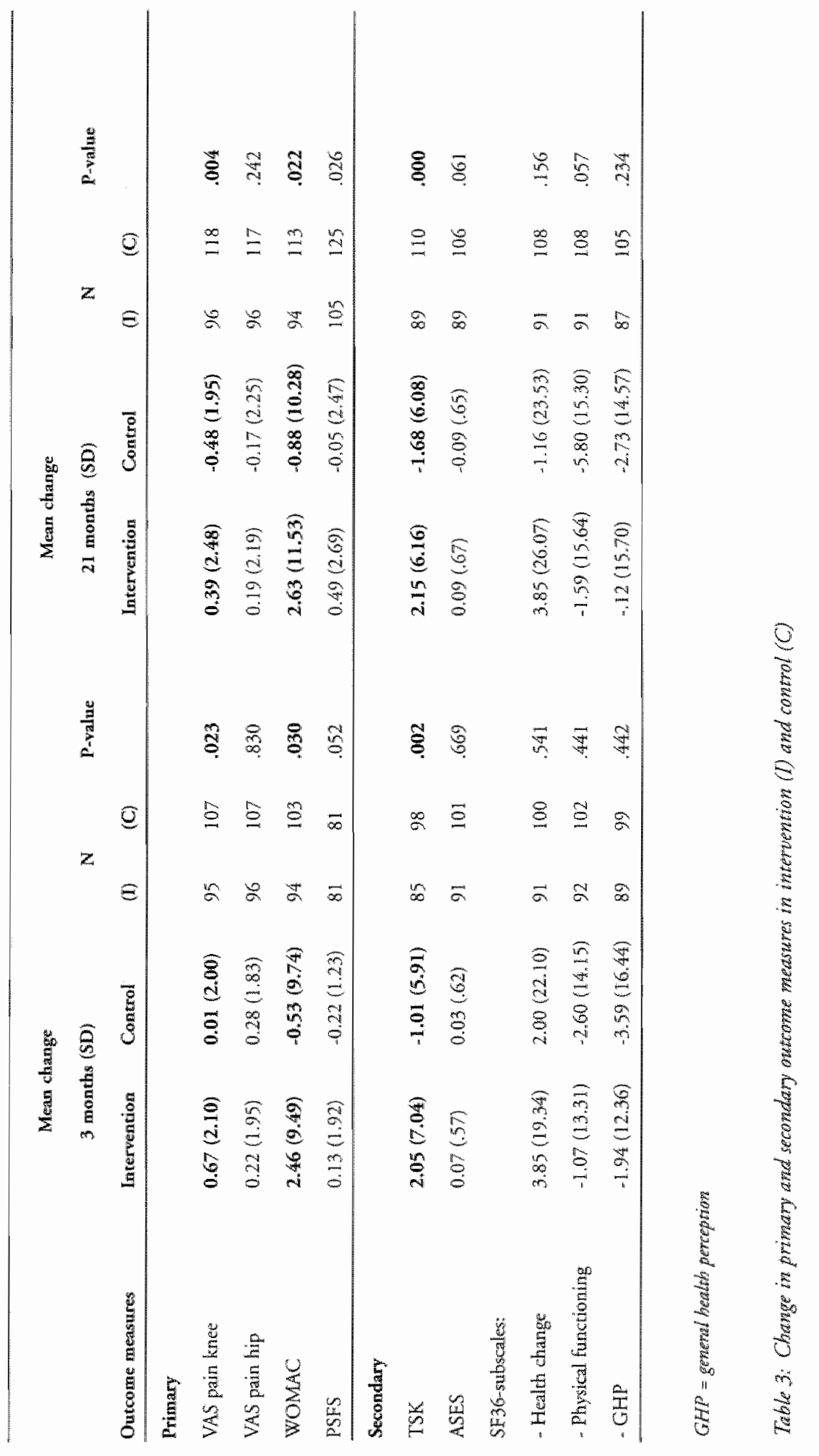




\begin{tabular}{|c|c|c|}
\hline Outicome measures & I & C \\
\hline \multicolumn{3}{|l|}{ Pipimary } \\
\hline WAs pain knee & $3.7(2,6)$ & $4.2(2.7)$ \\
\hline YAS pain hipp & $3.0(2.9)$ & $3.5(2.7)$ \\
\hline WOMAC & $30.1(16.8)$ & $35.1(17.6)$ \\
\hline PSES & $4.4(2.8)$ & $5.0(2.8)$ \\
\hline \multicolumn{3}{|l|}{ Siecondary } \\
\hline TSK & $34.1(6.7)$ & $37.7(8.0)$ \\
\hline$A S E S$ & $3.9(0.8)$ & $3.7(0.9)$ \\
\hline \multicolumn{3}{|l|}{ SF 36-subscalles: } \\
\hline - Health change & $47.7(21.6)$ & $41.7(1.8 .0)$ \\
\hline - Physical functioning & $61.5(21.3)$ & $55.4(22.8)$ \\
\hline$-G H P$ & $62.0(17.8)$ & $58.3(20.1)$ \\
\hline
\end{tabular}

Table 4: Mean values and sandard deviations of primary and secondary outcome measures at 21 montbs follow up

\subsection{Discussion}

The current study examined differences in outcome on pain and daily functioning in a group of osteoarthritis patients between 40 and 60 years after participating in selfmanagement intervention or care-as-usual. The effects on knee pain and self-reported daily functioning were better in the self-management group than in the control group. The differences were increasing over time in favour of the self-management intervention.

The following interesting aspects of the current study are to be mentioned:

Participants were recruited in a primary care population, not in specialised clinics, which is particularly interesring since this is a relevant (52) and under-investigated (5, 6). As far as we know this is the second published randomised controlled trial on selfmanagement in arthritis patients in a primary care setting. The recent study of 
Solomon et al demonstrated no significant clinical benefits at 4 months in patients recruited from primary care practices (6), in contrast to our study. However, Fries et al (53) recently pointed out several methodological flaws in the study of Solomon et al. concerning inadequate randomization (on a group level rather than on a patient level resulting in inadequate balanced groups, and transfer of part of the controls to the intervention arm), insufficient contrast between the two trial arms (the control intervention was also an active intervention by using The Arthritis Helpbook), while the period of follow up ( 4 months) was rather short. We claim that in our study these problems do not exist and the current study has a longer duration of follow up (21 months), which is evidently very important in the osteoarthritis population.

In the present study the self management programme was performed by physiotherapists in a primary health care setring. Therefore the conclusion can be drawn that there are possibilities for broad implementation in general health care settings for a broad population. For family doctors and physiotherapists this opens up treatment possibilities for the enormous group of osteoarthritis patients.

Furthermore, it's quite remarkable that a relative short intervention ( 6 sessions of each 2 hours in a group-format) positively influenced pain and self-reported daily functioning with measurable effects at long term follow up, while in the control group an overall deterioration is observed.

In a previous study on the effects of exercise in osteoarthritis patients positive effects of exercise were found at short term follow up. However, in the study mentioned these effects were not stable and disappeared over time $(54,55)$. It then was suggested that further studies were necessary to investigate the effect of interventions in which educational and/or self management strategies are integrated in order to improve the consolidation of positive effects on pain and daily functioning (54). The current study is an example of such a study and it confirms the positive influence of a self management programme with education on pain and self reported daily functioning on long term follow up.

In the present study the Stages of Change model was applied (37). For the purpose of better matching patients with trearment options, several authors recently have drawn attention to the transtheoretical model of behavioural change (56-62). This transtheoretical model, also frequently referred to as "Stages of Change" model, was 
first presented by Prochaska and DiClemente (63) and describes change as a process in which people move from a low to a high level of active participation (64). They can move through different stages ranging from no intention to change, e.g. with lack of motivation to adopt a self-management programme, to -on the orher side- optimal active participation with internalisation of the new behaviour. In the current study no differences in outcome were found in sub group analysis with the Stages of Change as variable. This is probably due to the fact that most of the participants are in the preparation or action stage. Few participants were in the Precontemplation and Contemplation Stages (37), which is not surprising because of the selection procedure of participants. This selection procedure may cause under representation of the people in the precontemplation stage, since the study sample was recruited especially for selfmanagement treatments. It rherefore seems unlikely thar many participants will be in the precontemplation stage, which would be quite contradictory to being prepared participating in a self management programme.

Another relevant aspect of the study concerns its societal impact. In the current study sample a considerable number of participants were fulfilling paying jobs. Improvement of pain and daily functioning in this group evidently has important consequences, because it positively influences opportunities of active societal participation and quality of life.

Possible limitations of the present study are the following:

First, it proved to be difficult to minimise and control the loss to follow up. At the end of the study loss to follow up was about $15 \%$. A constraint of the study was caused by incomplete response to questionnaires as is reported in table 3 . Nevertheless, it was shown to be possible -albeit complex- to perform a randomized clinical trial on selfmanagement in a primary health care setting and it was possible to draw valid and relevant conclusions.

Second, because of including individuals with Kellgren-grading 0 and 1 in this study ( $40 \%$ of the total group) which is a consequence of diagnosing $O A$ with classifications such as ICHPPC-2 or ACR, it could be that some of the study participants may not have $O A$ and we would be making false conclusions about the impact of selfmanagement on OA. Therefore it is important to note that the impact of the selfmanagement is primarily on functioning and pain in the person with chronic complaints ascribed to $O A_{3}$ rather than there is effect on the process of $O A$ irself. 
In sum, the effects of the current self-management intervention administered in a primary health care setting showed improvement in pain and self-reported daily functioning, while the control group deteriorated. The differences between the groups increased during follow-up in favour of the self-management group. These findings are in line with previous trials on self-management with positive outcome in osteoarthritis patients and therefore broader implementation of this intervention in primary care setrings is warranted.

\subsection{ACKNOWLEDGEMENTS}

We would like to express our gratitude to the family physicians of the academic networks of the universities in Maastricht ( $\mathrm{RNH}$ ) and Nijmegen (CMR/NMP) who participated in the recruitment of patients for this study. We also owe rhanks to Rene Weijers, Department of Radiology of Maastricht University Hospital, for reviewing all the radiographs and to Tjard Schermer for his contributions in the early stages of this study. This research was supported by grants of the Dutch Arthritis Association (Nationaal Reumafonds) and the Rehabilitation Foundation Limburg, both in the Netherlands. Of course, we are grateful to all the participating patients without whom it would have been impossible to perform this study.

\section{APPENDIX A. CONTENT OF TREATMENT PROGRAM}

\begin{tabular}{|c|c|c|c|c|c|c|}
\hline Topics per session & 1 & 2 & 3 & 4 & 5 & 6 \\
\hline selfhelp. & x & & & & & $x$ \\
\hline Whan is osteoarthrusts? & $x$ & & & & & \\
\hline Moving and exercizing & 8 & $x$ & म & $x$ & $x$ & $\mathrm{x}$ \\
\hline Relaxation & $x$ & & & & x & $\mathrm{x}$ \\
\hline Problemsolving & 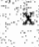 & & & & $x$ & $\mathrm{x}$ \\
\hline Communication and emo & & & 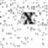 & s & & \\
\hline Health care providers tre & & & & & & \\
\hline denices & & $\mathrm{x}$ & & $x$ & 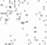 & 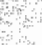 \\
\hline Enaluation & & & 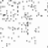 & & $\mathrm{x}$ & ४ः \\
\hline Acrionplan and feedladel & $x$ & $x$ & $s$ & $x$ & $\mathrm{x}$ & $\mathrm{x}$ \\
\hline
\end{tabular}


1. Ruwaard D., Kramers P., editors.1997: de Som der Delen. Volksgezondheid Toekomst Verkenning. Bilthoven: Rijksinsrituut voor Volksgezondheid en Milieu; 1997.

2. Continuous Morbidity Registration. In: Departement of General Practice, University of Nijmegen; 1997.

3. de Bock G.. Peripheral osteoarthritis in general practice. Leiden: Leiden University; 1994.

4. Hopman-Rock M., Kraaimaat F.W., Bijlsma J.W.J.. Quality of life in elderly subjects with pain in the hip or knee. Quality of life research 1997;6:67-76.

5. Lorig K., Bodenheimer T., Holman H., al e. Patient self-management of chronic disease in primary care. JAMA 2002;288:2469-2475.

6. Solomon D.H., Warsi A., Brown-Stevenson T., Farrell M., Gauthier S., Mikels D., et al. Does self-management education benefit all populations with arthritis? A randomized controlled trial in primary care physician network. Journal of Rheumatology 2002;29:362-8.

7. Davis P., Suarez-Almazor M.. An assessment of the needs of family physicians for a rheumatology continuing medical educational program: results of a pilot project. J Rheumatol 1995;22:1762-5.

8. Hochberg M.C., Alman R.D., Brandt K.D., Clark B.M., Dieppe P.A., Griffin M.R., et al. Guidelines for the medical management of osteoarthritis. Part I. Osteoarthritis of the hip. Arthritis \& Rheumatism 1995;38(11):1535-1540.

9. Hochberg M.C., Altman R.D., Brandt K.D., Clark B.M., Dieppe P.A., Griffin M.R., et al. Guidelines for the medical management of osteoarthritis. Part II: Osteoarthritis of the knee. Arthritis \& Rheumatism 1995;38(11):1541-1546.

10. Hawley D.J.. Psycho-educational interventions in the treatment of arthritis. Ballières Clinical Rheumatology 1995;9(4):803-823.

11. Lorig K., Holman H.. Arthritis self-management studies: a twelve-year review. Health Education Quaterly 1993;20(1):17-28.

12. Entinger W.H., Robert Burns S.P.M., William Applegate, W. Jack Rejeski, Timothy Morgan, Sally Shumaker, Michael J. Berry, Mary O’Toole, Johnny Monu, Timothy Craven. A randomized trial comparing aerobic exercise and resistance exercise with a health education program in older adults with knee osteoarthritis. JAMA 1997;277(1):25-31. 
13. Puett D.W., Griffin M.R.. Published trials of nonmedical and noninvasive therapies for hip and knee osteoarthritis. Ann Intern Med 1994;121:133-140.

14. Fisher N.M., S. C. White H.J.Y., R. J. Smolinski, D. R. Pendergast. Muscle function and gait in patients with knee osteoarthritis before and after muscle rehabilitation. Disability and rehabilitation 1997;19(2):47-55.

15. Weinberger M., Tierney W.M., Booher P., Katz B.P. Can the provision of information to patients with osteoarthritis improve functional status? A randomized, controlled trial. Arthritis and Rheumatism 1989;32(12):1577-1583.

16. Maisiak R., Austin J., Heck L.. Health outcomes of two telephone interventions for parients with rheumatoid arthritis or osteoarthritis. Arthritis \& Rheumatism 1996;39(8):1391-1399.

17. Lorig K.R., Mazonson P.D., Holman H.R.. Evidence suggesting that health education for self-management in patients with chronic arthritis has sustained health benefits while reducing health care costs. Arthritis and Rheumatism $1993 ; 36(4): 439-446$.

18. Hopman-Rock M.. Living with arthritic pain in the hip or knee: disability, health status, physical activity, coping with pain, quality of life, and health care utilization of community-leving elderly people. Utrecht; 1997.

19. Hopman-Rock M., Westhoff M.H.. The effects of a health educational and exercise program for older adults with osteoarthritis of the hip or knee. The Journal of Rheumatology 2000;27(8):1947-1954.

20. Mersemakers I., Höppener P., Knotnerus J.A., Kocken R., Limonard C. Computerized health information in the Netherlands: a registration network of family practices. British Journal of General Practice 1992;92:102-106.

21. Weel van C., Smith H., Beasly J.. Family practice research networks. Experience from three countries. J Fam Pract 2000;49:938-943.

22. Bock de G.. Peripheral osteoarthritis in general practice. Leiden: Leiden Universiry; 1994.

23. Bierma-Zeinstra S., Bohnen A., Ginai A., Prins A., Verhaar J.. Validity of American College of Rheumatology criteria for diagnosing hip osteoarthritis in primary care research. J Rheumatol. 1999;26:1129-33.

24. Kellgren J., Lawrence J.. Atlas of standard radiographs. The Epidemiology of chronic Rheumatism. Oxford UK; 1963. 
25. Bellamy N., W. Watson Buchanan C.H.G., Jane Campbell \& Larry W. Stitt. Validation study of WOMAC: a health status instrument for measuring clinically important patient relevant outcomes to antirheumatic drug therapy in patients of the hip or knee. The Journal of Rheumatology 1988;15(12):1833-1840.

26. Bellarny N., Jane Campbell I.S., Lawrence Pilch, Cindy Stewart \& Zahid Mahmood. Validation study of a computerized version of the Western Ontario and McMaster Universities VA3.0 Osteoarthritis Index. The Journal of Rheumatology $1997 ; 24(12): 2413-2415$.

27. Bellamy N.. Outcome measurement in osteoarthritis clinical trials. The Journal of Rheumatology 1995;22(1):49-51.

28. Köke A., Heuts P.H.T.G., Vlaeyen J.W.S., Weber W. Meerinstrumenten chronische piin: deel 1 functionele status. Maastricht; 1999.

29. Zee van der K.I., Sanderman R. Het meten van de algemene gezondheidstoestand met de RAND-36; een handleiding. Groningen: Noordelijk Centrum voor Gezondheidsvraagstukken; 1993.

30. Euroqol G.. Euroqol- a new facility for the measurement of health-related quality of life. Health policy 1990;16:199-208.

31. Dolan P., Gudex C., Kind P., Williams A.. Valuing health states: a comparison of methods. J Health Economics 1996; 15:209-31.

32. Lorig K., Chastain R., Ung E., Shoor S., Holman H.. Development and evaluation of a scale to measure perceived self-efficacy in people with arthritis. Arthritis Rheum 1989;32:37-44.

33. Taal E., Rasker J., Seydel E., Wiegrnan O.. Health status, adherence with health recommendations, self-efficacy and social support in patients with rheumatoid arthritis. Patient Education and Counseling 1993;20(2,3):63-76.

34. Kori S., Miller R., Todd D.. Kinesiophobia: A new view of chronic pain behavior. Pain Management 1990;Jan/Feb:35-43.

35. Miller R., Kori S., Todd D.. The Tampa Scale for Kinesiophobia; 1991.

36. Goubert L., Crombez G., Vlaeyen J.W.S., al e. The Tampa Schaal voor Kinesiofobie: Psychometrische karakteristieken en normering [The Tampa scale for Kinesiophobia: Psychometric properties and norms. Gedrag en Gezondheid 2000;28:54-62.

37. Heuts P.H.T.G., Bie de R.A., Dijkstra A., Aretz K., Vlaeyen J.W.S., Schouten H.J., et al. Assessment of readiness to change in patients with osteoarthritis. Development and application of a new questionnaire. Clinical Rehabilitation 2005;19(3):290-99. 
38. Taal E., Rasker J.J., Wiegman O.. Patient education and self-management in the rheumatic diseases: a self-efficacy approach. Arthritis Care and Research 1996;9(3):229-238.

39. Bandura A.. Self-efficacy: the exercise of control. New York: Freeman and Company; 1997.

40. Linton S.J.. The Challenge of Preventing Chronic Musculoskeletal Pain. In: Gebhart G.F., Hammond D.L., Jensen T.S., edirors. Proceedings of the 7th World Congress on Pain. Seartle: IASP Press; 1994. p. 149-166.

4.1. Linton S.J.. Urility of cognitive-behavioral pychological trearments. In: Nachemson A.L., Jonsson E., editors. Neck and back pain: the scientific evidence of causes, diagnosis, and treatment; 2000.

42. Linton S.J. Environmental and Learning Factors in the Development of Chronic Pain and Disability. In: Price DD, Bushnell CM, editors. Psychological Methods of Pain Control: Basic Science and Clinical Perspectives. Seattle: IASP Press; 2004. p. 143-167.

43. Linton S.J., Ryberg M.. A cognitive-behavioral group intervention as prevention for persistent neck and back pain in a non-patient population: a randomized controlled trial. Pain 2001;90:83-90.

44. Von Korff M. Perspectives on Management of Back Pain in Primary Care. In: Gebhart G.F., Hammond D.L., Jensen T.S., editors. Proceedings of the 7th World Congress on Pain. Seattle: IASP Press; 1994. p. 97-110.

45. Von Korff M. Pain management in primary care: an individualized stepped-care approach. In: Turk RJGDC, editor. Psychosocial factors in pain: critical perspectives. New York London: The Guilford Press; 1999. p. 360-373.

46. Moore J.E., Von Korff M., Cherkin D., Saunders K., Lorig K.. A randomized trial of a cognitive-behavioral program for enhancing back pain self care in a primary care setting. Pain 2000;88:145-153.

47. Morley S., Eccleston C., Williams A.. Systematic review and meta-analysis of randomized controlled trials of cognitive behaviour and behaviour therapy for chronic pain in adults, excluding headache. Pain 1999;80:1-13.

48. Hout van den J.H.C., Vlaeyen J.W.S., Heurs P.H.T.G., Sillen W.J.T., Willen J.E.H.L., Functional disability in non-specific low back pain: The role of painrelated fear and problem-solving skills. International Journal of Behavioural Medicine 2001;8:134-148. 
49. Hout van den J.H.C., Vlaeyen J.W.S., Heuts P.H.T.G., Zijlema J.H., Wijnen J.A.. Secondary Prevention of Work-Related Disability in Nonspecific Low Back Pain: Does Problem-Solving Therapy Help? A Randomized Clinical Trial. The Clinical. Journal of Pain 2003;19:87-96.

50. Hout van den J.H.C., Vlaeyen J.W.S., Kole-Snijders A.M.J., Heuts P.H.T.G., Willen J.E.H.L., Sillen W.J.T. Graded activity and problem solving therapy in subacute non-specific low back pain. Physiotherapy 1998;84:167.

51. Wright $\mathrm{C}$., Sim J.. Intention-to-treat approach to data from randomized controlled trials: A sensitivity analysis. Journal of Clinical Epidemiology 2003;56:833-842.

52. Warsi A., LaValley M.P., Wang P.S., Avorn J., Solomon D.. Arthritis SelfManagement Education Programs. A Meta-Analysis of the Effect on Pain and Disability. Arthritis \& Rheumatism 2003;48(8):2207-2213.

53. Fries J.F., Lorig K., Holman H.R.. Patient Self-Management in Arthritis? Yes! The Journal of Rheumatology 2003.

54. Baar van M.. Effectiveness of exercise therapy in osteoarthritis of hip or knee. Utrecht; 1998.

55. Baar van M., Dekker J., Oostendorp R., Bijl D., Voorn T., Lemmens J., et al. The effectiveness of exercise therapy in patients with osteoarthritis of the hip or knee: a randomized clinical trial. J Rheumatol 1998;25:2432-9.

56. Kerns R., Rosenberg R., Jamison R., Caudill M., Haythornthwaite J.. Readiness to adopt a self-management approach to chronic pain: The Pain Stages of Change Questionnaire (PSOCQ). Pain 1997;72:227-234.

57. Kerns R., Rosenberg R. Predicting responses to self-management treatments for chronic pain: application of the pain stages of change model. Pain 2000;84(1):4955.

58. Keefe F.J., Lefebvre J.C., Kerns R.D., Rosenberg R., Beaupre P., Prochaska J., et al. Understanding the adoption of arthritis self-management: stages of change profiles among arthritis patients. Pain 2000;87(3):303-313.

59. Jensen M.P.. Enhancing motivation to change in pain treatment. In: Turk R.J.G.D.C., editor. Psychological approaches to pain management. New York London: The Guilford Press; 1996. p. 78-111.

60. Habib S., Morrissey S.A., Helmes E. Readiness to adopt a self-management approch to pain: evaluation of the pain stages of change model in a non-pain-clinic sample. Pain 2003;104(1,2):283-290. 
61. Jensen M., Nielson W., Romano J., Hill M., Turner J.. Further evaluation of the pain stages of change questionnaire: is the transtheoretical model of change useful for parients with chronic pain? PAIN 2000;86:255-264.

62. Jensen M.P., Nielson W.R., Turner J.A., Romano J.M., Hill M.L.. Readiness to self-manage pain is associated with coping and with psychological and physical funcrioning among parients with chronic pain. Pain 2003;104:529-537.

63. Prochaska J., DiClemente C., Norcross J.. In search of how people change, applications to addictive behaviors. American Psychologist 1992;471:1102-1114.

64. Dijkstra A., Vlaeyen J.W.S., Rijnen H., Nielson W.. Readiness to adopt the selfmanagement approach to cope with chronic pain in fibromyalgic patients. Pain $2001 ; 90(1-2): 37-45$. 
Abstract

52

Introduction 53

Methods 54

Results 61

Outcome 62

Discussion 65

References $\quad 68$ 


\section{CHAPTER THREE}

IS A SELF-MANAGEMENT PROGRAM IN GENERAL PRACTICE COST-EFFECTIVE IN PATIENTS WITH OSTEOARTHRITIS?

Peter H.T.G. Heuts, ${ }^{1}$, Mariëlle E.J.B. Goossens, ${ }^{3}$, , Geert-Jan Dinant ${ }^{2}$, Rob de Bie ${ }^{5}$, Karin Aretz', Marion Drietelaar ${ }^{2}$, Chris van Weel', Onno C.P. van Schayck².

1. Rehabilitation Foundation Limburg, Hoensbroek, The Netherlands

2. Department of General Practice, Research Institute CAPHRI, Matstricht, "The Netherlands

3. Institute for Rehabilitation Research, Hoensbroek

4. Department of Medical, Clinical and Experimental Psychology, Mastricht Universiry

5. Deparment of Epiclemiology, Maastricht, The Netherlands

6. Deparment of Family Medicine, University Medical Centre St Radboud, Nijmegen, The Netherlands

Submitred 


\section{Objective}

To assess in a primary health care setting the cost-effectiveness of a self-management program in middle-aged parients with osteoarthritis (OA).

\section{Design}

Two-group randomized controlled trial. The experimental intervention was compared with care-as-usual. Duration of follow-up was 21 months after start of the intervention.

\section{Setting}

Recruitment of participants, treatments and follow-up measurement all were performed in a general health care setting and was done by GPs and via advertisements.

\section{Participants}

Two-hundred-and-seventy-three parients (age between 40 and 60 years) with osteoarthritis in hip(s) and/or knee(s).

\section{Main outcome measures}

Pain severity in hip(s) and/or knee(s), self-reported functional limitations (WOMAC), health-related quality of life (SF36 and EQ5D), cost dianies to measure direct heal h care and non-health care costs as well as indirect costs related to OA.

\section{Results}

After written informed consent the 297 parients were randomized: 149 selfmanagement and 148 controls. Before start of the intervention 24 participants withdrew for practical reasons (17 in self-management and 7 in control group). Ar 21 months follow-up the differences between the intervention and control group were in favor of the intervention group. Mean changes on all outcome measures were betrer in the self-management group, and statistically significant for VAS pain knee and WOMAC. Costs were not statiscically different between the rwo groups.

\section{Conclusions}

The self-management programme positively influenced knee pain and self-reported functional level in this sample of osteoarthritis patients. The investment of about 200 Euros (far less than 300 US dollars) per person was the price for improvement in pain and performance in this sample of osteoarthritis patients between 40 and 60 years. 


\subsection{INTRODUCTION}

Studies on the economical impact of osteoarthritis (OA) are important, as it is a condition with high prevalence (1-4). Moreover, because $\mathrm{OA}$ is associated with age, the aging of the population purs a higher proportion of the total population at risk for $\mathrm{OA}$ (5). Furthermore, in the older population the severity of the disease is greatest, which also is a factor aggravating the impact of OA $(5,6)$. Thus, because of this high and growing prevalence, and moderate to severe impact (7), osteoarthritis is an important condition in health policy concerns (8).

Yelin offers an overview of the studies concerning the economic impact of musculoskeletal disease. He summarizes the limited literature on the subject, referring to four studies of the costs of OA derived from clinical samples (9-12), and concludes (8):

"Musculoskeletal conditions account for as much as 1.1-2.9 per cent of the Gross National Product (GNP) of nations with advanced economies, including the direct costs associated with medical care and the indirect costs due to lost function and work disability. The direct costs among people with OA average between $\$ 1699$ and $\$ 2433$ per case, the majority of which were due to hospital admissions, prescription and nonprescription drugs and medical devices. Indirect costs dwarfed medical costs, being estimated at $\$ 12032$ per person with OA, in 1999 (8-12)."

Despite high prevalence, impact and costs, the condition has received relatively scant attention in the cost-of-illness literature (8) and cost-effective studies on selfmanagement programs are to our knowledge almost non-existent (13). The few costeffective studies in this field are mainly concerned with NSAIDs (14), arthroplasty (15), and physical, functional and other non-pharmacological interventions in osteoarthritis (16). Cost-effectiveness of many interventions is unknown, not only because of the paucity of studies, but also because of methodological flaws in published studies (17). Thus, given the enormous economic burden of osteoarthritis (18), there is a need for well designed cost-effectiveness studies on treatment as -for instance- selfmanagement programs $(8,13)$.

Self-management programmes are presented in recent papers as having the potential of improving health benefits while reducing health care costs $(13,19)$. Studies on the effecriveness of self-management programmes for arthritis showed positive and promising effects on health-related ourcomes like pain, disability and quality of life (20). 
The present paper presents the results of an economic evaluarion performed alongside a randomized controlled trial to evaluate the effects on health utilization and related costs as well as indirect costs relared to osteoarthritis. The randomized controlled trial compared the effects of care-as-usual versus a self-management program on pain and self-reported functioning in group osteoarthritis parients. The clinical effects in this randomized trial were statistically significant and clinically relevant in favor of the selfmanagement program. Details of this randomized controlled trial have been reported (21). In the current cost-effectiveness study the effects are assessed using generic healthrelated-quality-of-life outcome measures like SF36 and EQ5D (which are further described in the methods section). Direct and indirect costs related to osteoarthritis were assessed and compared between the two intervention groups. Main research question of the study was: is a self-management intervention more cost-effective than care as usual when administered in general practice in a young OA population?

\subsection{METHODS}

\section{Study population}

The study was approved by the Medical Ethical Committee of the Maastricht University Hospital. Approval was also received from the Review Committee of the Registration Network Family Practices (RegistratieNet Huisartspraktijken, RNH) (22, 23).

From July 1999 till December 2000, patients were recruited both from academic registration networks of primary care practices $(22,24)$ and by local advertisements (21). Two morbidity registration networks in the Netherlands, representing approximately 77 general practitioners participated in this study $(22,25)$. Additionally, letters were sent to 309 other general practices in Limburg (The Netherlands), which. resulted in $\mathbb{1 5}$ more general practitioners willing to refer patients to this study. The study population consisted of patients with osteoarthritis aged between 40 and 60 years. For inclusion in the study the ICHPPC-criteria (International Classification of Health Problems in Primary Care) (26) were used, which were administered in previous studies in general health care settings (see Appendix 1) (27). Patients with rheumatoid arthritis, ankylosing spondylitis and gout were excluded. A patient was included in the study when fulfilling the following: meeting the inclusion criteria, signed informed consent, able to participate (time and place) in the self-management groups if 
randomised so and complete baseline-measurements. Table 1 shows the characteristics of the participants in this study.

Self-mainagenent

\section{Patient characteristics (n)}

Number of participanes

Age in years (mean/SD)

Gender:

- miale

- fermalie

BMI (mean/SD)

Recruitmenc:

- general practice

69

63

80

- advertisement

Educarion:

- Compulisory school

- Secondary scthool

- Universing

Gainfully employed: yes/no

132

$51.0(5.0)$

54

78

$28.0(4.8)$
141

56

85

61

38

39

31

$55 / 44$

Control

$52.2(5.1)$

$28.3(5.2)$

$55 / 53$

\section{Outcome}

Pain (VASISD)

- knees

$4.3(2.4)$

$3.2(2.6)$

$32.7(14.7)$

$61.6(18.3)$

$54.3(42.6)$

$60.4(16.8)$

$61.0(17.0)$

$61.2(17.6)$

$78.6(19.0)$

$86.5(30.4)$

$75.5(15.0)$

$0.68(0.16)$
$3.8(2.9)$

$3.5(2.9)$

$35.7(17.3)$

$59.1(21.3)$

$55.9(41.3)$

$57.6(21.0)$

$58.9(19.2)$

$59.7(17.8)$

$77.0(20.5)$

$78.6(37.2)$

$73.7(17.4)$

$0.63(0.23)$

QQSD-score

Table 1: Chatracteristics of the participants at baselive (total $n=273$ ) 


\section{Randomization}

After admission the in- and exclusion criteria were checked. Participants signed the informed consent and were invited for baseline assessment. A computer-generated randomization scheme was prepared and kept by a secretary who was not further involved in the study.

\section{Interventions: self-management or care-as-usual}

The self-management program was based on earlier studies and publications $(13,28$ 32), rewritten and redesigned especially for the present study. The self-management intervention consisted of 6 sessions of each 2 hours and was lead by two physiotherapists.

Table 2 shows an overview of the content of the self-management intervention. The meetings were highly structured (see table 2). Standardized training materials were developed and administered. For the educational part of the intervention, sheets and audiovisual material were used by the physiotherapists. Participants received a short handbook on osteoarthritis and self-management with an overview of all relevant information. Furthermore, for the exercise and relaxation sessions and the action planning, as well as for all other parts of the intervention standardized materials were available and used. Essential in the self-management programme was the objective to support participants in taking responsibility for their personal health and functioning

\section{Sessînon number: $\quad \begin{array}{llllll}1 & 2 & 3 & 4 & 5 & 6\end{array}$}

Topics:

\begin{tabular}{|c|c|c|c|c|c|c|}
\hline Mackpround informarion on self ruanagement & $\mathrm{x}$ & & & & & $\mathrm{x}$ \\
\hline What is osteostrotwitis? & $\mathrm{x}$ & & & & & \\
\hline Moving and exercising & $x$ & $\mathrm{x}$ & $x$ & $\mathrm{x}$ & $\mathrm{x}$ & $\mathrm{x}$ \\
\hline Rellaxarion strategies & & $\mathrm{x}$ & & & $\mathrm{x}$ & $\mathrm{x}$ \\
\hline Problem solving & & & $x$ & & $x$ & $x$ \\
\hline Communücation and emorions & & & x & $x$ & & \\
\hline Help from health categivers & & $x$ & & $x$ & & \\
\hline Teehwical aids & & $x$ & & $x$ & & \\
\hline Program evaluation & & & & & $x$ & \\
\hline Acrion planming and feedback & $x$ & $x$ & $x$ & $\mathrm{x}$ & $\mathrm{x}$ & $x$ \\
\hline
\end{tabular}

7able 2. Overwien of the content of the Self-Management internention 
('empowerment'). The programme included the following: Participants learned to use adequate goal serting in combination with self-incentives as motivators to optimize level of acrivity. A rational adherence to prescribed medication and other treatments was discussed. Self-relaxation was trained both for pain control as well as for improvement of overall well-being. Problem-solving was part of the self-management programme for empowering the participant in handling daily hassles. Self-diagnostic skills were taught for monitoring and interpreting changes in one's health starus. Participants also received information about community resources and skills were trained to optimize use of health care services.

Physiotherapists performing the self-management intervention had to practice in primary care and have facilities in their practice to work with groups of 6 to 12 patients (instruction room, facilities for exercises, relaxation and reception of partners of the participants). They were prior to the study trained in the execution of the intervention program ( 3 sessions of each 4 hours). Care as usual was for the purpose of this study documented as detailed as possible by the general practitioners, physiotherapists and specialists, without modifying it.

\section{Design and outcome measures}

The baseline and outcome measurements were performed by independent research physiotherapists $(n=3)$ not involved in the treatment of participants. Measurements were taken at 5 moments: at baseline (prior to the intervention), and four times during follow up (at 3, 9, 15 and 21 months).

The following outcomes were used:

\section{Pain severity}

Pain intensity in the hips and knees was measured with visual analogue scales (VAS). Since the signs and symptoms of OA vary over time, three VAS-measurements were registered: intensity of pain today, intensity of pain last week, and intensity of pain last month. These three VAS scores strongly correlated (Pearson r ranged from 806 to .956; all significant at a $\mathrm{p}=0.01$ level). To obtain a reliable and reproducible indication of pain severity, mean VAS scores on these scales were entered in the analyses as a composite score. Anchors of the VAS scales were 'no pain at all' to 'the worst imaginable pain'. 


\section{Functional status}

The WOMAC (Western Ontario and McMaster Universities Osteoarthritis Index) is a three-dimensional (i.e., pain, stiffness, physical function), disease-specific (OA), selfadministered health status questionnaire, available in Likert- and VAS-versions, to measure outcome in OA-trials $(33,34)$. In this study the Likert version was used (35).

\section{Health-related quality of life}

Health-related quality of life was measured with Dutch versions of the SF-36 (36) and EQ-5D (37). Both instruments are internationally most frequently used.

\section{$S F-36$}

The SF-36 consists of 36 items from which scores are calculated on eight dimensions: physical funcrioning, role limitation due to physical health problems, bodily pain, general health, vitality, social functioning, role limitation due to emotional health problems, and mental health (36).

\section{EuroQol}

The EuroQol (EQ5D) provides a simple method for obraining a self-description of mobility, self-care, usual activities, pain/discomfort and anxiety/depression. It takes only a few minures to complete $(7,37)$. Each attribute of EQ5D has three levels: no problem, some problems, major problems, thus defining 243 possible health states, to which has been added "unconscious" and "dead" resulting in a total of 245. Each of the five artributes gives a score of 1, 2 or 3, thus resulting in the 5-digit score (e.g. 11223 or 32213 , et cetera). Dolan and colleagues have developed a scoring system for the use in cost-effectiveness studies (38-40). The maximum score of EQ5D is 1.0 (perfect health) (41). According to the system developed by Dolan et al scores are calculated by subtracting the relevant coefficients from 1.000 as follows: constant -0.081 , mobility (level 2) -0.069, mobility (level 3) -0.314, self-care (level 2) -.104, self-care (level 3) 0.214 , usual activity (level 2) -0.036 , usual activity (level 3) -0.094 , pain/discomfort (level 2) -0.123, pain/discomfort (level 3) -0.386, anxiety/depression (level 2) -0.071, anxiety/depression (level 3) -0.236 and N3 (used if any dimension is at level 3) -0.269 $(38,41)$. 


\section{Economic consequences}

For the evaluation of the economic consequences of $O A$ and its treatment in the population in this study, the direct health care and non-health care costs were calculated, as well as the indirect costs. The direct costs include the costs of the treatment programs (self-management and care-as-usual) and the costs of all OArelated health care utilization, which includes GP contacts, outpatient specialist contacts, physiotherapy, complementary health care, hospitalizations, home help, prescribed medications and over-the-counter medications. Direct non-health care costs include costs of paid and unpaid help, transportation costs, out of pocket expenses for OA-related activities and purchases. Indirect costs refer to the value of the production lost due to illness-related absence from work or days lost from house-keeping.

\section{Direct health care costs}

Gieneral practicioner (visit of maximum 20 minutes)

Physical therapist (visic of maximum 45 minutes)

Medical specialise care (outpatient visit):

- Rheumatologist

- Orthopedic surgeon

- Neurologist

- Rehabilitacion physician

Hospitalization (per day)

Professional home care (per hour)

Medication (costs per month)

\section{Direct non-health care costs}

Alternative therapist (per visit)

Home care (per hour)

Help from partner/friends (per hour)

\section{Indirect costs}

Absenteeism unpaid labor (per hour)

Absenreeism paid labor (per hour)

- The coss of medicarion were estimated on the basis of prices as published in tha Dutch Pharmacotherapeuric Compass. 
First, all relevant categories of health care utilization were identified. Second, the volume of each category was measured by cost diaries. Third, these volumes were multiplied by the costs per category (prices of 1999) (42). In table 3 the unit prices of cost components are shown. All costs were calculated in Euros. The direct health care and non-health care costs were valued according to Dutch guidelines for cost analysis in health care research (43). For visits to health care providers not described in these guidelines (for example, complementary medicine) the professional organizations were consulted to establish these costs.

\section{Cost-diaries}

Data were gathered using cost diaries as described by Goossens et al (44). Every patient had to fill in four times cost-diaries, at 3 months, 9 months, 15 and 21 months follow up. These cost-diaries each covered a period of four weeks, thus resulting in a sample of sixteen weeks representing the total follow up period of 21 months. The choice for this way of sampling is justified as follows. First, it was not feasible to ask participants to fill our the diaries during the whole follow up period of 21 months, because keeping the cost diary would become a burden for participants. Second, in previous studies this way of data gathering is investigated showing no significant different results to keeping the diary for the whole period or for a selected period of time (44). Third, since the process of $\mathrm{OA}$ is chronic and slowly progressive, costs are believed to be relatively stable over time.

\section{Statistical analysis}

All data analyses were done with SPSS statistical software. For analysis of the EQ5D the scores on the five irems ("5-digit"-score) were transformed with an algorithm presented by Dolan (41). To check for selecrive dropout of participants possibly causing invalid inferences we looked for differences at all variables of interest (baseline characteristics and outcome measurements) in the following groups: all participants at baseline, participants in self-management programme at baseline and participants in care-as-usual at baseline. We also compared the groups who completed the cost diaries at follow up compared with the dropouts. The clinical effecrs were compared between the group that completed the cost diaries and the group that did not complete the cost diaries at all four follow up moments.

Difference scores between T4 and baseline were calculated and for the effect measures T-tests were calculated for the mean difference scores of the borh intervention groups. 
Student T-tests (two-tailed; $0.05 \mathrm{p}$-value) were calculated in order to compare the mean values in both interventions of direct health care costs, direct non-health care costs, total direct costs, indirect costs and total costs. Thompson and Barber illustrated (45) that a T-test of untransformed costs is sufficient in spite of the usual skewness in the distribution of costs. They stated that the arithmetic mean is the most informative measure for healthcare policy decisions (45).

\section{Sensitivity analyses}

Sensitivity analyses were performed in two ways. First, comparisons between intervention and control group were performed with and without taking the costs of self-management into account. Second, because there were outliers in the selfmanagement group with extreme costs (for example reported direct non-health care costs because of buying a special bed, which caused exceeding maximum costs by eightfold compared to maximum costs in the other group). Therefore, T-tests were performed with and without these outliers.

\subsection{RESULTS}

\section{Participants and study sample}

A total of 297 patients signed informed consent and were randomized to selfmanagement $(n=149)$ and care as usual $(n=148)$. Before start of the intervention 24 participants withdrew for practical reasons (17 in self-management and 7 in control group). This resulted in a number of 273 osteoarthritis patients ( 110 male, 163 female) participating in the trial.

Table 1 shows the characteristics of the study population at baseline. Age, gender, body mass index, way of recruitment for the current study and level of education are described. Participants reported moderate pain intensity in the hips (mean score on VAS 3.36; SD 2.77) and knees (mean VAS 4.06; SD 2.66). An evident level of discomfort and disability (mean score on WOMAC: 34: SD 16.13) was noted. Scores on the several subscales of SF36 as well as EQ5D-scores (formula as described above $(38,41)$ ) are shown in table 1 , for both intervention groups. 
Figure 1 shows the numbers of patients in the cost-effectiveness study. Numbers of the respondents at the different follow up moments are described for each trial arm. For all important baseline characteristics presented in table lwe checked for selective dropout by performing $\mathrm{T}$-tests showing no significant differences between the complete study sample and the sample that completed the cost diaries.

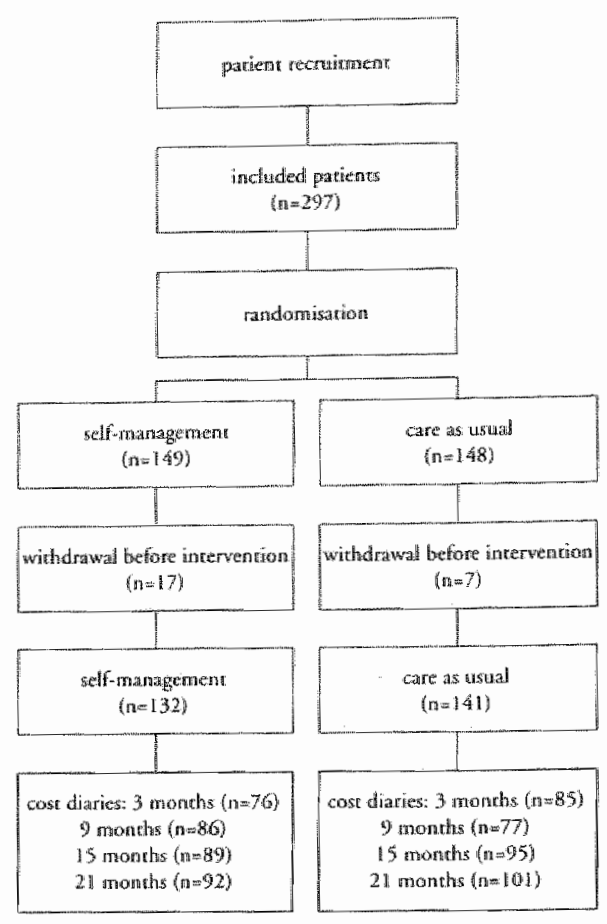

Figure 1: Numbers of patients in the costeffectiveness study

\subsection{OUTCOME}

In table 4 outcomes are reported at 21 months after baseline. The results on the diseasespecific outcome measures (WOMAC and VAS pain) have been published elsewhere and are as follows: at 3 months follow-up the self-management group significantly improved on knee pain and on functioning, while the control group showed stable knce pain and deterioration on functioning (21). At 21 months follow-up the differences between the self-management and control group significantly increased in favour of the self-management group. In table 4 the quality of life measures the 8 sub scales of SF36 and EQ5D are reported. (In all reported measures a positive mean change corresponds with improvement, while negative values reflect deterioration.) On all outcome measures performance of the self management group is better than in the care-as-usual group, but only VAS pain knee and WOMAC showed statistically significant differences on the mean changes. 
Mean change

21 months $(\mathrm{SD})$

\begin{tabular}{llllll} 
& \multicolumn{2}{c}{21 months $(S D)$} & & P-value \\
\hline & Intervention & Control & (I) & (C) & \\
\hline Outcome measures & & & & & \\
VAS pain knee & $0.39(2.48)$ & $-0.48(1.95)$ & 96 & 118 & .004 \\
VAS pain hip & $0.19(2.19)$ & $-0.17(2.25)$ & 96 & 117 & .242 \\
WOMAC & $2.63(11.53)$ & $-0.88(10.28)$ & 94 & 113 & .022 \\
SF36 & & & & & \\
- Physical functioning & $-1.59(15.64)$ & $-5.80(15.30)$ & 91 & 108 & .057 \\
- Role-physical & $-3.79(33.03)$ & $-5.22(38.84)$ & 90 & 107 & .785 \\
- Bodily pain & $-.02(18.25)$ & $-1.97(18.43)$ & 91 & 108 & .458 \\
- Greneral health & $-.12(15.70)$ & $-2.73(14.57)$ & 87 & 105 & .234 \\
- Vitality & $-.94(13.79)$ & $-3.12(16.17)$ & 89 & 108 & .316 \\
- Social functioning & $-3.85(20.64)$ & $-6.48(18.84)$ & 91 & 108 & .348 \\
- Role-emorional & $-5.13(37.49)$ & $-6.54(42.57)$ & 91 & 107 & .806 \\
- Mental health & $-1.90(13.46)$ & $-2.81(15.11)$ & 89 & 108 & .657 \\
EQ5D & 0.013 & -0.013 & 94 & 107 & .294 \\
\hline
\end{tabular}

Table 4: Outcome in intervention (D) and control (C) grousp 21 months after baseline measurtwent

\begin{tabular}{|c|c|c|c|}
\hline Type of utilization (unit of measurement) & $\begin{array}{l}\text { Care-as-usual } \\
\mathrm{n}=58\end{array}$ & $\begin{array}{l}\text { Self- management } \\
n=56\end{array}$ & $\begin{array}{l}\text { Total } \\
\mathrm{n}=114\end{array}$ \\
\hline General pracrice (number of wisirs) & $0.8(0 / 7)$ & $0.8(0 / 6)$ & $0.810 / 7)$ \\
\hline Physical therapy (number of treatment sessions) & $1.8(0 / 13)$ & $3.1 \quad(0 / 38)$ & $2.4(0 / 38)$ \\
\hline Medicall specialist care (number of outpatient visiss) & $0.3 \quad(0.4)$ & $0.4 \quad(0 / 9)$ & $0.4 \quad(0 / 9)$ \\
\hline Professional home care (number of hours) & $4.2(0.96)$ & $9.0 \quad(0 / 100)$ & $6.6 \quad(0 / 100)$ \\
\hline Heip from partner / friends (number of hours) & $4.5(0 / 61)$ & $11.8(0 / 304)$ & $8.1 \quad(0 / 304)$ \\
\hline Absenteism paid labor (number of hours) & $12.9(-116 / 292)$ & $26.1(-96 / 380)$ & $19.4(-116,380)$ \\
\hline Absenteeism unpaid labor (number of hours) & $12.9(-85 . / 248)$ & $7.9(-128 / 199)$ & $10.4(-128 / 248)$ \\
\hline
\end{tabular}

Table 5: Vtilization of health cate resources and work absenteetsm per intervention group diwring 21 months follow-up (min/max) 


\section{Utilization of health care resources}

Table 5 shows the urilization of health care resources as well as work absenteeism per intervention group as registered by using costs diaries (44).

\section{Costs}

The costs of participation in the self-management program were 207.55 Euro per patient ( 6 sessions of 2 hours). A comparison of the costs between intervention and control group is demonstrated in table 6 . These are the cumulative data of the complete follow up period. (It is relevant to note that table 6 presents a comparison of costs in both groups in which the costs of the self-management program are not included.) The means are presented of direct health care costs, direct non-health care costs, total direct costs, indirect costs and total costs, with the $95 \%$ confidence intervals and the p-values of the differences (at a 0.05 -level).

Because no relevant differences in costs were found between the two study groups, it was not relevant to calculate QUALY's.

\begin{tabular}{|c|c|c|c|c|c|}
\hline \multirow[t]{2}{*}{ Costs: } & $\begin{array}{l}\text { Care-as-Usual } \\
\text { mean (sd) } \\
n=58\end{array}$ & $\begin{array}{l}\text { Self-Management } \\
\begin{array}{c}\text { mean (sd) } \\
n=56\end{array}\end{array}$ & \multicolumn{2}{|c|}{ Care-as-Usual wersus Self-Management } & \multirow{2}{*}{$\begin{array}{c}\text { P-values }(0.05) \\
\text { difference } \\
\text { of means }\end{array}$} \\
\hline & & & difference of means & $95 \% \mathrm{CI}$ & \\
\hline Direct health care costs & 140.41 & 134.28 & 6.12 & $-90.02 / 102.27$ & .900 \\
\hline Direcr non-hiealth care costs & 78.85 & 222.64 & -143.78 & $-302.28 / 14.72$ & .075 \\
\hline Toral direct coses & $219: 26$ & 356.92 & -137.66 & $-352.93 / 77.61$ & .208 \\
\hline Indirect costs & 139.07 & 250.26 & -111.19 & $-290.98 / 68.60$ & .223 \\
\hline Total costs & 358.33 & 607.18 & -248.85 & $.554 .91 ; 57.2$ & .110 \\
\hline
\end{tabular}

Table 6: Differentes in mean total costs (SD) during the follow-up period of 21 months (in Euros)

\section{Sensitivity analyses:}

First, curmulative costs were analysed with and without taking the costs of the selfmanagement programme into account. These analyses showed no differences in significance levels when comparing costs between intervention and control groups. Second, because there were outliers in the self management group with extreme costs (for example direct non-health care costs because of buying a special bed, which caused 
exceeding maximum costs by eight-fold compared to maximum costs in the other group) the T-test was also run without these outliers. This didn't change the significance of the findings. Table 6 presents the results of the analyses of all available data including outliers.

\subsection{Discussion}

The present study addresses the question whether the self-management program is cost-effective in patients with osteoarthritis. The results of the current study are in favor of a positive answer to this question, because the effects are better in the selfmanagement than in the control group, while the costs show no statistically significant differences between the groups. Nevertheless, several remarks have to be made abour some strengths as well as limitations of the present study, in order to interpret the present results carefully enough.

First, one of the limitations of the study is the high level of dropouts, possibly causing bias in outcomes. It proved to be difficult to keep participants in the randomized clinical trial also to the economic evaluation, given the fact that out of 273 participants only 114 completed all the cost-diaries. This seems partly due to the fact that it takes time and effort to fill in these forms. The price paid for gathering the relevant data, is loss-to-follow-up resulting in small groups. It is a remarkable aspect of the randomization that in the end the two groups resembled in size $(n=56$ and $n=58$, i.e. participant completing all cost diaries at all follow up points). The relative small size of the two intervention groups -when compared with the sample size of the RCT $(\mathrm{n}=273)$-, implies that the present study has to be regarded as a sample out of a sample (i.e. a sample out of the study sample included in the $\mathrm{RCT}$ ). Therefore, the results have to be interpreted with caution. We handled this problem by checking for selecrive dropout. For that purpose, on all rellevant baseline characteristics and outcome measures the patients that completed all cost diaries were compared with the full range of patients entering the study. No significant differences berween these groups were found, so paving the way for cautiously making inferences to the whole study sample. Second, the data on costs were sampled during for periods of four weeks, because we expected an even higher rate of dropouts if we would have asked the participants to register during the full 21 months of follow up. In previous studies it was shown that it is valid to use cost diaries by "sampling" the follow up period $(18,44,46)$. In the 
studies mentioned the cost diaries were handed over by the researcher, while in the current study in a primary healthcare serting daca collection for reasons of feasibility was done by posted questionnaires with less personal contact berween participants and researchers and a lower level of control by the researchers.

Although there are no statistically significant differences, we would point to the next interesting observations. First, the only major expenses, for an expensive bed was in the self-management group. Second, the time off work was greater in the self-management group. It is at least plausible that self-management encourages individuals to spend more money and time on themselves, and to take more care of their joints by not working so hard. These might be clinically sensible.

In addition to the limitations, also several strengths of the present study are to be mentioned. The present study is one of the few economic evaluations in the research literature on OA. Strong features are the longitudinal data-gathering after a blinded randomization procedure, the choice of outcome measures especially designed for the cost-effectiveness study, and analyses according to the intention-to-treat principle. This makes the comparisons between the two intervention groups important and enhances the external validity of the study findings.

The results presented here are therefore regarded to be relevant, moreover because they suggest that implementing a self-management programme in a general health care setting can improve outcome in OA patients at low costs. For example, reduction of pain, improvement of self-reported level of functioning, can be reached at a price of about 207.55 Euros, while the mean direct and indirect medical and non-medical costs stay equal when compared to costs in usual care. Given the high prevalence and the impact of $O A$ in aging societies, this seems to be an important finding.

Taken together, it can be concluded that in the current study the self-management programme proved to be more effective than the care-as-usual intervention, while costs of both are nearly the same. The investment of about 200 Euros (far less than 300 US dollars) per person is the price for improvement in pain and performance in this sample of ostegarthritis patients between 40 and 60 years. 


\section{APPENDIX 1:}

Osceoarkbrits as defined in the $1 \mathrm{CHPPC} 2 \mathrm{Defined}(27)$ :

The diagnosis osteoarthitis must be based on at least one of the following:

(a) Charactenistic radiological appearance

(b) Heberden's nodes

(c) Joint disorder of at least 3 months duration, with no constirutional symptoms and at least three of the following:

1. Irregular swelling

2. Crepitation

3. Stiffeness or limitation of movement

4. Nonmal ESR, rheumatoid tests and unic acid

5. Patient over 40 years of age 
1. Brandt K.D., Doherty M., Lohmander L.S., Osteoarthritis. Oxford: Oxford University Press; 2003.

2. Felson D.. Epidemiology of hip and knee osteoarthritis. Epidemiol Rev 1988;10:128.

3. Felson D., Zhang Y.. An update on the epidemiology of knee and hip osteoarthritis with a view to prevention. Arthr Rheum 1998;41:1343-1355.

4. Felson D.T.. Epidemiology of osteoarthritis. In: Brandt K.D., Doherty M., Lohmander L.S., editors. Osteoarthritis. Oxford: Oxford University Press; 2003. p. 8-16.

5. Dennison E., Doherty M.. The natural history and prognosis of osteoarthritis. In: Brandt K.D., Doherty M., Lohmander L.S., editors. Osteoarthritis. Oxford: Oxford University Press; 2003. p. 227-233.

6. O'Reilly S., Doherry M.. Signs, symptoms, and laboratory tests. In: Brandt K.D., Doherty M., Lohmander L.S., editors. Osteoarthritis. Oxford: Oxford University Press; 2003. p. 197-210.

7. Picavet H., Hocymans N.. Health related quality of life in multiple musculoskeletal diseases: SF-36 and EQ-5D in the DMC3 study. Ann Rheum Dis 2004;63:723729.

8. Yelin E.. The economics of osteoarthriris. In: Brandt K.D., Doherty M., Lohmander L.S., editors. Osteoarthritis. Oxford: Oxford Universiry Press; 2003.

9. Liang M., Larson M., Thompson M., Eaton H., McNamera E., Karz R., et al. Costs and outcome in rheumatoid and osteoarthritis. Arthritis Rheumatism 1984;27:522-9.

10. Holman H., Lubeck D., Dutton D., Brown B.. Improving health service performance by modifying medical practices. Trans Assoc Am Phys 1988:101:173-9.

11. Gabriel S., Crowson C., O'Fallon W.. Costs of osteoarthritis: estimates from a geographically defined population. J Rheumatol 1995;22 (Suppl.43):23-5.

12. Lanes S., Lanza L., Randensky P., Yood R., Meenan R., Walker A., et al. Resource utilization and cost of care for rheumatoid arthritis and osteoarthritis in a managed care setting. Arthritis Rheumatism 1997;40:1475-81.

13. Lorig K.R., Mazonson P.D., Holman H.R.. Evidence suggesting that health education for self-management in patients with chronic arthritis has sustained health benefits while reducing health care costs. Arthritis and Rheumatism 1993;36(4):439-446. 
14. Yen Z., Lai M., Wang C., Chen L., Chen S., Chen W., et al. Cost-effectiveness of treatment strategies for osteoarthritis of the knee in Taiwan. J Rtheumatol 2004;31(9):1797-803.

15. Chang R., Pellisier J., Hazen G.. A cost-effectiveness analysis of total hip arthroplasty for osteoarthritis of the hip. JAMA 1996;275(11):858-65.

16. Hurley M., Walsh N.. Physical, functional and other non-pharmacological interventions in osteoarthritis. Best Pract Res Clin Rheumatol 2001:15(4):569-81.

17. Drummond M., Maetzel A., Gabriel S., March L.. Towards a reference case for use in future economic evaluations of interventions in osteoarthritis. $J$ Rheumatol 2003; Suppl(68):26-30.

18. Goossens M.E.J.B.. Economic aspects of chronic musculoskeletal pain. In: S.J. Linton, editor. New Avenues for the Prevention of Chronic Musculoskeletal Pain and Disability. Amsterdam: Elsevier; 2002.

19. Lorig K., Sobel D., Stewart A., et al. Evidence suggesting that a chronic disease selfmanagement program can improve health status while reducing hospitalization: a randomized trial. Med Care 1999;37:5-14.

20. Warsi A., LaValley M.P., Wang P.S., Avorn J., Solomon D.. Arthritis SelfManagement Education Programs. A Meta-Analysis of the Effect on Pain and Disability. Arthritis \& Rheumatism 2003;48(8):2207-2213.

21. Heuts P.H.T.G., Bie de R.A., Drietelaar M., Aretz K., Hopman-Rock M., Bastiaenen C.H., et al. Self-Management in Osteoarthritis of Hip or Knee: A Randomized Clinical Trial in a Primary Healthcare Setring. The Journal of Rheumatology 2005;32:543-49.

22. Metsemakers J., Höppener P., Knottnerus J.A., Kocken R., Limonard C.. Computerized health information in the Netherlands: a registration network of family pracrices. British Journal of General Practice 1992;92:102-106.

23. Akker van den M., Metsemakers J.F., Limonard C.B., Knotmerus J.A.. General practice: a gold mine for research. Data and scientific use of the Registration Network Family Practices. Maastricht: Unigraphic, Universiteit Maastricht; 2004.

24. Weel van $\mathrm{C}$., Smith H., Beasly J.. Family practice research networks. Experience from three countries. J Fam Pract 2000;49:938-943.

25. Continuous Morbidity Registration. In: Departement of General Practice, University of Nijmegen; 1997. 
26. The Classification Committee of WONCA (World Organisation of National Colleges $A_{b}$ and Academic Associations of General Practitioners/Family Physicians) in collaboration with the World Health Organization, editor. ICHPPC-2-Defined (Inrernational Classification of Health Problems in Primary Care). Oxford: Oxford Universiry Press; 1983.

27. Bock de G.. Peripheral osteoarthritis in general practice. Leiden: Leiden University; 1994.

28. Lorig K., Holman H.. Arthritis self-management studies: a twelve-year review. Health Education Quaterly 1993;20(1):17-28.

29. Taal E., Rasker J.J., Wiegman O.. Patient education and self-management in the rheumatic diseases: a self-efficacy approach. Arthritis Care and Research 1996;9(3):229-238.

30. Hopman-Rock M., Kraaimaat F.W., Bijlsma J.W.J.. Quality of life in elderly subjects with pain in the hip or knee. Quality of life research 1997;6:67-76.

31. Hopman-Rock M., Westhoff M.H.. The effecrs of a health educational and exercise program for older adults with osteoarthritis of the hip or knee. The Journal of Rheumatology 2000;27(8):1947-1954.

32. Bandura A. Self-efficacy: the exercise of control. New York: Freeman and Company; 1997.

33. Bellamy N., W. Watson Buchanan C.H.G., Jane Campbell \& Larry W. Stitt. Validation study of WOMAC: a health status instrument for measuring clinically important patient relevant outcomes to antirheumatic drug therapy in patients of the hip or knee. The Journal of Rheumatology 1988;15(12):1833-1840.

34. Bellamy N., Jane Campbell J.S., Lawrence Pilch, Cindy Stewart \& Zahid Mahmood. Validation study of a computerized version of the Western Ontario and McMaster Universities VA3.0 Osteoarthritis Index. The Journal of Rheumatology $1997 ; 24(12): 2413-2415$.

35. Bellamy N.. Outcome measurement in osteoarthritis clinical trials. The Journal of Rheumatology 1995;22(1):49-51.

36. Zee van der K.I., Sanderman R. Het meten van de algemene gezondheidstoestand met de RAND-36; een handleiding. Groningen: Noordelijk Centrum voor Gezondheidsvraagstukken; 1993.

37. Euroqol $G$.. Euroqol- a new facility for the measurement of health-related quality of life. Health policy 1990;16:199-208. 
38. Dollan P., Gudex C., Kind P., Williams A.. A social tariff for EuroQol; Results from a UK general population survey. Discussion Paper No. 138. York: Centre for Health Economics, University of York; 1995.

39. Dolan P., Gudex C., Kind P., Williams A.. Valuing health states: a comparison of methods. J Health Economics 1996;15:209-31.

40. Dolan P., Gudex C., Kind P., Williams A. The time trade-off method: results from a general population study. J Health Economics 1996:141-54.

41. Drummond M.F., O'Brien B., Stoddart G.L., Torrance G.W. Methods for the Economic Evaluation of Health Care Programmes. Second Edition. Oxford: Oxford University Press; 1997.

42. Kuy van der A.. Farmacotherapeutical Compas [In Dutch: Farmacotherapeutisch Kompas 1999: medisch farmaceutische voorlichting]. Utrecht: Health Care Insurance Council [In Dutch: College voor zorgverzekeringen]; 1999.

43. Oostenbrink J., Koopmanschap M., Rutten F. Handbook for cost studies, methods and guidelines for economic evaluation in health care [In Dutch: Handleiding voor kostenonderzoek, methoden en richtlijnprijzen voor economische evaluaties in de gezondheidszorg. College van Zorgverzekeringen]. Health Care Insurance Council; 2000.

44. Goossens M.E.J.B., Rutten-van Mölken M.P.M.H., Vlaeyen J.W.S., Linden van der S.M.J.P. The cost diary: a method to measure direcr and indirect costs in costeffectiveness research. Journal of Clinical Epidemiology 2000;53:688-695.

45. Thompson S.G., Barber J.A.. How should cost dara in pragmatic randomised trials be analysed? BMJ 2000;320:1197-1200.

46. Goossens M.E.J.B., Evers S.M.A.A., Vlaeyen J.W.S., Rutten-van Mölken M.P.M.H., P vdLSMJ. Principles of economic evaluation for interventions of chronic musculoskeletal pain. European Journal of Pain 1999;3(4):343-353. 
Abstract 74

Introduction 75

Merhods 77

Results 79

Discussion $\quad 82$

Acknowledgements 86

References 87 


\section{CHAPTER FOUR}

\section{ASSESSMENT OF READINESS TO CHANGE IN PATIENTS WITH OSTEOARTHRITIS. DEVELOPMENT AND APPLICATION OF A NEW QUESTIONNAIRE}

Peter H.T.G. Heuts ${ }^{1}, 2$, Rob A. de Bie, Arie Dijkstra, Karin Aretz' Johan W.S. Vlaeyen', Hubert J.A. Schouten ${ }^{6}$, Marijke Hopman-Rock', Chris van Weel ${ }^{8}$, Onno C.P. van Schayck².

1. Rehabiliation Foundation Limburg, Zandbergsweg 111, 6432 CC Hoensbroek, The Netherlands.

2. Department of General Practice, Research Institute CAPHRI, Maastricht Universicy, P.O. Box 616, $6200 \mathrm{MD}$ Mastricht, The Nerherlands.

3. Deparment of Epidemiology, Research Institute CAPHRT, Maastricht University, P.O. Box 616. $6200 \mathrm{MD}$ Mastrictr, The Netherlands.

4. Depattment of Social and Organizacional Psychology, Uniwersity of Groningen, The Netherlands.

5. Department of Medical, Clinical and Experimental Psychology, Mastricht Universiry, P.O. Box 616. $6200 \mathrm{MD}$ Matstrichr, The Necherlands.

6. Department of Methodology and Statistics, Maastricht University, PO. Box 616,6200 MD Mastricht, The Wetherinds.

7. Deparment Physical Activity and Health, TMO Prevertion and Health, PO. Box 2215, 2301 CE Leiden, The Netherinds.

8. Deparment of Family Medicine, University Medical Centre St Radboud, Nijmegen, The Nerherlands.

Published in: Clunical Rehabilitation 2005;19(3):290-99. 


\subsection{ABSTRACT}

\section{Objective}

To develop a self-report measure for assessment of the Stage of Change in patients with osteoarthritis, in order to identify those patients who will benefit from participating in a self-management programme.

\section{Methods}

According to the "stages-of-change"-model, firstly presented by Prochaska and DiClemente, a questionnaire was developed with three groups of items corresponding with respectively the precontemplation stage (Pre), the contemplation (Cont) and the action (Act) stage. Internal consistency and factor structure of this questionnaire were investigated by assessing Cronbach"s alphas and by performing factor analysis.

\section{Subjects and setting}

The questionnaire was offered to 273 patients, who entered a randomized clinical trial on self-management in at general health care setring.

\section{Results}

Factor analysis revealed that most items were corresponding to the a priori described groups, while some items were not loading on the presumed factor. In each subgroup some items were deleted, resulting in a 15-item questionnaire. After this item reduction Cronbach's alpha's were .72 (Pre), 76 (Cont) and .79 (Act) and all factor loadings were satisfactory (above .35). Classification revealed some differences berween parts of the total group, for example in the proportion of patients in the preparation stage (rectuited by general practitioner $=33.6 \%$; advertisement $=49.2 \%$.

\section{Conchusions}

The Stages of Change Questionnaire in Osteoarthritis, a 15-item-questionnaire to assess the "stage-of-change" of a patient with osteoarthritis, showed good internal consistency and adequate factor structure. These findings warrant further studies on vallidity and applicability in a clinical context. 


\subsection{INTRODUCTION}

The Stages of Change model has recerved considerable attention in the literature on health promotion (1) and is recently introduced in the field of musculoskeletal pain (25). Although the model has become popular in both research and the health education field, several critical issues need to be solved (6-9). A recent review on the status of evidence and outcomes in Stages of Change research (1) reveals the existence of a discrepancy between theoretical and empirical studies on the subject: in a total number of 239 studies, 178 are concerned with structure, 50 with process and 11 with outcome of the Stages of Change model. Whitelaw and colleagues (1) recommend high quality quantitative studies with a focus on practirioner and organizational utilization of the model. In the current paper a new questionnaire is presented, designed for empirical studies on the Stages of Change model in osteoarthritis patients.

Osteoarthritis is a common clinical syndrome characterised by joint pain and stiffness. In pathological terms osteoarthritis is usually described as a condition of cartilage degeneration, subchondral bone stiffening, and active new bone formation (10-14). Osteoarthritis is accompanied by loss of function and it frequently hampers the parient in daily activities. Not only from this patient perspective but also from a societal viewpoint is osteoarthritis very important, regarding its high prevalence (15).

For patients with arthritic conditions self-management programmes are applied on a large scale (16). In a self-management programme people are taught how to take a greater initiative in their personal health and functioning (17). In short, these types of treatment-programmes are characterised by including at least the following issues: training in adequate goal setting, optimisation level of activity, self-relaxarion, problemsolving strategies and self-diagnostic skills for monitoring and interpreting changes in one's health status. Participants also receive information about community resources and skills are trained to optimise use of health care services (16).

Although several studies have demonstrated favourable effects of these kind of selfmanagement programmes on pain, the level of functioning and subjective "quality of life" (18-20), it is not yet clear which patients benefit most from it and who do not (4, 21). Since self-management programmes are behaviourally oriented, they can only be successful if the particular person is willing to change habits according to these newly 
trained skills. For practical as well as for research purposes (22) it would be helpful to be able to determine beforehand whether or not a particular person is motivated to perform a self-management programme in order to avoid unmet expectations on the side of the patient or the physician.

For this purpose of better matching patients with treatment options, several authors recently have drawn attention to the transtheoretical model of behavioural change ( 2 4, 23-26). This transtheoretical model, also frequently referred to as "Stages of Change" model, was first presented by Prochaska and DiClemente (27) and describes change as a process in which people move from a low to a high level of active participation (5). They can move through different stages ranging from no intention to change, e.g. with lack of motivation to adopt a self-management programme, to -on the other sideoptimal active participation with internalisation of the new behaviour.

\begin{tabular}{|c|c|c|}
\hline Stage of change & Description & Example \\
\hline \multirow[t]{2}{*}{ Precontemplation } & Not yet considering to & "Exercising is not useful for me. \\
\hline & change behaviour & Why should I do it?" \\
\hline \multirow[t]{3}{*}{ Contemplation } & Thinking about change and & "Maybe, it's worthwhile ro exercise. \\
\hline & idoption of a new behaviour, & And maybe I should do ir. I will start \\
\hline & but no real commiment & exercising, whenever ..." \\
\hline \multirow[t]{2}{*}{ Preparacion } & Plannaing to engage in new & "I've made an appointment. Nexr week \\
\hline & behawiour in the near furure & I will starr learning how to exercise." \\
\hline \multirow[t]{2}{*}{ Action } & Adopting and execuring the & "Twice a week I'm going to the gym \\
\hline & new behaviour & and exercise. I'm making progression." \\
\hline \multirow[t]{3}{*}{ Relapse } & After a period of pertorming & "I don't spend enough rime on exercising \\
\hline & new belzaviour relapsing to the & Maybe I shoulld do more..." \\
\hline & "old lyalbiss" & \\
\hline
\end{tabular}

Table 1: Stages of chang

In the present study a new questionnaire was developed for the assessment of the stage of change of osteoarthritis patients, because already existing questionnaires were designed for other study populations, e.g. chronic pain syndromes $(3-5,24)$. A Dutchlanguage questionnaire used in a recent study in fibromyalgia patients (5) was not appropriate for the osteoarchritis group. The present questionnaire is especially 
developed for osteoarthritis parients in a community sample.

The goals of the present study were (1) to determine the internal consistency and the factor structure of the Stages of Change Questionnaire in Osteoarthritis, and (2) to compare methods for classifying patients according to the stage-of-change questionnaire in order to know which of these is to be used.

\subsection{METHODS}

\section{Participants}

The study population consisted of patients with osteoarthritis age 40 to 60 years recruited for a randomized controlled study on the efficacy of self-management in a general practice setting. Osteoarthritis was diagnosed along standardised criteria applied in research in general health care settings previously (28). Patients with rheumaroid arthritis, ankylosing spondylitis and gour were excluded. Patients were recruited in general practices and by advertisements in the open population.

\section{Procedure}

First, a questionnaire was developed in line with the protorype of all stages of change questionnaires: the University of Rhode Island Change Assessment questionnaire (URICA; McConnaughy, Prochaska \& Velicer, 1983). This questionnaire, adapted to a Dutch population with osteoarthritis, consisted of 21 -items divided in three subscales of 7 items each: 7 iterns on Precontemplation, 7 items on Contemplation and 7 items on Action. It takes 3 to 5 minutes to fill in this self-administered questionnaire. The items are scored with a 5-point Likert-scale (strongly disagree - disagree - neutral agree - strongly agree). The questionnaire is shown in Appendix A. Internal consistency of the questionnaire was checked by computing Cronbach's Alphas on the items of the subscales and a factor analysis is done to see whether or not these items load on the presumed subscale.

Further, three different classification methods were compared in this study sample: the highest score method, the meaningful cut-off point method (9) and the five point difference classification. The highest score method to assign patients to one specific stage is based on the highest score on the dimension scales $(2,29)$. If the patient shows 
equally high scores in two or more scales, the patient is considered to belong to the most progressed stage in the Stages of Change model. In the meaningful cut-off point method the parient is assigned to one specific stage by using meaningful cut-off points $(5,9,30)$. This method is based on the presumption that patients in a certain stage have the characteristic of that stage but not the characteristic of the other stages. On the 5 point-scale ranging from 1 ("strongly disagree") to 5 ("strongly agree") a score of higher than 3 is indicative of the presence of that characteristic. Using this method with three dimension scales, eight permurations are possible (see table 2). Three out of the eight permutations are called "unclassifiable", because they don't seem to fit in the Stages of Change model, for example when all three sub scales show high scores. Dijkstra et al (2001) described the following stages using this cur-off point merhod: precontemplation, contemplation, preparation (scoring high on contemplation and on action), action and a group called relapse (characteristics of both precontemplation and action).

\begin{tabular}{llll}
\hline Precontemplation & Contemplation & Action & \\
\hline+ & + & + & Undlassifiable 1 \\
+ & + & - & Undassifiable 2 \\
+ & - & + & Relapse \\
+ & + & $*$ & Precontemplation \\
- & + & + & Preparation \\
- & + & - & Conternplation \\
- & + & + & Action \\
\hline
\end{tabular}

Table 2: Classiffation along the stages of change madel with the "utwoff point method" (i.e: cowsidering that a patient can score positive or negative in cach of the three groups of items, there are 8 possible permuations, as illwatrated in this table; besides Pre, Cont and Action, wo otber descriptions are introduced: 1 , prepatiation including parss of Cont and part of Action and 2 , relapse, i.e. partly in action and partly "Buck" in Pres. 3 perratutations are called "unclassiffable", because they do not seem. wo fit clearly in the stages of change-model)

Five point difference methods in this particular study on osteoarthritis patients an additional and not earlier published method was described and tested in an attempt to overcome some drawbacks of the already existing methods. In each category sub scores 
were counted by the sum of the scores of the questions, allowing for possible scores between 5 and 25 points. In the data we regarded a difference of 5 points or more as relevant per sub score. Thus, when the sum score in the Precontemplation-items was 5 points higher than in the other two (Contemplation and Acrion), this person was counted as a Precontemplator.

\section{Otber measures}

For the purpose of characterising the present sample of osteoarthritis patients two other measures are reported here. Visual analogue scales (VAS) were used to assess severity of pain (31). To assess outcome in osteoarthritis research Bellamy and colleagues developed the WOMAC: the Western Ontario and McMaster Universities Osteoarthritis Index $(32,33)$. This is a three-dimensional (pain, stiffness, physical function), disease specific (OA), self-administered health status questionnaire. Scores per irem vary from 0 (no problem) to 4 (extreme difficulty). Thus, the sum scores on this 24 irem questionnaire in theory range from 0 to 96 . At baseline radiological investigations of knees and hips were done (34).

\section{Data analysis}

For all above described analyses SPSS 11.0 for Windows was used. Analyses started with the above described 21 -item questionnaire. Factor structure of the questionnaire was analysed applying a Principal Component Analysis. The rotation procedure was done with an orthogonal (VARIMAX) method with Kaiser normalization. The following criteria were used in order to determine the definite number of items: adequate reproducibility $(>.70)$ and factor loadings of .35 or higher on the presumed factor. After item-reduction again Cronbach's Alphas and factor analysis was repeated to check for changes.

\subsection{Results}

In the present study 273 osteoarthritis patients participated (110 male, 163 female) who were recruited by advertisement or by general practitioners, thus representing a community sample. Participants reported moderate pain intensity in the hips (mean score on VAS 3.36; SD 2.77) and knees (mean VAS 4.06; SD 2.66). An evident level of discomfort and disability (mean score on WOMAC: 34; SD 16.13) was noted. 
Radiological changes were reported in $78.4 \%(n=214)$ of the patients, while physical examination showed Heberden's nodes in $15.4 \%(n=41)$ and crepitation in knees in $66.3 \%(n=181)$. Stiffness was reported by $88.6 \%(n=242)$ of participants.

In appendix A the 21-item questionnaire (Stages of Change Questionnaire in Osteoarthritis) is shown. Cronbach's Alphas calculated prior to the factor analysis were for the Action scales .74, for the precontemplation scales. 70 and for the contemplator scales .77. Before running factor analysis Bartlett's test of sphericity and the KaiserMayer-Olkmin (KMO) measure of sampling adequacy was checked and proved to be .778 , which is well above the requested .5 (35). Factor analysis revealed that item 7, 12, 18 and 20 did not load on the presumed subscale and item 3 and 16 was nondiscriminative (factor loading bellow .35). Consequently these items were excluded from the questionnaire. In the resulting 15-itemlist Cronbach's Alphas were again assessed showing .79 on the action, .72 on the precontemplation and .76 on the contemplation scales. So, reproducibility of the presumed subscales is considered to be good.

Repeating the factor analysis with rotation method (Varimax) in the 15-item list showed satisfactory loading of the items on the presumed subscales. Thus, three factors were extracted explaining for $45 \%$ of variance, which in itself is modest and probably caused by the rather high percentage of "unclassifiable". This 15 -item list, called Stages of Change Questionnaire in Osteoarthritis, was used for the remaining analyses in this study.

The cut-off point method yields in this data set the following classification. See table 4. Like in other studies (5) this method of scoring resulted in a considerable percentage unclassifiable.

\section{Three classification methods}

Remarkable differences in classification were noted using the three described methods, as follows. Using the bighest score method $10.3 \%$ was in the "precontemplation stage", $22.3 \%$ in the "contemplation stage", $67.0 \%$ was "in action", and there were no unclassifiable participants. The cut-off point method yielded in this data set like in orher studies (5) a considerable percentage of unclassifiable (see table 4). Administering the 5-point difference method many participants were not classifiable in one of the predefined categories, for example because they showed high scores both in precontemplator and contemplator subscales (with a difference of less than 5 points). 
Factor analysis

\begin{tabular}{|c|c|c|c|c|c|c|}
\hline \multirow[t]{2}{*}{ Itendist } & \multicolumn{3}{|c|}{21 items } & \multicolumn{3}{|c|}{15 ittems } \\
\hline & $1 \mathrm{P}$ & $2 C$ & $3 \mathrm{~A}$ & $1 \mathrm{P}$ & $2 \mathrm{C}$ & $3 \mathrm{~A}$ \\
\hline 1 & .587 & .109 & .022 & .599 & .091 & .043 \\
\hline 2 & .062 & .392 & .235 & .077 & 363 & .242 \\
\hline 3 & .267 & -.124 & .285 & & & \\
\hline 4 & .699 & -.113 & .085 & .704 & -158 & .101 \\
\hline 5 & -.070 & .565 & .337 & -.049 & .541 & .334 \\
\hline 6 & -.089 & .235 & .749 & -.087 & .234 & .749 \\
\hline 7 & .291 & .500 & .239 & & & \\
\hline 8 & .009 & .316 & .567 & -.021 & .307 & .569 \\
\hline 9 & .685 & .220 & -.045 & .715 & .188 & -.019 \\
\hline 10 & .063 & .791 & .111 & .075 & 826 & .106 \\
\hline 11 & .182 & .705 & .077 & .216 & .682 & .103 \\
\hline 12 & .054 & .306 & .403 & & & \\
\hline 13 & .1 .5 & -.024 & .786 & .117 & -.048 & .792 \\
\hline 14 & .530 & -.040 & ${ } 012$ & 484 & -.049 & .001 \\
\hline 15 & .107 & .709 & -.028 & -.087 & .706 & -.037 \\
\hline 16 & .258 & -.254 & .307 & & & \\
\hline 17 & .529 & .145 & -.063 & .511 & .103 & -.051 \\
\hline 18 & .122 & .243 & .303 & & & \\
\hline 19 & .099 & .168 & .643 & .111 & .138 & .668 \\
\hline 20 & .333 & -.272 & .173 & & & \\
\hline 21 & -.037 & .013 & .581 & -.039 & .012 & .579 \\
\hline
\end{tabular}

Table 3. Factor matrix of 21-itemlist and of 15-itemlist, using Confirmatory Principal Camponent Analysis. exthoting whree factors (WARIMAX rotation). Items were deleted wher factor loadings wew less than .35 ar whon an item loaded on another factor than predicted 


\begin{tabular}{lccc}
\hline Stage & $\begin{array}{c}\text { General practitioner } \\
\mathbf{n} \approx 149(\%)\end{array}$ & $\begin{array}{c}\text { Advertisentent } \\
\mathbf{n}=124(\%)\end{array}$ & Chi-square \\
\hline Preconremplation & $6(4.0)$ & $2(1.6)$ & n.s. \\
Contemplation & $8(5.4)$ & $4(3.2)$ & n.s. \\
Preparation & $49(32.9)$ & $61(49.2)$ & 0.006 \\
Action (act) & $27(18.1)$ & $23(18.5)$ & n1.5. \\
Relapse & $13(8.7)$ & $9(7.3)$ & nn.s. \\
Uncilassifiable & $46(30.8)$ & $25(20.1)$ & 0.045 \\
\hline
\end{tabular}

Table 4: Classification of Readiness to Change of two samples of patients with different ways of recruitment: referwal by general practinoner or afther advertisement

Therefore, a range of data-groups was developed according to the rationale of the theoretical concept: "precontemplator", "precontemplator + contemplator", "contemplator", "precontemplator + contemplator + action", "contemplator + action", "action". In this order a logical sequence is recognisable ranging from precontemplation, i.e. not ready to adopt an active self-management approach on the one hand, to "in action", i.e. changing and adopting the new approach. This 5-point difference method however yielded many subclasses which were difficult to interprer.

\subsection{Discussion}

The main purpose of this study was to develop a questionnaire on Stages-of-Change and investigate its applicability in osteoarthritis patients, with as ultimate goal a better match of osteoarthritis patients and self-management programmes. The facror analysis showed a facture structure that was like the three groups that were described beforehand (Pre, Cont and Act). After reduction of 6 items, repeated factor analysis showed loadings all above .35 and they were all in line with the described groups. Internal consistency also appears to be good regarding the Cronbach's Alphas ranging from .72 to .79 . A remarkable finding is the variety in results when in one study sample three different methods of scoring are applied. The new method of scoring which was introduced in the present study (five point difference) in order to overcome drawbacks like high percentage of "unclassifiable" seems to have caused more problems in classifying patients than the pre-existing ones. The addition of the five-point difference 
method of scoring has not helped and therefore we recommend it not for further use. There are differences and similarities with previous studies $(2-5,24,29)$ making comparisons worthwhile, of which some briefly will be described here. First, to our knowledge this is the first study on the applicabillity of the Stages of Change model in a sample of osteoarthritis patients in a general practice setting. Second, although the Stages of Change Questionnaire in Osteoarthritis is especially designed for an osteoarthritis population and for use in a general practice setting, there is a considerable overlap with the Pain Stages of Change Questionnaire (PSOCQ) presented by Kerns and colleagues (3). Though, the PSOCQ was primarily developed for chronic pain conditions and the first studies on characteristics and use of the PSOCQ were performed in specialised pain clinics, most of them situated in tertiary health care settings (2-4). The PSOCQ focuses on pain management, while the current Stages of Change Questionnaire in Osteoarthritis focuses on coping with osteoarthritis. In the study by Keefe and his colleagues the PSOCQ was administered in two study samples (one with rheumatoid arthritis patients and one with OA patients), recruited from rheumatology clinics, public posters, and newspaper advertisements (2). Recently, Habib published a study in which the PSOCQ is applied in a non-pain-clinic sample of patients. These authors conclude that the stages of change model requires modification before it can be used in the treatment planning in a non-pain-clinic sample (24). The current study is an example of the development of a questionnaire on stages of change for use in a general health care setting. Furthermore, the Stages of Change Questionnaire in Osteoarthritis was originally written for a Dutch-language study sample, while the PSOCQ is primarily designed in an English-language population. At the moment there is no authorised Dutch-language version of the PSOCQ available.

Possible limitations of the present study to be mentioned are the following. First, the selecrion procedure of participants may cause under representation of the people in the precontemplation stage, since the study sample was recruited especially for selfmanagement treatments. It therefore seems unlikely that many participants will be in the precontemplation stage, which would quite contradictory to being prepared participating in a self management programme. It would be interesting to investigare the Stages of Change Questionnaire in Osteoarthritis in another population in which the proportion of precontemplation is expected to be more prominent. The second limitation of this study is the fact that there are no data available on the validity of the 
new questionnaire used. An interesting finding in this respect is the significant difference of participants in the preparation phase, detected with this questionnaire. This makes sense while it can be expected that patients selected by advertisements are more prepared to act than patients that are approached by their GP. This seems to be in favour of the validity of the current questionnaire.

We conclude that the Stages of Change Questionnaire in Osteoarthritis, a 15-itemquestionnaire to assess the "stage-of-change" developed for use in a group of osteoarthritis patients in a general health care setting, showed good internal consistency and adequate factor structure. The findings of the current study indicate that further development and research is needed for example on aspects of validity. So far, the Stages of Change Questionnaire in Osteoarthritis can be used in osteoarthritis-populations for research purposes, but it seems not to be ready yet for use in healthcare settings. 


\section{APPENDIX A:}

Stages of Change Questionnaire in Osteoarthritis

The items $3,7,12,16,18$ and 20 are deleted (reason between brackets).

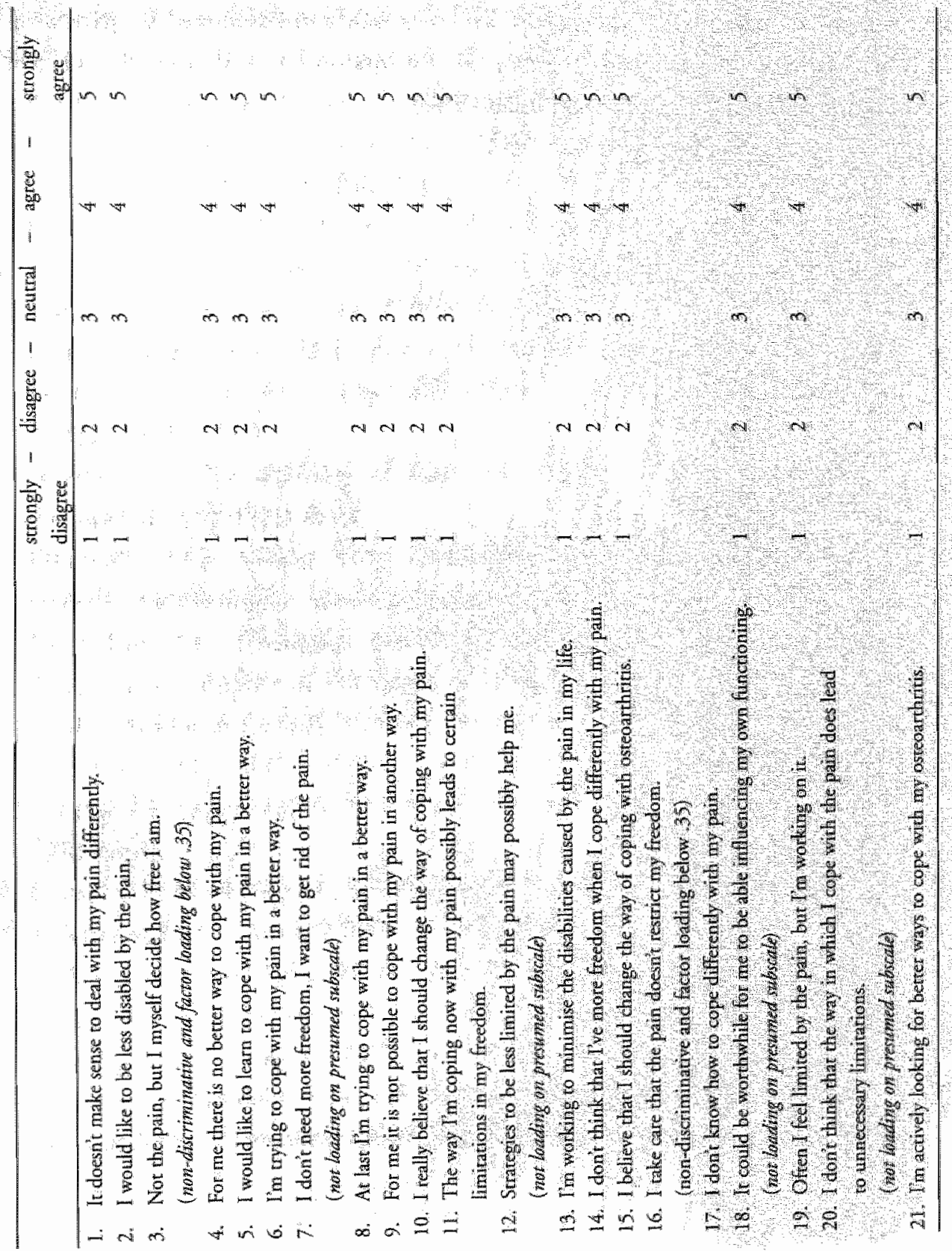




\subsection{ACKNOWLEDGEMENTS}

We would like to express our gratitude to Marion Drietellaar for her work in collecting the data. We also owe thanks to the family physicians of the academic networks of the universities in Maastricht (RNH) and Nijmegen (CMRNMP) who participated in the recruitment of patients for this study. This research was supported by grants of the Dutch Arthritis Association (Nationaal Reumafonds) and the Rehabilitation Foundation Limburg, both in the Netherlands. 


\subsection{REFERENCES}

1. Whitelaw S., Baldwin S., Bunton R., Flynn D.. The status of evidence and outcomes in Stages of Change research. Health education research 2000;15(6):707-718.

2. Kerns R., Rosenberg R.. Predicting responses to self-management treatments for chronic pain: application of the pain stages of change model. Pain $2000 ; 84(1): 49$ 55.

3. Kerns R., Rosenberg R., Jamison R., Caudill M, Haythornthwaite J.. Readiness to adopt a self-management approach to chronic pain: The Pain Stages of Change Questionnaire (PSOCQ). Pain 1997:72:227-234.

4. Keefe FJ., Lefebvre J.C., Kerns R.D., Rosenberg R., Beaupre P., Prochaska J., et al. Understanding the adoption of arthritis self-management: stages of change profiles among arthritis patients. Pain 2000;87(3):303-313.

5. Dijkstra A., Vlaeyen J.W.S., Rijnen H., Nielson W.. Readiness to adopt the selfmanagement approach to cope with chronic pain in fibromyalgic patients. Pain 2001;90(1-2):37-45.

6. Bandura A. The anatomy of stages of change. American Journal of Health Promotion 1997;12(1):8-10.

7. Prochaska J.O., Velicer W.F. Misinterpretations and misapplications of the transtheoretical model. American Journal of Health Promotion 1997;12(1):1 1-12.

8. Samuelson M.. Changing unhealthy lifestyle: who's ready... who's not?: an argument in support of the stages of change component of the transtheoretical model. American Journal of Health Promorion 1997:12(1):13-14.

9. Dijkstra A.. The validity of the Stages of Change model in the adoption of the selfmanagement approach in chronic pain. The Clinical Journal of Pain accepred for publication.

10. Creamer P., Hochberg M.. Osteoarthritis. "The Lancet 1997;350:503-509.

11. Hochberg M.C., Altman R.D., Brandt K.D., Clark B.M., Dieppe P.A., Griffin M.R., et al. Guidelines for the medical management of osteoarthritis. Part I. Osteoarthritis of the hip. Arthritis \& Rheumarism 1995;38(11):1535-1540.

12. Hoctrberg M.C., Altman R.D., Brandt K.D., Clark B.M., Dieppe P.A., Griffin M.R., et al. Guidelines for the medical management of osteoarthriris. Part II: Osteoarthritis of the knee. Arthritis \& Rheumatism 1995;38(11):1541-1546. 
13. Altman R.D., Hochberg M.C., Moskowitz R.W., Schnitzer T.J.. Recommendations for the medical management of osteoarthritis of the hip and knee; 2000 update. Arthritis \& Rheumatism 2000;43(9):1905-1915.

14. Pendleton A., Arden N., Dougados M., Doherty M., Bannwarth B., Bijlsma J., et al. EULAR recommendations for the management of knee osteoarthritis: report of a task force of the Standing Cormmittee for International Clinical Studies $\llbracket$ ncluding Therapeutic Trials (ESCISIT). Annals of the Rheumaric Diseases 2000;59(12):936-944.

15. Ruwaard D., Kramers P., editors.1997: de som der delen. Volksgezondheid Toekomst Verkenning. Bilthoven: Rijksinstituut voor Volksgezondheid en Milieus 1997.

16. Bandura A. Self-efficacy: the exercise of control. New York: Freeman and Company; 1997.

17. Barlow J.. How to use education as an intervention in osteoarthritis. Best Practice \& Research Clinical Rheumatology 2001;15(4):545-558.

18. Lorig K., Holman H.. Arthritis self-management studies: a twelve-year review. Health Education Quaterly 1993;20(1):17-28.

19. Lorig K.R., Mazonson P.D., Holman H.R. Evidence suggesting that health education for self-management in patients with chronic arthritis has sustained health benefits while reducing health care costs. Arthritis and Rheumarism 1993;36(4):439-446.

20. Hopman-Rock M., Westhoff M.H.. The effects of a health educational and exercise program for older adults with osteoarthritis of the hip or knee. The Journal of Rheumatology 2000;27(8):1947-1954.

21. Keefe FJ., Kashikar-Zuck S., Robinson E., Salley A., Beaupre P., Caldwell D., et al. Pain coping strategies that predict patients' and spouse's ratings of patients' selfefficacy. Pain 1997;73:199-191.

22. Wade D.T. Research into rehabillitation. What is the priority? Clinical Rehabilitation 2001;15(3):229-232.

23. Jensen M.P. Enhancing motivation to change in pain treatment. In: Turk R.J.G.D.C., editor. Psychological approaches to pain management. New York London: The Guilford Press; 1996. p. 78-111.

24. Habib S., Morrissey S.A., Helmes E.. Readiness to adopt a self-management approch to pain: evaluation of the pain stages of change model in a non-pain-clinic sample. Pain 2003;104(1,2):283-290. 
25. Jensen M., Nielson W., Romano J., Hill M., Turner J.. Further evaluation of the pain stages of change questionnaire: is the transtheoretical model of change useful for patients with chronic pain? PAIN 2000;86:255-264.

26. Jensen M.P., Nielson W.R., Turner J.A., Romano J.M., Hill M.L.. Readiness to self-manage pain is associated with coping and with psychological and physical functioning among patients with chronic pain. Pain 2003;104:529-537.

27. Prochaska J., DiClemente C., Norcross J.. In search of how people change, applications to addictive behaviors. American Psychologist 1992;471:1102-1114.

28. de Bock G.. Peripheral osteoarthritis in general practice. Leiden: Leiden University; 1994.

29. Biller N., Arnstein P., Caudill M.A., Federman C.W., Guberman C.. Predicting Completion of a Cognitive-Behavioral Pain Management Program by Initial Measures of a Chronic Pain Patient's Readiness for Change. The Clinical Journal of Pain 2000;16:352-359.

31. Jensen M.P., Karoly P.. Self-reporr scales and procedures for assessing pain in adults. In: Turk D.C., Melzack R., editors. Handbook of pain assessment. New York \& London: The Guilford Press; 1992.

32. Bellamy N., W. Watson Buchanan C.H.G., Jane Campbell \&: Larry W. Stitt. Validation study of WOMAC: a health status instrument for measuring clinically important patient relevant outcomes to antirheumatic drug therapy in patients of the hip or knee. The Journal of Rheumatology 1988;15(12):1833-1840.

33. Bellamy N.. Outcome measurement in osteoarthritis clinical trials. The Journal of Rheumatology 1995;22(1):49-51.

34. Kellgren J., Lawrence J.. Arlas of standard radiographs. The Epidemiology of chronic Rheumatism. Oxford UK; 1963.

35. Field A.. Discovering Statistics using SPSS for Windows. London, Thousand Oaks, New Delhi: SAGE Publications; 2000. 
Abstract 92

Introduction 93

Methods 94

Measures 95

Results 97

Discussion 102

Acknowledgements 105

References 106 


\section{CHAPTER FIVE}

PAIN-RELATED FEAR AND DAILY FUNCTIONING IN PATIENTS WITH OSTEOARTHRITIS.

NOVEL INVESTIGATIONS WITH THE TAMPA SCALE FOR KINESIOPHOBIA

Peter H.T.G. Heuts, ${ }^{2}$, Johan W.S. Vlaeyen, Jeffrey Roelofs', Rob A. de Bie', Karin Aretz ${ }^{2}$, Chris van Weel's, Onno C.P. van Schayck?

1. Rehabilitation Foundation Limburg, Zandbergsweg 111,6432 CC Hoensbroek, The Nethettands

2. Department of General Practice, Research Institure CAPHRI, Maastricht Uniwersiry, PO. Box 616, $6200 \mathrm{MD}$ Mastricht, The Nerllerlands.

3. Department of Medical, Clinical and Experimental Psychology, Maastricht Uniwersity, P.O. Box 616, $6200 \mathrm{MD}$ Maastricht

4. Deparment of Epidemiology, Research Insticute CAPHRI, Maastricht University, BO. Box 616. 6200 MD Mastricht, The Netherlands

5. Deparment of Family Medicine, University Medical Centre St Radboud, Nijmegen, The Netherlands

Published in: Pain 2004:110:228-235. 


\subsection{ABSTRACT}

\section{Objective}

To investigate the degree to which pain-related fear, measured with the Tampa Scalle for Kinesiophobia (TSK), influences daily functioning in OA parients.

\section{Background}

There is growing evidence supporting the relationship between pain-related fear and functional disability in chronic musculoskeletal pain conditions. In osteoarthritis (OA) patients the role of pain-related fear and avoidance has received little tesearch attention so far.

\section{Methods}

The purpose of the present study was twofold: (1) to investigate the factor structure of the TSK in a sample of OA patients by means of confirmatory factor analysis (CFA); and (2) to investigate the role of pain-related fear in OA compared to other factors, such as radiologicall findings and level of pain intensity, by means of regression analyses.

\section{Results}

The TSK consists of two factors, called "activity avoidance" and "somatic focus", which is in line with other studies in low back pain and fibromyalgia. Furthermore, pain-related fear occurred to a considerable extent in this sample of osteoarthritis patients and was negatively associated with daily functioning. Level of pain and level of pain-related fear were significantly associated with funcrional limitations. Radiological findings were not significant predictors and when compared to painrelated fear they were not significant.

\section{Conclusions}

These findings underscore the importance of pain-related fear in daily functioning of OA patients. Therefore, treatment strategies aiming at reduction of pain-related fear in $O A$ patients need to be developed and investigated. 


\subsection{INTRODUCTION}

Osteoarthritis $(O A)$ is a clinical syndrome characterised by joint pain and stiffness. It is accompanied by loss of function and it frequently hampers the patient in performing daily activities. In pathological terms, $O A$ is usually described as a condition of cartilage degeneration, subchondral bone stiffening, and active new bone formation (Altman et al. 2000; Creamer and Hochberg 1997; Hochberg et all. 1995a; Hochberg et al. 1995b; Pendleton et al. 2000). OA is a major cause of musculoskeletal pain and is therefore an important burden in community health care. $O A$ is associated with increasing age and since the proportion of elderly in our society is growing steadily, optimal management of this condition is of paramount importance.

Pain intensity and physical impairment only partly predict the level of (daily) functioning. It is well documented that functional limitations are also severely influenced by several other factors such as coping strategies and mood (Baron et al. 1987; Dekker et al. 1992; Hopman-Rock et al. 1997; Keefe et all. 1987; McAlindon et al. 1993; Steultjens 2001). The negative role of pain-related fear on functioning recently gained considerable atrention in the field of musculoskeletal pain research (Asmundson et al. 1999; Vlaeyen 2003; Vlaeyen and Linton 2000). Recently, also in OA patients the influence of fear on functioning is shown to be important (Steultjens et al. 2001; Steultjens et al. 2002). Several investigators have raised questions about the role of fear-avoidance in $\mathrm{OA}$, yet little empirical work addressing this issue is available. The present study addresses the influence of biological (e.g. X-ray changes) as well as psychological aspects (e.g. self-reported pain intensity and level of pain-related fear) on self-reported daily funcrioning in $\mathrm{OA}$ patients.

To assess the level of pain-related fear in patients with chronic pain, several questionnaires have been developed such as the Pain Anxiety Symptoms Scale (PASS; (McCracken et al. 1992)), the Fear-Avoidance Beliefs Questionnaire (FABQ; (Waddell et al. 1993)) and the Tampa Scale of Kinesiophobia (TSK; (Miller et al. 1991; Vlaeyen et al. 1995)). In the present study the TSK was used, because it taps into fear of movement. To date, the factor structure of the TSK has not been investigated in a sample of $O A$ parients. 
To reach a better understanding of pain-relared fear in OA patients the present study was performed. The purpose op the present paper was twofold. First, the present study provides a first attempt to examine the factor structure of the TSK in OA patients by means of confirmatory factor analysis. Second, the role of pain-related fear in $O A$ disability was investigated. Following the results of the confirmatory factor analysis, the best-fitting model was applied in the analyses to assess the role of pain-related fear in this sample of OA patients. The main research question was to examine the degree to which pain-related fear as measured with the TSK, compared to other factors, such as radiological findings and level of pain intensity, influences daily funcrioning in $O A$ patients.

\subsection{METHODS}

\section{Participants}

The study was a cross-sectional comparison of pain-related fear with features of $\mathrm{OA}$ and funcrional status. It was part of a randomised controlled trial of self-management in OA. The population consisted of $254 \mathrm{OA}$ patients between 40 and 60 years of age in a primary health care setring. Patients were recruited from the practices of the academic networks of family medicine $(n=140)$ of the universities of Mastricht (Metsemakers et al. 1992) and Nijmegen (Graww de et al. 2002; Weel van et al. 2000), and by announcements in local newspapers $(n=114)$. The diagnosis of OA in patients who were referred by their general practicioner was checked at study entry with a checklist, containing criteria for diagnosing OA in primary care research (Bock de 1994) (see appendix 1). Exclusion criteria were: rheumatoid arthritis, ankylosing spondylitis, and gout. In patients recruited from the open population the diagnosis OA was confirmed by an experienced physician (first author), using the same criteria and checklist. The protocol of this study was approved by the Medical Ethical Committee of Maastricht University and the Maastricht University Hospital. Approval was also received from the Review Committee of the Registration Network Family Practices (RegistratieNet Huisartspraktijken, RNH) (Metsemakers er al. 1992). All patients were informed about the protocol of the study and signed a written consent. Patient characteristics are presented in table 1 . 


\begin{tabular}{lll}
\hline & Mean & SD \\
\hline WOMAC-function $(\mathrm{n}=244)$ & 22.8 & 11.7 \\
Kellgren $(\mathrm{n}=24 \mathrm{n})$ & 4.0 & 2.9 \\
TSK-AA $(\mathrm{n}=25.4)$ & 17.7 & 4.9 \\
TSK-SF $(\mathrm{n}=254)$ & 1.0 .6 & 3.2 \\
VAS pain hip $(\mathrm{n}=248)$ & 3.3 & 2.7 \\
VAS pain knee $(\mathrm{n}=248)$ & 4.0 & 2.6 \\
Age (in years) $(\mathrm{n}=254)$ & 51.7 & 5.0 \\
\hline
\end{tabular}

Table 1. Descriptive statistict of the stady population

\subsection{MEASURES}

\section{Disability}

The WOMAC (Western Ontario and McMaster Universities Osteoarthritis Index) has been developed by Bellamy and colleagues aimed to assess outcome in OA trials (Bellamy 1995; Bellamy and Jane Campbell 1997; Bellamy and W. Watson Buchanan 1988). This measure is a three-dimensional (i.e., pain, stiffness, physical function), disease-specific (OA), self-administered health status questionnaire, available in Likertand VAS-versions. In this study the Likert version was used. As the main interest was to examine daily functioning, only sum scores of the 17 items reflecting daily (physical) functioning were analyzed for the present study.

\section{Radiographs}

A total rating score was obtained according to the scoring system proposed by (Kellgren and Lawrence 1963). In our study, radiographs were taken at baseline from the hips and the knees. All radiographs were scored by an experienced radiologist who was blinded with respect to other study data. The Kellgren score obtained in each of the four joints (two knees and hips) ranged from 0 to 4 . Consequently, total Kellgren scores ranged from 0 to 16 .

\section{Pain severity}

Pain intensity in the hips and knees was measured with visual analogue scales (VAS).

Since the signs and symptoms of OA vary over time three questions were answered with 
three VAS-measurements: intensity of pain today, intensity of pain last week, and intensity of pain last month. These three VAS scores were highly intercorrelared (Pearson $r$ tanged from .806 to .956 ; all significant at a .01 level). To obtain a reliable indication of pain severity, mean VAS scores on these scales were entered in the analyses as a composite score. Anchors of the VAS scales were 'no pain at all' to 'the worst imaginable pain'. Mean scores of the measures are shown in table 1.

\section{Pain-related fear}

The Dutch version of the Tampa Scale for Kinesiophobia (TSK) was used to assess pain-relared fear. The TSK (Kori et al. 1990; Miller et al. 1991) is a 17-item questionnaire that is aimed at the assessment of fear of (re-)injury due to movement. Each item is provided with a 4-point Likert scale with scoring alternatives ranging from "strongly agree" to "strongly disagree". Psychometric properties of the Dutch version of the TSK have found to be good (Goubert et al. 2000).

\section{Procedure}

At entry of the study WOMAC, TSK and VAS scales were filled in by the participants and radiological investigations were performed. Written instructions about the questionnaires were offered to all participants by a research assistant.

\section{Statistical analyses}

The goodness-of-fit of the four-factor (Vlaeyen et al., 1995) and two-factor model (Clark er all, 1996) of the TSK was examined by means of confirmatory factor analysis (CFA) using the statistical package LISREL version 8.54 . In line with previous studies (Goubert et al., 2004), one-facror models with and withour negatively phrased items were also examined. Thus, the goodness-of-fit of four different models was evaluated.

The Maximum Likelihood algorithm was used to assess the fit of the various models. The models were estimated while allowing the latent variables to correlate. Each item was assumed to load only on one factor. In addition, residuals of each item were assumed to be uncorrelated. The goodness-of-fit for each factor solution was evaluated using several descriptive criteria: (a) the Root Mean-Square Error of Approximation (RMSEA); (b) the Non-Normed Fit Index (NNFJ); (c) the Comparative Fit Index $(C F I)$; (d) the Goodness of Fit index, and (e), the Expected Cross-Validation Index (ECVI). The RMSEA quantifies the divergence between the data and a proposed 
model per degree of freedom. For the RMSEA, values below 0.05 or lower indicate a close fit, whereas values up to 0.08 represent reasonable errors of approximation. A $90 \%$ confidence interval of the RMSEA point estimate is also provided. The NNFI, CFI, and GFI indices measure how much better the model fits as compared to a baseline model, in which the observed variables (items) are assumed to be uncorrelated (i.e., the independence model). For the NNFI, CFI, and GFI values above 0.90 are considered as indicative of an adequate fic whereas values above 0.95 are indicative of a good to very good fit. The ECVI is a relative measure to compare competing models: the model with the lowest value has the best fit. As the one-factor solution without negatively phrased items (model 3, see table 2) is a special case of the two-factor solution (model 4), these models can be compared with a likelihood ratio test. More specifically, under the null hypothesis that the special model fits as well as the more general one, the difference between their Chi-square values is itself Chi-square distributed with degrees of freedom equal to the difference between their degrees of freedom. This analysis of the factor structure offers clinicians several possibilities for adaptation and shortening of the questionnaire.

Regression analyses were carried out to examine the extent to which pain-related fear, radiological changes, pain, age and gender are associated with daily (physical) functioning. Daily functioning (WOMAC) is the dependent variable. Independent variables are: radiological findings (Kellgren score), pain-related fear (factor Acrvity Avoidance and Somatic Focus of TSK), pain (VAS hip and VAS knee), age and gender. First, the forced entry method was applied in order to be able comparing the standardised beta's (table 3). Second, a stepwise procedure was applied to get insight in the changes of adjusted R-squares (table 4) when entering the several independent variables. It should be noted that these analyses were conducted in a cross-sectional fashion such that relationships are to be interpreted as associations. Before starting the regression analyses, all variables were checked on deviation from normality.

\subsection{RESULTS}

\section{Factor structure of the TSK}

Table 2 presents the goodness-of-fit indices for the one-factor solution (model 1), in which all 17 items were included, the four-factor solution (model 2) proposed by Vlaeyen et al (Vlaeyen et al. 1995), the one-factor sollution (model 3) without the four 
negatively phrased irems, and the two-factor solution (model 4), as proposed by Clark et al (Clark et al. 1996). With respect to the goodness-of-fit indices depicted in table 2, RMSEA values were reasonable for model 1,2 and 3 , and good for model 4 . The NNFI, CFI and GFI clearly favored model 4, the two-factor model (Clark et al.. 1996). The lowest values for ECVI were also found for this model, indicating that this model provided the best fit compared to the other models tested. Since model 3 (one-factor model without the four negatively phrased items) is a special case of model 4 (twofactor solution) in that model 4 is nested in model 3, these models can be compared with a likelihood ratio test. The goodness-of-fit of model 4 was substantially better and statistically significant $\Delta \mathrm{x}_{(1)}^{2}=39, \mathrm{p}<0.001$. Taken together, the two-factor model provided the best fit in patients with osteoarthritis. Figure 1 presents factor loadings of the two-factor model. In this two-factor model, TSK-AA and TSK-SF were moderately associated (Pearson $r=0.519, \mathrm{p}<0.001$ ). Internal consistency of TSK-AA was reasonable (Cronbach's alpha $=0.743$ ) and for the TSK-SF moderate (Cronbach's alpha $=0.641)$. It should be noted that deleting item 5 from reliability analyses increased Cronbach's alpha of TSK-SF to 0.669 .

\begin{tabular}{lllllll}
\hline & $\chi^{2}$ (df) & RMSEA $(90 \%$ CI) & NNFI & CFI & GFI & ECVI \\
\hline Model 1 & $318(119)$ & $0.085(0.074-0.096)$ & 0.82 & 0.84 & 0.86 & 1.60 \\
Model 2 & $141(48)$ & $0.081(0.065-0.099)$ & 0.86 & 0.90 & 0.92 & 0.75 \\
Model 3 & $159(65)$ & $0.075(0.060-0.090)$ & 0.90 & 0.92 & 0.91 & 0.83 \\
Model 4 & $121(64)$ & $0.055(0.038-0.071)$ & 0.94 & 0.95 & 0.94 & 0.66 \\
\hline
\end{tabular}

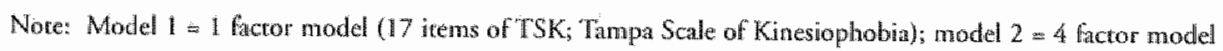
frested in 17 item TSK: harm, tert of (re)injury, importance of exercise and atoidance of activiry; (Vlacyen et al. 1 1995); model $3=1$ Gar model $(13$ items; TSK minus whe rewersed trems $4,8,12,16)$; model $4=2$ factor model (nested in 13 item TSK: somatic focus and activity avoidance: (Clark et al. 1996). RMSEA = Root Mean Square

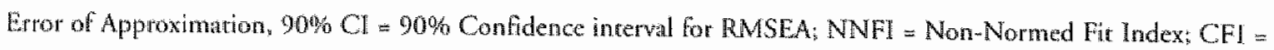
Comparative Fit lndex; GFI = Goodness of Fic Index, ECVI $=$ Expecred Cross-Valiclarion Index.

Table 2: Goodness-offit indices for warious TSK in osrearthritis patients ( $n=254$ ) models obutaned by means of confurmatory factor analysis 


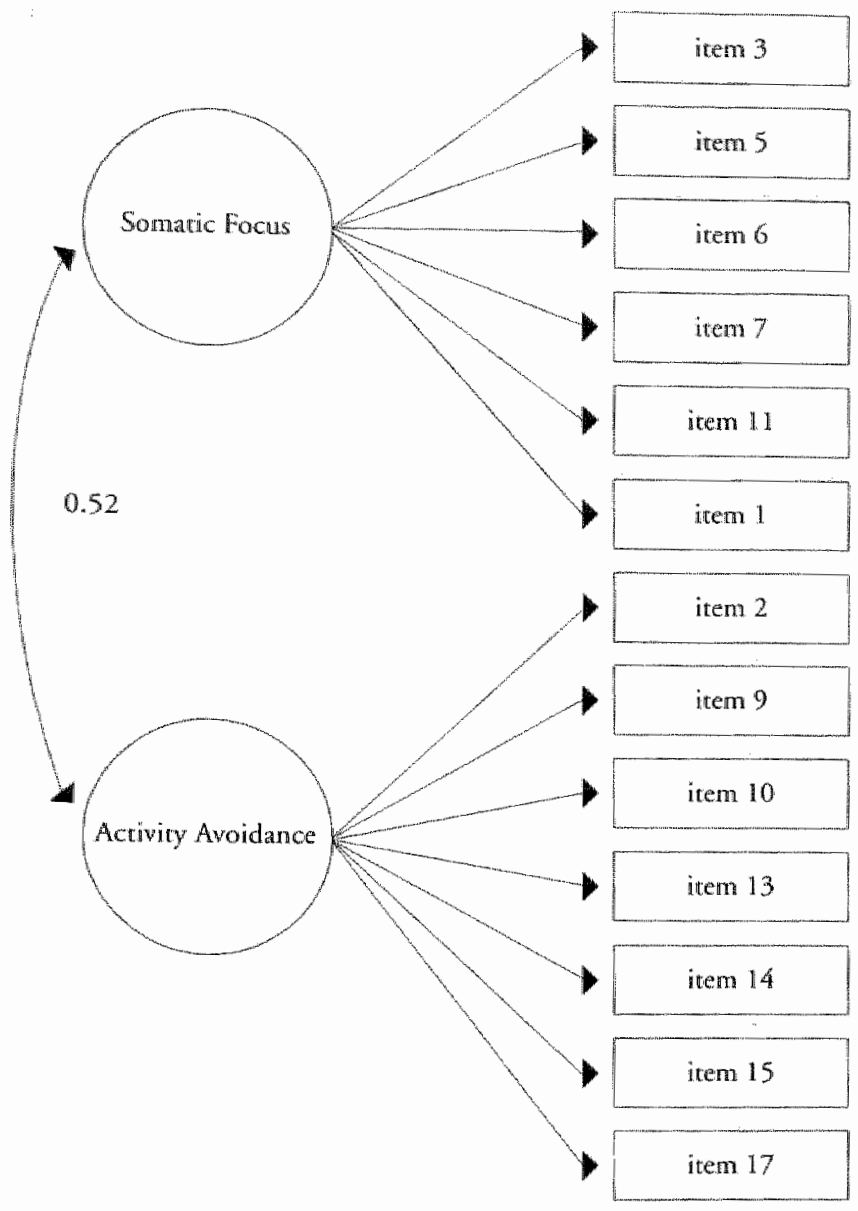

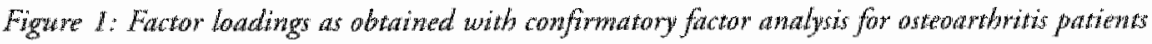

\section{Pain-related fear}

Before addressing the main results of the regression analyses some remarks have to be made. Non-normality of the dependent and independent variables was checked before the regression analyses were carried out. No serious deviation from normality was found for each of the variables. The data were checked with regard to collinearity. In all current models the VIF values are below 1.4 and the tolerance statistics are above 0.7 . Since VIF should be well below 10 and tolerance statisrics well above 0.2 (Field 2000), we can safely conclude that there was no collinearity within our data. 
Table 3 presents the main results of the regression analyses with the forced entry method resulting in two models, one in which the TSK-AA and radiological changes, age, gender, knee pain and hip pain were entered as independent variables, and another with the TSK-SF along with the same other independent variables. Patients with missing values were omitted from the analyses leaving a total number of 227 patients for the regression analyses. The dependent variable was daily functioning as measured with the WOMAC of which only 17 item-subscales measuring functioning were included. In the forced entry regression analyses, TSK subscales and pain measures (VAS pain knee and VAS pain hip) were significantly associated with daily functioning (WOMAC). The radiological findings, however, did not significantly contribute to functioning, R-square values were 387 for model 1 and .403 for model 2 . It should be noted that for analyses without knee pain and hip pain (VAS) as predictors, TSK-AA $(B=0.30, p<0.001)$ and TSK-SF $(B=0.36, p<0.001)$ remained significant predictors of daily functioning.

\begin{tabular}{|c|c|c|c|c|}
\hline & Beta & SE beta & $95 \% \mathrm{CI}$ & P'value \\
\hline \multicolumn{5}{|l|}{ Model I } \\
\hline Kellgren & .056 & .056 & $.055-.167$ & .320 \\
\hline TSK AA & .147 & .057 & $.035-.260$ & .011 \\
\hline VAS pain hip & .463 & .056 & $.354-.573$ & $<001$ \\
\hline VAS pain knee & .257 & .057 & $.1455-.370$ & $<.001$ \\
\hline Age & .073 & .054 & $. .034-.179$ & .181 \\
\hline Gender & -.002 & .055 & $. .110-.110$ & .970 \\
\hline \multicolumn{5}{|l|}{ Model 2} \\
\hline Kellgren & .055 & .055 & $-.054-.165$ & .319 \\
\hline TSK SF & .200 & .056 & $.090-.310$ & $<.001$ \\
\hline VAS pain hip & .438 & .056 & $.328-.548$ & $<.001$ \\
\hline VAS pain knee & .260 & .055 & $.152-.369$ & $<.001$ \\
\hline Age & .082 & .053 & $-.023-.188$ & .125 \\
\hline Géndër & .007 & .054 & $. .099-.114$ & .893 \\
\hline
\end{tabular}

Note: Kellgren=measure of radiological changes: TSK AA=activity woidance subscale of TSK; TSK SF = somatic Cockin; VAS wisnal analogue scale

Table 3: Standardized beta weights and confidence intervals (CD) from regression analyses (forced entry method), including TSK AA (model D), TSK SF (model 2) and other predictors of douty functioning in osteodrtoritis patients $(n=227)$. 
Table 4 presents the main results of the stepwise regression analyses. Two sets of models are presented, one with factor TSK-AA and another set with factor TSK-SF. In both sets the independent variables were entered in the same sequence: TSK factor, Kellgren, VAS pain knee, VAS pain hip, age and gender. In both sets, TSK factor, VAS pain knee and VAS pain hip were significantly associated with daily (physical) functioning, while Kellgren, age and gender did not contribute significantly. In the first set of models TSK-AA counted for about 9\% of explained variance (see adjusted R-squares), while VAS pain knee and VAS pain hip added each about $9 \%$ and $19 \%$, resulting in a total of $37 \%$ explained variance. In the second set of models TSK-SF counted for $10 \%$, while VAS pain knee and VAS pain hip added each about $12 \%$ and $16 \%$, resulting in a total of $38 \%$ of explained variance.

\begin{tabular}{|c|c|c|c|c|c|c|c|}
\hline $\begin{array}{l}\text { Set of models } \\
\text { AA }\end{array}$ & TSK AA & Kellgren & $\begin{array}{l}\text { VAS } \\
\text { pain lanee }\end{array}$ & $\begin{array}{l}\text { VAS } \\
\text { pain huip }\end{array}$ & Age & gender & $\begin{array}{l}\text { Adjusted } \\
\text { R-square } \\
\end{array}$ \\
\hline 1. & $<.001$ & & & & & & .088 \\
\hline 2. & $<.001$ & .805 & & & & & .074 \\
\hline 3. & .006 & .598 & $<.001$ & & & & .178 \\
\hline 4. & .012 & .202 & $<.001$ & $<.001$ & & & .371 \\
\hline 5. & .010 & .283 & $<.001$ & $<.001$ & .309 & & .371 \\
\hline 6 & .012 & .290 & $<.001$ & $<.001$ & .311 & .993 & .368 \\
\hline $\begin{array}{l}\text { Set of models } \\
\text { PSF }\end{array}$ & TSK SF & Kellgren & $\begin{array}{l}\text { VAS } \\
\text { pain knee }\end{array}$ & $\begin{array}{l}\text { VAS } \\
\text { pain hip }\end{array}$ & Age & gender & $\begin{array}{l}\text { Adjusted } \\
\text { R-square }\end{array}$ \\
\hline 1. & $<.001$ & & & & & & .102 \\
\hline 2. & $<.001$ & .937 & & & & & .112 \\
\hline 3. & $<.001$ & .635 & $<.001$ & & & & .217 \\
\hline 4. & .001 & .195 & $<.001$ & $<.001$ & & & .386 \\
\hline 5. & $<.001$ & .293 & $<.001$ & $<.001$ & .221 & & .387 \\
\hline 6. & $<001$ & .289 & $<.001$ & $<.001$ & .226 & .870 & 384 \\
\hline
\end{tabular}

Note: Kellgren=measure of radiological changes; TSK AA=acrivity awoidance subscale of TSK; TSK SF somatic $^{\circ}$ focus; VAS=visual analogue scale

Table 4: P-walues of the independent wariables entered in stepwise regression analyses, with explaind watrinct of the modsts: dependent wariable is daily functioning (measured with WOMAC-function items) $(n=227)$ 


\subsection{Discussion}

The present study examined the influence of pain-related fear on daily functioning in OA patients. For that purpose investigations were performed on the factors of the TSK (Miller et al., 1991) and on the question to what extent pain-related fear as measured with the TSK compared to other factors such as radiological findings and level of pain intensity influences daily functioning in $\mathrm{OA}$ patients. With respect to the factor structure of the TSK, confirmatory factor analysis clearly showed that the two-factor model (Clark et al., 1996) provided the best fit in OA patients. In line with previous research, the two factors were labeled "activity avoidance" and "somatic focus". To our knowledge, this is the first study that examined the factor structure of the TSK in OA patients and the results from the present study add to some recent studies that have successfully replicated the two-factor model proposed by Clark and colleagues (Geisser et al. 2000; Goubert et al. 2004; Swinkels-Meewisse et al. 2003). These findings pave the way for clinical use of this questionnaire in OA patients.

Regression analyses showed substantial and significant positive association between both pain intensity and pain-related. fear (two TSK subscales), and the level of daily functioning as measured with the WOMAC. Together with pain intensity (knees and hips), pain-related fear accounted in both analyses for about $40 \%$ of the variance in the level of impaired functional level. Age, gender, and radiological findings were not significantly associated with scores on the functioning scale of the WOMAC. Thus, pain-related fear (i.e., TSK-AA and TSK-SF) and self-reported pain intensity (VAS pain) were found to have the strongest associations with daily functioning (WOMAC). The results of the regression analyses were comparable for a model containing either TSK-AA or TSK-SF. The percentage of variance explained by pain-related fear (i.e., TSK-AA and TSK-SF) was modest. However, it should be borne in mind that physical function, pain, and stiffness (as reflected by the three subscalles of the WOMAC) is influenced by a complex ser of facrors of which pain-related fear is only one important contributor. Interestingly, radiological findings as an objective measure of joint damage were not significantly associated with daily funcrioning (WOMAC). These findings underscore the relevance of the present study and the importance of pain-related fear in daily functioning of $O A$ patients. Thus, this may implicate that the level of selfreported pain-related fear might be considered a better indicator of level of functioning than radiological investigations. 
The two factors called TSK-AA and TSK-SF that were found in the present study sample of $\mathrm{OA}$ patients warrant further interpretation. The usefulness of these constructs for clinical purposes is interesting. "Activity avoidance" reflects the belief that activity may result in (re)injury or increased pain. "Somatic focus" reflects the belief in an underlying somatic-medical problem. Since both "activity avoidance" and "somatic focus" were negatively associated with daily functioning in this sample of OA patients, it might be hypothesized that these high scores on TSK-AA and TS-SF are related with avoidance of activities leading to a lower level of activities and movements. Hence high scores on TSK-AA and TSK-SF are likely to reflect obstacles for adequate movement and exercise, which may result in a deterioration of physical condition and muscle weakness. In previous studies it is demonstrated that exercise has a beneficial effect on functioning in OA patients (Baar van 1998). Therefore ir appears relevant to study the role of pain-related fear in OA patients further and investigate treatment strategies to teduce these fears. This may be helpful in adopting an active lifestyle with enough exercise. It is only in recent years, that exercise and movement have been viewed as safie and recommended for OA patients. Nonetheless, patients with severe $O A$ need to be screened medically before participating in certain types of exercise. Avoidance of certain functional activities may be, in some OA pacients, less of a fear than a matter of following advice given by health practitioners. The results of the present study highlight the importance of pain-related fear in OA. TSK-AA and TSK$\mathrm{SF}$ appeared to be relevant determinants of disability and therefore are important from a clinical point of view. In OA patients the following question needs to be addressed: to what extend are "somatic focus" and "activity avoidance" maladaptive?

The present study has the following limitations. The cross-sectional character of the study design makes it impossible to draw conclusions about causality. It is not yet possible to make inferences about the way in which pain-relared fear influences functioning in osteoarthritis populations. Because the findings however demonstrate a clear relationship, longitudinal studies are needed to clarify possible causality. Furthermore, in longitudinal studies it can be examined whether TSK-SF changes parallel with changes in TSK-AA or otherwise. 
The results of the present study can be used for further investigations in OA patients with high score on TSK. For instance, new treatment strategies can be developed in this population in line with recent developments in adjacent fields of musculoskeletal problems. There is for example emerging evidence indicating that graded exposure to movement can be an effective treatment in patients with low back pain who report substantial pain-related fear (Vlaeyen 2003; Vlaeyen et al. 2001; Vlaeyen et al. 2002). Given the results of the present study it is important to start investigations on treatments for (subgroups) of osteoarthritis patients with high levels of pain-related fear in order to optimize daily functioning. It opens up opportunities for tailoring treatment. Exploratory, single case experiments with graded exposure in osteoarthritis patients with high scores on the TSK are warranted. Because this is a new treatment strategy in the OA population, it is evident that studies are needed to test both the applicability and efficacy of graded exposure in this population.

\section{Summarizing}

When answering the above formulated research questions one may conclude that in osteoarthritis patients the 13-item version of the TSK is applicable. It contains two factors: "acrivity avoidance" and "somatic focus". Furthermore, pain-related fear occurred to a considerable extent in this sample of osteoarthritis patients and was negatively associated with daily functioning. Level of pain and level of pain-related fear are significantly associated with functional limitations. Radiological changes, age and gender were not significandy associated to the level of functioning in this study sample. These findings warrant further research both in the processes in which fear interferes with function, as well as in the development of tailored treatments for the benefir of this huge group of patients. 


\subsection{ACKNOWLEDGEMENTS}

We would like to express our gratitude to the family physicians of the academic networks of the universities in Maastricht (RNH) and Nijmegen (CMR/NMP) who participated in the recruitment of patients for this study. We also owe thanks to Rene Weijers, Department of Radiology of Maastricht University Hospital, for reviewing all the radiographs and to Marion Drietelaar, for her work in collecting the data. This research was supported by grants of the Dutch Arrhritis Association (Nationaal Reumafonds) and the Rehabilitation Foundation Limburg, both in the Netherlands.

\section{APPEND IX 1: OSTEOARTHRITIS AS DEFINED IN THE ICHPPC-2 - DEFINED (BOCK DE 1994):}

The diagnosis osteoarthritis must be based on at least one of the following:

(a) characteristic radiological appearance

(b) Heberden's nodes

(c) joint disorder of at least 3 months' duration, with no constitutional symptoms and at least three of the following:

1. irregular swelling

2. crepitation

3. stiffness or limitation of movement

4. normal ESR, theumatoid tests and uric acid

5. patient over 40 years of age. 


\subsection{REFERENCES}

1. Altman R.D., Hochberg M.C., Moskowirz R.W. and Schnirzer T.J.. Recommendations for the medical management of osteoarthritis of the hip and knee; 2000 update., Arthritis \& Rheumatism, 43 (2000) 1905-1915.

2. Asmundson G., Norton P and Norton G.. Beyond pain: the role of fear and avoidance in chronicity., Clin Psychol Rev, 19 (1999) 97-119.

3. Baar van M. Effectiveness of exercise therapy in osteoarthritis of hip or knee, thesis (1998).

4. Baron M., Dutil E., Berkson L., Lander P. and Becker R.. Hand function in the elderly: Relation to osteoarthritis, Journal of Rheumatology, 14 (1987) 815-819.

5. Bellamy N.. Outcome measurement in osteoarthritis clinical trials, The Journal of Rheumatology, 22 (1995) 49-51.

6. Bellamy N. and Jane Campbell J.S., Lawrence Pilch, Cindy Stewart \&x Zahid Mahmood. Validation study of a computerized version of the Western Ontario and McMaster Universities VA3.0 Osteoarthritis Index, The Journal of Rheumatology, 24 (1997) 2413-2415.

7. Bellamy N. and W. Warson Buchanan C.H.G., Jane Campbell \& Larry W. Stitt.. Validation study of WOMAC: a health status instrument for measuring clinically important patient relevant outcomes to antirheumatic drug therapy in patients of the hip or knee, The Journal of Rheurnatology, 15 (1988) 1833-1840.

8. Bock de G.. Peripheral osteoarthritis in general practice, Leiden University, Leiden, 1994, pp. 155.

9. Clark M., Kori S. and Brockel J.. Kinesiophobia and chronic pain: psychometric characteristics and factor analysis of the Tampa Scale., American Pain Sociey Abstracts (1996) 77.

10. Creamer P. and Hochberg M.. Osteoarthritis, The Lancer, 350 (1997) 503-509.

11. Dekker J., Boot B., Woude L.v.d. and Bijlsma J.W. Pain and disability in osteoarthitis: a review of biobehaviorall mechanisms., J Behav Med, 15 (1992) 189 214.

12. Field A.. Discovering Statistics using SPSS for Windows, SAGE Publicarions, London, Thousand Oaks, New Delhi, 2000, 496 pp.

13. Geisser M., Hang A, and Theisen M.. Activity avoidance and function in persons with chronic back pain, Journal of Occupational Rehabilitation, 10 (2000) 215 227. 
14. Goubert L., Crombez G., Van Damme S., Vlaeyen J.W.S., Bijttebier P. and Roelofs J.. Confirmatory factor analysis of the Tampa Scale for Kinesiophobia: invariant two-factor model across low back pain patients and fibromyalgia patients, Clinical Journal of Pain 20(2004):103-110.

15. Goubert L., Crombez G., Vlaeyen J.W.S. and al, e.. The Tampa Schaal voor Kinesiofobie: Psychometrische karakteristieken en normering [The fampa scale for Kinesiophobia: Psychometric properties and norms, Gedrag en Gezondheid, 28 (2000) 54-62.

16. Grauw de W., Gerwen van W., Lisdonk van de E., Hoogen van den H., Bosch wan den W. and Weel van C.. Outcomes of audit-enhanced monitoring of patients with type 2 diabetes., I Fam Pract, 51 (2002) 459-464.

17. Hochberg M.C., Altman R.D., Brandt K.D., Clark B.M., Dieppe P.A., Griffin M.R., Moskowitz R.W. and Schnitzer T.J.. Guidelines for the medical management of osteoarthritis. Part 1. Osteoarthritis of the hip, Arthritis \& Rheumatism, 38 (1995a) 1535-1540.

18. Hochberg M.C., Altman R.D., Brandt K.D., Clark B.M., Dieppe P.A., Griffin M.R., Moskowitz R.W. and Schnitzer T.J.. Guidelines for the medical management of osteoarthritis. Part II: Osteoarthritis of the knee, Arthritis \& Rheumatism, 38 (1995b) $1541-1546$.

19. Hopman-Rock M., Kraaimaat F.W. and Bijlsma J.W.J.. Quality of life in elderly subjects with pain in the hip or knee, Quality of life research, 6 (1997) 67-76.

20. Keefe F.J., Caldwell D.S., Queen K., Gil K.M., Martinez S., Crisson J.E., Ogden W. and Nunley J.. Osteoarthritic knee pain: a behavioral analysis, Pain, 28 (1987) 309-321.

21. Kellgren J. and Lawrence J.. Atlas of standard radiographs. The Epidemiology of chronic Rheumatism, Vol. 2, Oxford UK, 1963.

22. Kori S., Miller R. and Todd D.. Kinesiophobia: A new view of chronic pain behavior., Pain Management, Jan/Feb (1990) 35-43.

23. McAlindon T.E., Cooper C., Kirwan J.R. and Dieppe PA. Determinants of disability in osteoarthritis of the knee, Annals of the Rheumatic Diseases, 52 (1993) 258-262. 
24. McCracken L., Zayfert C. and Gross R. The Pain Anxiery Symptoms Scale: development and validation of a scalle to measure fear of pain, Pain, 50 (1992) 67 73.

25. Metsemakers J., Höppener P., Knottnerus J.A., Kocken R. and Limonard C. Computerized health information in the Netherlands: a registration network of family practices., British Journal of General Practice, 92 (1992) 102-106.

26. Miller R., Kori S. and Todd D.. The Tampa Scale for Kinesiophobia, 1991.

27. Pendleton A., Arden N., Dougados M., Doherty M., Bannwarth B., Bijlsma J., Cluzeau F., Cooper C., Dieppe P., Günther K.-P., Hauselmann H., HerreroBeaumont G., Kaklamanis P., Leeb B., Lequesne M., Lohmander S., Mazieres B., Mola E.-M., Pavelka K., Semi U., Swoboda B., Verbruggen A., Weseloh G. and Zimmerman-Gorska I.. EULAR recommendations for the management of knee osteoarthritis: report of a task force of the Standing Committee for International Clinical Studies Including Therapeutic 'Trials (ESCISIT), Annals of the Rheumatic Diseases, 59 (2000) 936-944.

28. Steultjens M.P. Determinants of pain and disability in osteoarthritis. Thesis, Nivel, Utrecht, 2001, 134 pp.

29. Steultjens M.P., Dekker J. and Bijlsma J.W. Coping, pain and disability in osteoarthritis: a longitudinal study, The Journal of Rheumatology, 28 (2001) 106872 .

30. Steultjens M.P., Delkker J. and Bijlsma J.W. Avoidance of activity and disability in patients with osteoarthricis of the knee: the mediaring role of muscle strength, Arthritis \& Rheumatism, 46 (2002) 1784-1788:

31. Swinkels-Meewisse 1.E., Roelofs J., Verbeek A.L., Oostendorp R.A. and Vlaeyen J.W.S.. Fear of movement/(re)injury, disability and participation in acute low back pain., Pain, 105 (2003) 371-379.

32. Vlaeyen J.W.S., Fear in musculoskeletal pain. In: J. Dostrovsky, D. Carr and M. Koltzenburg (Eds.), Proceedings of the 10th World Congress on Pain, Vol. 24, IASP Press, Seartle, 2003, pp. 631-650.

33. Vlaeyen J.W.S., Kole-Snijders A.M.J., Rotteveel A., Ruesink R. and Heuts P.H.T.G.. The role of fear of movements/(re)injury in pain disabiliry., J Occup Rehab, 5 (1995) 363-372.

34. Vlaeyen J.W.S. and Linton S.. Fear-avoidance and its consequences in chronic musculoskeletal pain: A state of the art, Pain, 85 (2000) 317-332. 
35. Vlaeyen J.W.S., de Jong J., Geilen M., Heurs P.H.T.G. and van Breukelen G.. Graded exposure in vivo in the treatment of pain-related fear: a replicated singlecase experimental design in four patients with chronic low back pain., Behav Res Ther, 39 (2001) 151-66.

36. Vlaeyen J.W.S., de Jong J., Geilen M., Heurs P.H.T.G. and van Breukelen G.. The treatment of fear of movement/(re)injury in chronic low back pain: further evidence on the effecriveness of exposure in vivo, Clinical Journal of Pain, 18 (2002) 251-261.

37. Waddell G., Newton M., Henderson I., Somerville D. and Main C.. A FearAvoidance Beliefs Questionnaire (FABQ) and the role of fear-avoidance beliefs in chronic low back pain and disability., Pain, 52 (1993) 157-168.

38. Weel van C., Smith H. and Beasly J.. Family practice research networks. Experience from three countries. I Fam Pract, 49 (2000) 938-943. 
General discussion 112

Clinical implications 112

Implementation issues $\mathbb{1 1 7}$

Implications for future research 119

Epiloque 125

References 126

110 whopper sux 


\section{CHAPTER SIX}

GENERAL DISCUSSION 


\section{GENERAL DISCUSSION}

The general aim of the current thesis was to add to the diagnostic and therapeutic arsenal in general practice for patients with osteoarthritis. In this general discussion the following questions will be addressed:

1. What are implications of the studies presented in this thesis for daily, clinical practice?

2. What are opportunities in implementing self-management programmes, for example with regard to organizational aspects?

3. What are implications of the studies for furure research?

While in most of the previous chapters the conventional format of scientific articles (IMRADS: introduction, methods, results and discussion, summary) was used, the present general discussion, although carefully structured, is written with more degrees of freedom in mind of Christoph Wolff:

"in order to actualize and adapt the picture (...) to the newest science, as objective as possible and as subjective as permitted"

(From the preface in the biography on Bach, by Christoph Wolff (1).)

\subsection{Clinical implications}

In this paragraph, we will focus on the characteristics of self-management programmes and make some remarks on the clinical implications. Because of the posirive findings in our randomized clinical trial, it is relevant to mention the consequences and look for its implications for clinical care in patients with osteoarthritis.

A remarkable result of the current studies is the finding that outcome in a group osteoarthritis patients is better on long term than on short term follow up with a selfmanagement programme than with care-as-usual. On all primary outcome parameters (pain and playsical functioning) results were better in the self-management group. Also with regard to the secondary outcome measures (self-efficacy, pain-related fear, and quality of life) there were differences, some of them statistically significant, in favor of 
the self-management group and with a greater difference on long term follow up. These findings are both remarkable as well as clinically important. An interesting question is how these differences between short and long term follow up results can be explained. The finding of better long term outcome is described earlier in an intervention study aiming at improvement of self-management (18). In that particular study a training programme on problem solving was added to the treatment in order to minimize disability, improve daily activities and quality of life in people with non-specific low back pain. In these both studies $(18,24)$ the role of self-efficacy is crucial.

Bandura has defined self-efficacy (43):

Perceived self-efficacy refers to beliefs in one's capabilities to organize and execute the courses of actions required to produce given attainments. Self-efficacy is concerned with human enablement. This key-concept may play a crucial role in the explanation of better long term than short term results of our study. Interventions that influence not only the primary outcome measures but also possibly improve self-efficacy may have better long-lasting results.

In an earlier study on the exercise in osteoarthritis (30) short term results were better in the exercise than in the control group, but the effects disappeared over time (after 3 months). One of the recommendations of that study was to incorporate educational and self-management strategies in combination with exercises in order to improve long term outcome in osteoarthritis patients (general discussion in (30)). Interestingly, in the present study the combination of actions (exercises, information, action planning, relaxation, et cetera) seems to have been responsible for the better long term results. Self-reported self-efficacy (ASES) also better in the self-management group. We conclude that active treatment both aiming at improvement of primary ourcome goals (for example better activity patterns and pain reduction) in combination with improvement of self-efficacy (for example by using acrion planning and problem solving strategies) are to advised.

Self-management principles have several consequences for dinical practice. First, they emphasize the central role of patients in managing their illness. Second, they are aimed at helping patients in maintaining life roles and managing negative emotions, such as fear and depression. As a consequence of this, self-management programmes prepare patients to collaborate with health care professionals. 
In a recent review paper Barlow and co-workers provided an overview of selfmanagement approaches for people with chronic conditions. Purpose of that review was to identify approaches to self-management and to consider the effectiveness of the different approaches to self-management (2). Searching in databases using the key words "self-management" and "chronic" yielded 1129 papers of which the titles were checked for relevancy. Abstracts were obtained for the 323 papers meeting the inclusion/exclusion criteria. After reviewing full text versions of about 220 papers, a total of 145 papers met the study criteria and were read by the authors (2). This resulted in a description of the chronic conditions for which the self-management interventions were applied, as well as details on countries, target populations, delivery locations, self-management tutors, modes (individualized, group-format, materials and audiotapes, et cetera), and content. Although no "golden standard" definition of selfmanagement is available, for the purpose of the review, self-management was defined as follows (2):

Self-management refers to the individual's ability to manage the symptoms, treatment, physical and psychosocial consequences and life style changes inherent in living with a chronic condition. Effucacious self-management encompasses ability to monitor one's condition and to affect the cognitive, behavioral and emotional responses necessary to maintain a satisfactory quality of life. Thus, a dynamic and continuous process of selfregulation is establiched.

In chapter 6 the self-management intervention as it was applied in our study is briefly described and it was also mentioned that the denomination "self-management" is probably not the most appropriate one. For the intervention applied here the term "self-management" was chosen, because the 6-session intervention resembles the ASMP (Arthritis Self Management Programme) developed by Kate Lorig (3-8). It should be kept in mind, however that the intervention is an example of a cognitive behavioral intervention (CBT) since it includes several techniques such as problem solving and goal setting which are typical CBT interventions (9-19).

What are the characteristics of self-management programmes different from current approach in the treatment of osteoarthritis? 
In short these are the following:

- the group format of the programme,

- the broad approach to functioning of the person with OA,

- the focus on skills training,

- the consequences for the working-relationship between patient and health caregiver.

\section{Group format}

Working with a group format is not usual in care for osteoarthritis patients. This should be reconsidered, because of the positive results of self-management programmes, as well as recent publications on cognitive-behavioral therapy.

A trearment in group format offers several unique possibilities and is an efficient learning environment for both patients and health caregivers. First, it is an opportunity for efficient knowledge transfer, in that patients can be given background information about osteoarthritis, self-management principles, health resources, et cetera. Discussions in the group can be informative for all participants. Role modeling can be used as an effective learning tool. In acquiring new information and skills people learn from each other. Action planning, for example, which is a central skill in selfmanagement, needs training and feedback to be mastered adequarely. Working in groups offers a rich environment to master action planning.

For the delivery of group sessions in self-management several requirements are to be met, such as:

- Optimall timing, frequency and length of the interventions.

- Which tutors are best for whom? (professionals, lay persons, mix)

- Venues (e.g. hospital, local clinic, community, home).

- Implementation (e.g. health care system and/or voluntary organizations).

- Resource issues (who pays? International differences).

\section{Broad approach}

In a self-management programme a broad approach of osteoarthritis is needed. The groups' sessions are not focusing on one specific joint, for example knee or hip. Very important is the fact that impairments, activities, participation are taken into account as well as personal and envirommental influences. The shift is made from a mere "somatic" point of view towards a more "biopsychosocial" stance as described in paragraph 1.4 to 1.6 in the introduction to this thesis. As a consequence the domains 
of the International Classification of Functioning, Disability and Healich (ICF) (20) receive attention. The intervention thus will cover all important domains and prevents "narrowing" views too much.

It is important not to mistake or misunderstand this. A biopsychosocial stance is not a matrer of "leawing or "gnoring the medical domain". Actually, it is a marter of integrating all relevant aspects, whether they are somatic, psychological or environmental by nature, and paying attention to diagnostics regarding impairments, activities as well as participation (the ICF-domains). For example, in such an approach fadiological diagnostics is part of a continuous process in which the question always is: "What are the consequences for this person, regarding impairment, activities and social functioning?" This opens up a search for possibilities for the person to influence functioning in a positive direction.

\section{Skills training}

It takes time and training to make the shift from: "What do I have?" to "What can I do?" In the self-management programme action planning is a key ingredient. Acquiring skills in action planning is worthwhile. From participating patients and physical therapists we learned this was "new and in the beginning a little strange" . But all agreed that after a while it became "natural attitude" that was very helpful and effective. It is evident that action planning needs training and that education alone is not enough. Skills are to be trained and will not be mastered by reading and listening alone.

Besides action planning several skills are part of the self-management programme, such as problem solving, relaxation and exercising.

\section{Collaborative partiership}

Self-management has consequences for the relationship between patient and health caregiver: Responsibility for functioning with a chronic disease like OA is not simply a matter of doctors and other caregivers, but should be properly shared. "Collaborative partmership" is an adequate term for this. A person with a chronic condition like OA needs to learn about the condition, its consequences and its management and thus in a certain way becoming a partner in the process of care.

Examples of shared responsibility are:

- not ignoring signs and symptoms, but learning how to interpret them adequately,

- choosing adequate timing of specific diagnostics and treatment in cooperation;

- learning what kind of activities are helpful. 
After the initial "learning period" all of these primarily become the task of the patient, of course from time to time needing some help from doctors, therapists or other caregivers, but always temporarily and based on collaborative partnership.

\section{Conclusions}

Self-management programmes are rather brief interventions, which may render long term effects. They enhance possibilities of collaborative partnership between patients and caregivers and therefore should be available for $\mathrm{OA}$ patients in their early stages.

\subsection{IMPLEMENTATION ISSUES}

Enabling a wider provision of self-management programmes requires resolving several issues, such as training and reimbursement of health care providers, organising facilities and informing general public, as well as partner, family and friends of participating patients. Probably tailored programmes have to be developed for subgroups: i.e., ethnic minorities, patients not motivared to change et cetera.

For implementing a self-management approach in a highly prevalent condition like $O A$ the stepped care model offers promising opportunities. Von Korff introduced this concept in the care for chronic back pain $(13,14)$. In paragraph 1.7 the stepped care approach was briefly described.

A stepped care approach can be helpful in organizing and delivering cost-effective care in several chronic conditions. It also can establish links between several medical services, for example between general care services, hospital care and rehabilitation facilities in the delivery of care for certain chronic conditions. Stepped care approaches have been advocated for the treatment of a wide range of chronic conditions (21).

Here, we will describe the example of the application of a stepped care approach in the back pain population. Thereafter, the question of applicability in the OA population will be addressed.

A stepped care approach provides a framework allocating limited resources to the greatest effect on a population basis, combined with care that is firted to the needs of an individual person $(13,14,22,23)$. A stepped care approach guides care based on 
the observed outcome of an individual patient. It intiates care with the least expensive, least intensive and restrictive treatment deemed sufficient to meet the parient's needs, increasing treatment intensity until a favorable outcome has been achieved.

In the care of back pain three intervention steps are described, based on recent research findings.

Step 1 aims at all back pain patients, identifying and addressing specific patients' worries and encouraging return to nomal activities.

Step 2 aims at back patients with activity limitations continuing at 6-8 weeks. In step 2 the objectives are:

- to help patients identifying difficulties, setting functional goals, and defining and carrying out plans to achieve their goals;

- to provide support for resumption of activities and exercise.

Step 3 is designed for back pain patients with significant disability in work and/or family roles, and patients with co-morbid mental illness which may impede recovery efforts. Interventions in step 3 aim at restoring work and family role function. This may require a graded activity programme and treatment of co-morbid mental illness if present.

This example in chronic back pain illustrates the links between the different health care sertings. Step 1 can be provided in general care serrings, when supported by minimal educational interventions. Step 2 can be provided in low-cost group format programs or on an individual basis, supported by self-care educational materials $(13,14,22)$. Step 3 needs referral for rehabilitation and (if indicated) psychological treatment in primary or specialty care.

For the enormous group of $\mathrm{OA}$ a self-management programme could be part of step 1 in a stepped care approach, as illustrated in the figure.

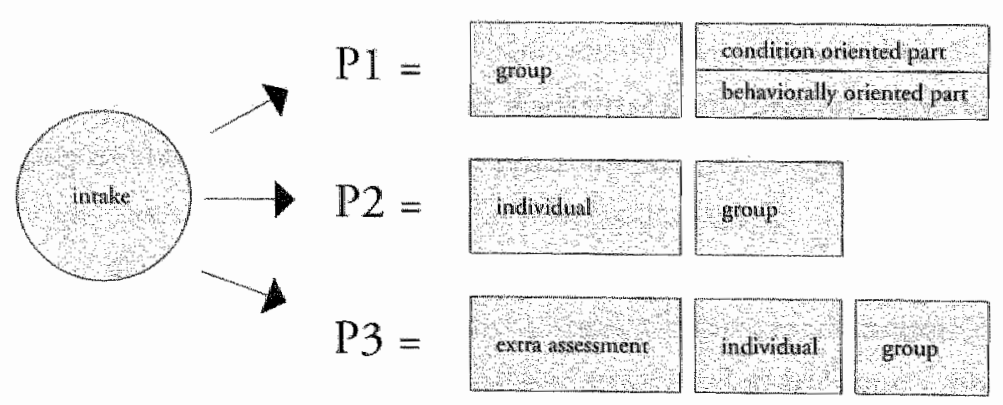

Figure 1: Stepped Care Approach (Poprogramme) 


\subsection{IMPLICATIONS FOR FUTURE RESEARCH}

Since the randomized controlled trial on self-management in OA is the "back bone" of the current dissertation, we will start in paragraph 8.3 .1 with remarks about future research questions related to self-management and education in chronic diseases. In paragraph 8.3.2 we will commend on the diagnostic issues raised in the current thesis.

\section{Randomized controlled trial}

Undoubtedly, the randomized trial described in chapter 2 and $3(24,25)$ is a pragmatic trial. It was embedded in a general health care setring. During the trial diagnostics were mainly performed by family physicians, while treatments were provided by physiocherapists. A pragmatic study like the current RCT has several strengths and limitations. Some of these will be discussed and suggestions for further research will be given.

In a recent article (2), Barlow and colleagues reviewed self-management approaches for people with chronic conditions. Among the many relevant topics on the subject discussed in the paper, they offer a brief and clear synopsis of methodological issues concerning outcome studies in self-management. In the present discussion we follow Barlow and her colleagues in this matter, comparing their remarks (in (2) on page 1.80181) with the characteristics of our trial.

In sum, Barlow et al describe the following aspects of studies on self-management programmes:

Most of the self-management programmes are treatment "packages" consisting of many components, which make it difficult to tease out the precise mechanism leading to change among parricipants. Further, many of the self-management studies were randomized controlled trials based on small sample sizes (for example 20-30) with shorr follow-up periods (typically 4-6 months). Barlow et al stress that there is a need to conduct RCTs of sufficient size to enable change on key outcome measures to be detected. Not all studies have adopted an intention-to-treat approach. Only few studies have considered cost effectiveness. Furthermore, many research designs are based on the use of waiting-list control groups, with follow-up periods between 3 and 6 months, after which point the control group receives the intervention, thus making long term follow up comparison of the intervention groups impossible. 
With these remarks about self-management in mind we would highlight the following aspects as strengths and limitations of our RCT $(2,24,25)$.

\section{Strengths:}

1. good sample size $(\mathrm{n}=273)$;

2. adequate choice of outcome measures (both disease-specific with focus on functioning and generic quality of life measures as well as some process variable like TSK and ASES);

3. rather long duration of follow up (21 months);

4. analysis using an intention-to-treat approach;

5. study on cost-effectiveness (25).

\section{Limitations:}

1. difficult to tease out the "essential working components" from the multicomponent treatment package;

2. limitation of outcome measures (mostly self-reported questionnaires, and partially performance based).

In a second recent review Julie Barlow has described education as an intervention in osteoarthritis (26). In that particular article she sets the stage for research on selfmanagement in the near future. Barlow underscores the idea that education in osteoarthritis can be conceived as part of an ongoing process of self-management. The chronicity of OA implies that education needs to continue throughout the course of disease to ensure that patients are updated about the latest treatments and therapeutic recommendations and are maintaining self-management behaviours $(2,26)$. Yet, many issues remain to be clarified and need further research and development. This leads to a research agenda, containing several issues and questions about delivery of education in the osteoarthritis population, its evaluation and opportunities for wider provision (26). Questions remain for example in the field of evaluation (choice of outcome measures, long term outcome studies, cost-effectiveness studies, questions like "Who benefits most from which intervention?", et cetera).

Linton has recenty described cognitive-behawioural treatment approaches in the prevention of musculoskeletal pain $(9-11,27)$. In his overview and clinicall trials selfmanagement plays a pivotal role. The strength of self-management programmes lies in the opportunity for broad use and good perspectives on implementation, because they are "treatment packages". The strength of Linton's advice to describe this kind of 
intervention as cognitive-behavioural strategies offers good opportunities to tease out the different components, i.e "unwrapping the packages". This may enable further research into the processes involved in these kinds of treatment approaches. Recendly, several examples of studies evaluating effectiveness of components of CBT are published (17-19, 28-31).

To conclude, the current findings provide a firm foundation on which systematic expansion of self-management approaches for people with osteoarthritis can be based. Meanwhile, further research along the above described lines is needed. Those research efforts will enable clarification of remaining questions and can improve the delivery of self-management programmes.

\section{Diagnostic issues}

Here we will elaborate on the studies described in chapter 4 and 5.

\section{Readiness to change}

In this paragraph we will start with some remarks on the empirical study described in chapter 4 (32). Thereafter, we will summarize an interesting debate between proponents of the transtheoretical model of behaviour change and a crirical theorist (33-37). That discussion sheds light on the possibilities and limitations of this concept of "stages of change". It also helps in clarifying some of the difficulties we have encountered in applying and investigating this concept of "readiness to change". In the literature on this subject several terms are in use: "rranstheoretical model of health behaviour change", "stages of change" and "readiness to change". In this thesis, all these terms refer to the same theoretical concept, as introduced by Prochaska and his colleagues $(38,39)$.

The transtheoretical model for behaviour change received considerable attention and debare in recent years. The model is presented as an innovative approach to health promotion that emphasizes behaviour change viewed as a progression through a series of stages (precontemplation, contemplation, preparation, action and maintenance). It is claimed that the model is useful in designing health promotion interventions that meet the needs of the individual at each stage of change $(33,34,40,41)$.

In developing a questionnaire for the use of the stages of changes model in OA (as described in chapter 4) we have encountered some problems that had to be considered 
and dealt with (32). For instance, because of the remarkable lack of empirical data on the scoring systems currently in use, we tried to compare strengths and weaknesses of three different scoring systems in one study sample (the highest score method, the cutoff point method and a newly developed five point difference method) (42). We chose for the cut-off point method, but further research hereon is necessary. There is more evidence needed to make a rational choice between the scoring systems. It is still uncertain how to score in the most adequate way, thus determining whether a person belongs to one or another stage of change. This is not as simple and well-understood as it seems to be, nor as the proponents of the model suggest.

Although our study gave some hints about the validity (table 4 in chapter 4) (32), evidence on validity of the concept with regard to self-management programmes in the $O A$ population is scant. Because it is important whether or not the results of any new questionnaire on the model of change predicr who will or will nor change, further studies are badly needed (42).

An interesting discussion about the pros and cons of the stages of change model was published (33-37), shedding light on the foundations, strengths and flaws of the model from a theoretical point of view (43). In a critical editorial Bandura states (35): "Stage theories lead into a thicket of problems. Human functioning is simply too multifaceted and multiderermined to be categorized into a few discrete stages."

From a theoretical stance Bandura explains that a genuine stage theory has three cardinal defining properties $(35,43)$ : qualitative transformation across stages, invariant sequence of change, and nonreversibility. Offering examples of these properties and comparing them with the stages of change model, Bandura concludes that the stages of change model will not be helpful in the long term. He proposes process modeling in stead of categorizing approaches. "Unlike the categorizing approach, a process model specifies the deterninants and intervening mechanisms that govern the different facts of change." $(35,43)$

In a response to Bandura's criticisms Prochaska and Velicer describe what they call misinterpretarions of the transtheoretical model (36). They hold their plea in favor of the model in line with earlier publications $(33,34,36,38,39,44)$. In a commentary in the same issue of the American Journal of Health Promotion Michael Samuelson declares the stages of change concept to be the most important theoretical health promotion development of the decade (37). The approach of Samuelson to this debate 
seems very pragmatic to me, but maybe theoretically rather poor while stating: "I applaud those who specialize in the science of health promotion. Most, practitioners recognize the complexity of behaviour change and understand that the boundaries are feathered, not distinct."

Whitelaw and colleagues have recommended (45) high quality quantitative studies with focus on practitioner and organizational utilization of the model. In line with this, we have performed and presented empirical research on a questionnaire about readiness to change in OA patients $(24,32)$. We indeed nearly got stuck in a "thicket of problems" -as Bandura has called it-, because of difficulties in classification. Nevertheless, the factor analyses yielded interesting information, interpretable according to the stages of change model. Hence, further research is needed, first on validity of the questionnaire and second on the applicability in practice (42). An interesting contribution to this field recently was published by Burns and colleagues (46) in Pain, concluding:

Findings suggest that patients initially taking a predominant action stance toward a selfmanagement approach to chronic pain and who demonstrated further movement toward solidifying this perspective during early-treatment showed pronounced late-treatment improvements in pain severity, interference and activity level. Although patients initially reporting a predominant precontemplation stance showed levels of early-treatment precontemplation and action attitude changes comparable to those of action-oriented patients, these changes did not appear to affect late-treatment gains.

The discussion berween proponents and opponents of the stages of behavioural change model is going on and plays on several levels -theory, operationalization and application in practice- and remains for the time being, an open-ended discussion.

We conclude that "readiness to change" in the OA population is importan, because people can benefit from life style changes. However, attention should be focused on the process of change and not on the categorization of people into stages.

\section{Pain-related fear and osteoarthritis}

Recently there has been an increase in theoretical and empirical efforts to delineate the precise nature of the relationship between fear, anxiety and chronic pain (47). For several reasons, we have investigated some aspects of the role of pain-related fear in $O A$ patients. First, in a recent study Steultjens and colleagues reported on data about the 
influence of avoidance of acrivities on functioning in a sample of OA patients (48). Second, because of our own experience in treating low back pain patients with high levels of pain-related fear, we are interested in the question whether pain-related fear also puts a higher risk in OA patients on the development of disability $(28,29,49)$. Third, Von Korff and colleagues present data on assessment and treating fear-avoidance beliefs and disability in parients seeking help for back pain in primary care (50). Fourth, in a recent review Linton underscored the importance of fear-avoidance in the development of future pain and disability (51). Fear-avoidance appears to be a central risk factor and good predictor of furure disability. Therefore, we are interested and performing studies on the role of pain-related fear in musculoskeletal disorders like here for example, in osteoarthritis.

In chapter 5 we have described research on the factor structure of the Tampa Scale of Kinesophobia in a sample of patients with OA (52-54). The TSK showed to contain two factors, called "activity avoidance" and "somatic focus". Furthermore, pain-related fear as measured with the TSK occurred to a considerable extent in this sample of OA patients and was negatively associated with daily functioning (54). These findings pave the way for further research in the processes in which fear interferes with function in $\mathrm{OA}$, as well as in the development of tailored treatment for this sub group of parients. In our randomized clinical trial we have observed changes in scores on TSK over time that were significantly better in the self-management group than in the control group (24).

In a recent publication Von Korff and colleagues reported on a trial of an activating intervention for chronic back pain in primary care and physical therapy settings (55). Interestingly, a brief, individualized program showed greater reductions in pain-related fear, average pain and activity limitacions due to back pain relative to control parients after a 2 year follow-up period (55), which is in line with the results of our trial in OA.

Since the research presented in chapter 5 is part of a cross-sectional study with limited explanatory power, it is worthwhile to develop longitudinal analyses of TSK measurements in a group of OA patients. That will offer the opportunity of enhancing our understanding of this phenomenon of pain-relared fear.

With regard to treatment, one of the questions to be answered is whether graded exposure is feasible and effective in improving functioning in OA patients with a high level of pain-related fear. For that reason we are planning to perform replicated single- 
case experiments in vivo applying graded exposure in OA patients with high scores on TSK (in line with $(28,29)$ ).

Both assessing as well as treating fear of pain has become an important topic for further research and in this regard in the field of OA much work remains to be done.

\subsection{EPILogue}

In general, the findings in this thesis are in agreement with the conclusions of Fries and colleagues (56). Of particular interest is the finding that at long term follow up the selfmanagement group performs better than the control group (24).

Self-management programmes should be available and implemented more broadly. A stepped care approach may be very helpful in organizing this, because it offers a model in which assessment and treatment options can be matched with the needs of the individual person with osteoarthritis. 


\subsection{REFERENCES}

1. Wolff C. Johann Sebastian Bach; the learned musician. [In Dutch translated by Clemens Romijn]. Utrecht: Bijleveld; 2000.

2. Barlow J., Wright C., Sheasby J., Turner A., Hainsworth J.. Self-management approaches for people with chronic conditions: a review. Patient Education and Counseling 2002;48:177-187.

3. Lorig K. Self-Management Education. More than a nice extra. Medical care 2003;41(6):699-701.

4. Lorig K., Bodenheimer T., Holman H., al e. Parient self-management of chronic disease in primary care. JAMA 2002;288:2469-2475.

5. Lorig K., Holman H.. Arthritis self-management studies: a twelve-year review. Health Education Quaterly 1993;20(1):17-28.

6. Lorig K., Sobel D., Ritter P., al e. Effect of a self-management program on patients with chronic disease. Eff Clin Practice 2001;4:256-262.

7. Lorig K., Sobel D., Stewart A., al e. Evidence suggesting that a chronic disease selfmanagement program can improve health status while reducing hospitalization: a randomized trial. Med Care 1999;37:5-14.

8. Lorig K.R., Mazonson P.D., Holman H.R.. Evidence suggesting that health educarion for self-management in patients with chronic arthritis has sustained health benefits while reducing health care costs. Arthritis and Rheumatism $1993 ; 36(4): 439-446$.

9. Linton S.J.. The Challenge of Preventing Chronic Musculoskeletal Pain. In: Gebhart G.F., Hammond D.L., Jensen T.S., editors. Proceedings of the 7th World Congress on Pain. Seattle: LASP Press; 1994. p. 149-166.

10. Linton S.J.. Urility of cognitive-behavioral pychological treatments. In: Nachemson A.L., Jonsson E., editors. Neck and back pain: the scientific evidence of causes, diagnosis, and treatment; 2000.

11. Linton S.J.. Environmental and Learning Factors in the Development of Chronic Pain and Disability. In: Price D.D., Bushnell C.M., editors. Psychological Methods of Pain Control: Basic Science and Clinical Perspectives. Seattle: IASP Press; 2004. p. $143-167$.

12. Linton S.J., Ryberg M.. A cognitive-behavioral group intervention as prevention for persistent neck and back pain in a non-patient population: a randomized controlled trial. Pain 2001;90:83-90. 
13. Von Korff M. Perspectives on Management of Back Pain in Primary Care. In: Gebhart G.F., Hammond D.L., Jensen T.S., editors. Proceedings of the 7th World Congress on Pain. Seartle: IASP Press; 1994. p. 97-110.

14. Von Korff M.. Pain management in primary care: an individualized stepped-care approach. In: Turk R.J.G.D.C., editor. Psychosocial factors in pain: critical perspectives. New York London: The Guilford Press; 1999. p. 360-373.

15. Moore J.E., Von Korff M., Cherkin D., Saunders K., Lorig K. A randomized trial of a cognirive-behavioral program for enhancing back pain self care in a primary care setting. Pain 2000;88:145-153.

16. Morley S., Eccleston C., Williams A. Systematic review and meta-analysis of randomized controlled trials of cognitive behaviour and behaviour therapy for chronic pain in adulss, excluding headache. Pain 1999;80:1-13.

17. Hout van den J.H.C., Vlaeyen J.W.S., Heurs P.H.T.G., Sillen W.J.T., Willen J.E.H.L.. Functional disability in non-specific low back pain: The role of painrelated fear and problem-solving skills. International Journal of Behavioural Medicine 2001;8:134-148.

18. Hout van den J.H.C., Vlaeyen J.W.S., Heuts P.H.T.G., Zijlema J.H., Wijnen J.A.. Secondary Prevention of Work-Related Disability in Nonspecific Low Back Pain: Does Problem-Solving Therapy Help? A Randomized Clinical Trial. The Clinical Journal of Pain 2003;19:87-96.

19. Hout van den J.H.C., Vlaeyen J.W.S., Kole-Snijders A.M.J., Heuts P.H.T.G., Willen J.E.H.L., Sillen W.J.T.. Graded acrivity and problem solving therapy in subacute non-specific low back pain. Physiotherapy 1998;84:167.

20. WHO, Organisation WH. International Classification of Functioning, Disability and Health. Geneva; 2001.

21. Von Korff M., Tiemens B.. Individualized stepped care of chronic illness. West ] Med 2000;134:133-137.

22. Balderson B.H., Von Korff M.. The stepped care approach to chronic back pain. In: Linton S., editor. New Avenues for the Prevention of Chronic Musculosskeletal Pain and Disability. Amsterdam: Elsevier; 2002. p. 238-243.

23. Pruitt S.D., Von Korff M.. Improwing the Management of Low Back Pain: a Paradigm Shift for Primary Care. In: Turk D.C., Gatchel R.J., editors. Psychological Approaches to Pain Management. Second ed. New York London: The Guilford Press; 2002. 
24. Heuts P.H.T.G., Bie de R.A., Drietelaat M., Aretz K., Hopman-Rock M., Bastiaenen C.H., et al. Self-Management in Osteoarthritis of Hip or Knee: A Randomized Clinical Trial in a Primary Healthcare Setring. The Journal of Rheumatology 2005;32:543-49.

25. Heuts P.H.T.G., Goossens M.E.J.B., Dinant G-J, Bie de R.A., Drietelaar M., Aretz $\mathrm{K}$, et al. Is a self-management programme in general practice cost-effective in patients with osteoarthritis? (Submitred). 2005.

26. Barlow J.. How to use education as an intervention in osteoarthritis. Best Practice \& Research Clinical Rheumatology 2001;15(4):545-558.

27. Linton S.. New avenues for the prevention of chronic musculoskeletal pain and disability. Amsterdam: Elsevier; 2002.

28. Waeyen J.W.S., de Jong J., Geilen M., Heuts P.H.T.G., van Breukelen G.. Graded exposure in vivo in the treatment of pain-related fear: a replicated single-case experimental design in four patients with chronic low back pain. Behav Res Ther 2001;39(2):151-66.

29. Vlaeyen J.W.S., de Jong J., Geilen M., Heuts P.H.T.G., van Breukelen G.. The treatment of fear of movement/(re)injury in chronic low back pain: further evidence on the effectiveness of exposure in vivo. Clinical Journal of Pain 2002;18:251-261.

30. Baar van M., Dekker J., Oostendorp R., Bijl D., Voorn T., Lemmens J., et al. The effectiveness of exercise therapy in parients with osteoarthritis of the hip or knee: a randomized clinical trial. J Rheumatol 1998;25:2432-9.

31. Kole Snijders A.M.J., Vlaeyen J.W.,S. Goossens M.E.J.B., Rutren-van Mölken M.P., Heuts P.H.T.G., van Breukelen G., et al. Chronic low-back pain: what does cognitive coping skills training add to operant behavioral treatment? Results of a randomized clinical trial. J Consult Clin Psychol 1999;67(6):931-44.

32. Heuts P.H.T.G., Bie de R.A., Dijkstra A., Arezz K., Vlaeyen J.W.S., Schouten H.J., et al. Assessment of readiness to change in patients with osteoarthritis. Development and application of a new questionnaire. Clinical. Rehabilitation 2005:19(3):290-99.

33. Prochaska J.O., Velicer W.F. Introduction. American Journal of Health Promotion 1997;12(1):6-7.

34. Prochaska J.O., Velicer W.F. The Transtheoretical Model of Health Behavior Change. American Journal of Health Promotion 1997;12(1):38-48. 
35. Bandura A. The anatomy of stages of change. American Journall of Health Promotion 1997;12(1):8-10.

36. Prochaska J.O., Velicer W.F. Misinterpretations and misapplications of the transtheorerical model. American Journal of Health Promotion 1997;12(1):11-12.

37. Samuelson M.. Changing unhealthy lifestyle: who's ready... who's not?: an argument in support of the stages of change component of the transtheoretical model. American Journal of Health Promotion 1997;12(1):13-14.

38. Prochaska J., DiClemente C., Norcross J.. In search of how people change, applications to addictive behaviors. American Psychologist 1992;471:1102-1114.

39. Prochaska J.O., DiClemente C.C.. Stages and processes of self-change of smoking: Toward an integrative model of change. Journal of Consulting and Clinical Psychology 1983;51:390-395.

40. Kerns R., Rosenberg R. Predicting responses to self-management treatments for chronic pain: application of the pain stages of change model. Pain 2000;84(1):4955.

41. Kerns R., Rosenberg R., Jamison R., Caudill M., Haythornthwaite J.. Readiness to adopt a self-management approach to chronic pain: The Pain Stages of Change Questionnaire (PSOCQ). Pain 1997;72:227-234.

42. Dijkstra A.. The validity of the Stages of Change model in the adoption of the selfmanagement approach in chronic pain. The Clinical Journal of Pain 2005;21(1):27-37.

43. Bandura A.. Self-efficacy: the exercise of control. New York: Freeman and Company; 1997.

44. Prochaska J.O., Marcus B.H.. The transtheoretical model: applications to exercise. In: Dishman R., editor. Advances in exercise adherence. Champaign, IL: Human Kinerics; 1994. p. 161-80.

45. Whitelaw S., Baldwin S., Bunton R., Flynn D.. The status of evidence and outcomes in Stages of Change research. Health education research 2000;15(6):707-718.

46. Burns J.W., Glenn B., Lofland K., Bruehl S., Harden R.N.. Stages of change in readiness to adopt a self-management approach to chronic pain: the moderating role of early-trearment stage progression in predicting outcome. Pain 2005; 115(3):322-331.

47. Asmundson G.J., Vlaeyen J.W.S., Crombez G.. Understanding and treating fear of pain. Oxford: Oxford University Press; 2004. 
48. Steultjens M.P., Dekker J., Bijlsma J.W. Avoidance of activiry and disability in patients with osteoarthritis of the knee: the mediating role of muscle strength. Arthritis \& Rheumatism 2002;46(7):1784-1788.

49. Heuts P.H.T.G., Vlaeyen J.W.S., Ruesink R.. Bewegingsvrees bij lage rugpijn. Nederlands Tijdschrift woor Pijn en Pijnbestrijding 1996;16(4):45-48.

50. Balderson B.H., Lin E.H., Von Korff M.. The management of pain-related fear in primary care. In: Asmundson G.J., Vlaeyen J.W.S., Crombez G., editors. Understanding an treating fear of pain. Oxford: Oxford University Press; 2004.

51. Linton S.J., Boersma K.. The role of fear-avoidance in the early identification of parients risking the development of disability. In: Asmundson G.J., Vlaeyen J.W.S., Crombez G., editors. Understanding and treating fear of pain. Oxford: Oxford University Press; 2004.

52. Miller R., Kori S., Todd D.. The Tampa Scale for Kinesiophobia; 1991.

53. Kori S., Miller R., Todd D.. Kinesiophobia: A new view of chronic pain behavior. Pain Management 1990;jan/Feb:35-43.

54. Heuts P.H.T.G., Vlaeyen J.W.S., Roelofs J., Bie de R.A., Aretz K., Weel Cv, et al. Pain-related fear and daily functioning in patients with osteoarthritis. Pain 2004;1 10:228-235.

55. Von Korff M., Balderson B.H., Saunders K., Miglioretri D.L., Lin E.H., Berry S., et al. A trial of an activating intervention for chronic back pain in primary care and physical therapy settings. Pain 2005;113(3):323-330.

56. Fries J.F, Lorig K., Holman H.R.. Patient Self-Management in Arthritis? Yes! The Journal of Rheumatology 2003. 
SUMMARY

swamatry 133 


\section{CHAPTRI-INTRODUCTION}

This doctoral thesis is entitled: Osteoartbritis, a rehabilitative approach in generd practice.

The following questions were addressed in the general introduction:

1. What are the main characteristics of osteoarthritis and its consequences?

2. What are specific issues in general care for osteoarthritis patients?

3. Why do we refer to the current approach as a rehabilitative approach?

4. What is the use and usefulness of self-management in osteoarthritis patients?

5. What is meant with "a stepped care approach" and why is it considered to be helpful in the care for osteoarthritis patients?

Osteoarthritis $(O A)$ is a clinical syndrome characterised by joint pain and stiffness, usually described in pathological terms as a condition of cartilage degeneration, subchondral bone stiffening, and acrive new bone formation. In the patient, OA is mainly perceived as joint pain, (morning) stiffness and loss of function.

The goals of contemporary management of the patient with OA consist of control of pain and improvement in function and health-related quality of life, with avoidance, if possible, of adverse effects of therapy.

Care for people with OA fits nicely in general practice. However, several challenges concerning managing $\mathrm{OA}$ in a general care setring still are to be met. What comprehensive treatment modalities are available that really meet the questions and problems of OA patients and are evidence based and tested for application in general care? For this purpose a rehabilitative approach and self-management is explored and researched. The current thesis adopts a biopsychosocial approach.

$\mathrm{OA}$ is considered to be an incurable chronic disorder. Since no successful treatments for OA exist that resolve all signs and symptoms of the disease, the person with this condition has to manage both the consequences of pain and stiffness and the consequences of treatment procedures (e.g. medications, exercises, operations, changes in lifestyle, etcetera). A number of $O A$ symptoms as well as several of the prescribed treatments influence daily activities like work, family life and leisure time, which may hamper quality of life considerably. Therefore, people with $\mathrm{OA}$ are not only -as is the case in many other chronic conditions- confronted with changed bodily functions but 
frequently also need to change activity-patrerns. This may require a rehabilitative approach.

Management of OA is partly pharmacological and surgical, but also educational and non-pharmacological (for example in applying exercise programs, assistive devices, bracing joint protection and energy conservation). A recent guideline emphasizes that improved communication and education are important factors in decreasing pain and improving function in patients with OA. A rehabilitative approach can be helpful in integrating the various treatment modalities in the care of $\mathrm{OA}$ patients. A way to achieve this may be a self-management programme as part of a rehabilitative approach.

For arthritic conditions the prototype of a self-management program has been developed, introduced and widely tested by Lorig and co-workers. Self-management starts with the idea of partnership between patients and health professionals. The beliefs and problems of people with chronic conditions are central. Health professionals are asked what knowledge patients must have and what behaviours they must change to manage their condition. These points of view are then combined into the content of a self-management program. Self-management programs are built on self-efficacy theory. They are designed to enhance patients' confidence to manage their lives while living with chronic disease. Lorig summarizes: "In simple terms, this theory states that if people think they can do something, they probably can."

Stepped care is a framework for organizing services based on the intensity of patients' needs. It has been described as a useful strategy for organizing general care services for health problems such as hypertension, hypercholesterolemia, nicotine dependence, depression, alcohol dependence, behaviorally based problems and low back pain. In general, a stepped approach initially provides the least intensive, and often least expensive, intervention as a first step in improving outcomes. If pacients do not experience a favorable result, services are intensified-sometimes called "stepped-up" - to the next level of intervention that typically is more complex and probably more expensive. The obvious benefit of a stepped-care approach is that services are better matched to patients' needs, and excessive, expensive or unnecessary services are minimized resulting in greater efficiency and cost savings.

The specific research questions formulated for this study were threefold: 
1. What are the effects of self-management on pain, functional limitations, selfreported acrivities, quality-of-life and self-efficacy in middle-aged OA patients?

2. Which individual patient-characteristics determine the effectiveness of teaching self-management in middle-aged OA patients in a general health care setting?

3. What are the effects of self-management on health-behavior, health-care consumption, and indirect costs related to $\mathrm{OA}$ in the middle-aged group of $\mathrm{OA}$ parients?

\section{Chapter 2 - SElf-MANAGEMENT: A RANDOMIZED CLINICAL} TRIAL IN GENERAL PRACTICE

The objective of this study was to assess the efficacy of a self-management programme in middle-aged patients with osteoarthritis in a primary health care setting. The study design was a two-group randomized controlled trial. The experimental intervention was compared with care-as-usual. Duration of follow-up was 21 months after start of the intervention. Recruitment of participants, treatments and follow-up measurement all were performed in a general health care serring and was done by GPs and via advertisements. Self-management was instructed by physiotherapists. In the study participated two-hundred-and-seventy-three patients (age between 40 and 60 years) with osteoarthritis in hip(s) and/or knee(s). Main outcome measures were pain severity in hip(s) and/or knee(s), main other complaints and self-reported functional limitations.

After written informed consent the 297 parients were randomized: 149 selfmanagement and 148 controls. Before start of the intervention 24 participants withdrew for practical reasons (17 in self-management and 7 in control group). Ar 3 months follow-up the intervention group significantly improved on VAS pain knee (0.67; SD 2.10) and WOMAC (2.46; SD 9.49), while the control group showed stable VAS knee pain $(0.01 ;$ SD 2.00) and deterioration on WOMAC (-0.53; SD 9.47). At 21 months follow-up the differences between the intervention and control group increased in favour of the intervention group (VAS pain knee: p-values from 0.023 at 3 months to 0.004 at 21 months; WOMAC p-values from 0.030 to 0.022 ). 


\section{Conclusions}

The self-management programme pasitively influenced knee pain and self-reported funcrional level in this sample of osteoarthritis patients. Interestingly, the differences between the groups increased during follow-up in favour of the intervention group.

\section{CHAPTER 3 - IS A SELF-MANAGEMENT PROGRAM IN GENERAL PRACTICE COST-EFFECTIVE IN PATIENTS WITH OSTEOARTHRITIS?}

The objective of this study was to assess in a primary health care setring the costeffectiveness of a self-management program in middle-aged patients with osteoarthritis (OA). The study design was a two-group randomized controlled trial. The experimental intervention was compared with care-as-usual. Duration of follow-up was 21 months after start of the intervention. Recruitment of participants, treatments and follow-up measurement all were performed in a general health care setting and was done by general practitioners and via advertisements. In the study participated twohundred-and-seventy-three patients (age between 40 and 60 years) with osteoarthritis in hip(s) and/or knee(s). Main outcome measures were pain severity in hip(s) and/or knee(s), self-reported functional limitations (WOMAC), health-related quality of life (SF36 and EQ5D), cost diaries to measure direct health care and non-health care costs as well as indirect costs related to $\mathrm{OA}$.

After written informed consent the 297 patients were randomized: 149 selfmanagement and 148 controls. Before start of the intervention 24 participants withdrew for practical reasons ( 17 in self-management and 7 in control group). At 21 months follow-up the differences between the intervention and control group wete in favour of the intervention group. Mean changes on all outcome measures were better in the self-management group, and statistically significant for VAS pain knee and WOMAC. Costs were not statistically different between the two groups.

\section{Conclusions}

The self-management programme positively influenced knee pain and self-reported functional level in this sample of osteoarthritis patients. The investment of about 200 Euros (far less than 300 US dollars) per person was the price for improvement in pain and performance in this sample of osteoarthritis patients berween 40 and 60 years. 


\section{CHAPTER 4-READINESS TO CHANGE}

Objective of the study was to develop a self-report measure for assessment of the Stage of Change in patients with osteoarthritis, in order to identify those patients who will benefit from participating in a self-management programme. For this purpose a questionnaire was developed according to the "stages-of-change"-model, firstly presented by Prochaska and DiClemente. This questionnaire consists of three groups of items corresponding with respectively the precontemplation stage (Pre), the contemplation (Cont) and the action (Acr) stage. Internal consistency and factor structure of this questionnaire were investigated by assessing Cronbach's alphas and by performing factor analysis.

\section{Subjects, setting and results}

The questionnaire was offered to 273 patients, who entered a randomized clinical trial on self-management in a general health care serting. Factor analysis revealed that most items were corresponding to the a priori described groups, while some items were not loading on the presumed factor. In each subgroup some items were deleted, resulting in a 15-item questionnaire. After this item reduction Cronbach's alpha's were .72 (Pre), .76 (Cont) and .79 (Act) and all factor loadings were satisfactory (above .35). Classification revealed some differences between parts of the total group, for example in the proportion of patients in the preparation stage (recruited by general practitioner $=33.6 \%$; advertisement $=49.2 \%$ ).

\section{Conclusions}

The Stages of Change Questionnaire in Osteoarthritis, a 15-item-questionnaire to assess "readiness-to-change" of a patient with osteoarthritis, showed good internal consistency and adequate factor structure. These findings warrant further studies on validity and applicability in a clinical context. We do not recommend the questionnaire for clinical use until tresults of these studies are available. 


\section{Chapter 5 PAIN-RELATED FEAR AND DALly FUnCTIONING IN PATIENTS WITH OSTEOARTHRITIS}

The purpose of the present paper was twofold: (1) to investigate the factor structure of the TSK in a sample of OA patients by means of confirmatory factor analysis (CFA); and (2) to investigate the role of pain-related fear in OA compared to other factors, such as radiological findings and level of pain intensity.

There is growing evidence supporting the relationship berween pain-related fear and functional disability in chronic musculoskeletal pain conditions. In osteoarthritis (OA) parients the role of pain-related fear and avoidance has received little research attention so far. The present study investigates the degree to which pain-related fear, measured with the Tampa Scale for Kinesiophobia (TSK), influences daily functioning in OA patients. The results show that TSK consists of two factors, called "activity avoidance" and "somatic focus", which is in line with other studies in low back pain and fibromyalgia. Furthermore, pain-relared fear occurred to a considerable extent in this sample of osteoarthritis patients and was negatively associated with daily functioning. Level of pain and level of pain-related fear were significantly associated with funcrional limitations. Radiological findings were not significant predictors and when compared to pain-related fear they were not significant.

\section{Conclusions:}

These findings underscore the importance of pain-related fear in daily functioning of OA patients. Therefore, treatment strategies aiming at reduction of pain-related fear in OA patients need to be developed and investigated.

\section{CHAPTER 6 GENERAL DISCUSSION}

The general aim of the current thesis was to add to the diagnostic and therapeutic arsenal in general practice for parients with osteoarthritis. In the general discussion the following questions was addressed:

1. What are implications of the studies presented in this thesis for daily, clinical practice?

2 What are opportunities in implementing self-management programmes, for example with regard to organizational aspects?

3. What are implications of the studies for future research? 


\section{Clinical implications}

The most remarkable result of the current studies is the finding that outcome in a group osteoarthritis patients is better on long term than on short term follow up with a self-management programme than with care-as-usual. On all primary outcome parameters (pain and physical functioning) results were better in the self-management group. Also with regard to the secondary outcome measures (self-efficacy, pain-related fear, and quality of lifë) there were differences, some of them statistically significant, in favor of the self-management group and with a greater difference on long term follow up. These findings are both remarkable as well as clinically important.

We concluded that active treatment both aiming at improvement of primary outcome goals (for example better acrivity patterns and pain reduction) in combination with improvement of self-efficacy (for example by using action planning and problem solving strategies) are to be advised.

Self-management principles have several consequences for clinical practice. First, they emphasize the central role of patients in managing their illness. Second, they are aimed at helping parients in maintaining life roles and managing negative emotions, such as fear and depression.

Self-management programmes are rather brief interventions, which may render long term effects. They enhance possibilities of collaborative partnership between patients and caregivers and should be available for OA patients in their early stages.

The current findings provide a firm foundation on which systematic expansion of selfmanagement approaches for people with osteoarthritis can be based.

\section{Implications for future research}

Meanwhile, further research along several described lines is needed. Those research efforts will enable clarification of remaining questions (like: timing and, frequency needed, and length of interventions, which may further improve the delivery of selfmanagement programmes.

With regard to the readiness-to-change model we summarized an interesting debate in which strengths and limitations of the theoretical concept were highlighted. We concluded that "readiness to change" in the OA population is important, because people can benefit from life style changes. However, artention should be focused on the 
process of change and not on the categorization of people into stages. And many research questions on the model need to be solved.

The concept of pain-related fear showed to be relevant and testable in the OA population. Since the research on pain-relared fear presented in this thesis is crosssectional with limited explanatory power, it is worthwhile to develop longitudinal analyses of TSK measurements in a group of OA patients. That will offer the opportunity of enhancing our understanding of this phenomenon of pain-related fear. With regard to treatment, one of the questions to be answered is whether graded exposure is feasible and effective in improving funcrioning in OA patients with a high level of pain-related fear. Both assessing as well as treating fear of pain has become an important topic for further research and in this regard in the field of OA much work remains to be done. 
142 samethstatsing 
SAMENVATTING

sayserswatring 143 


\section{VOORAF}

Deze samenvatting van het proefschrift "Artrose, een revalidatiegeneeskundige benadering in de huisartsgeneeskunde" is geschreven voor geïnteresseerde leken. Het onderzoek wordt in algemene Nederlandse taal uitgelegd, met vermijding van jargon en vakrerminologie. Collega-onderzoekers en behandelaars kunnen de inhoudelijke details, specifieke valktermen en methodologische gegevens vinden in de Engelstalige hoofdstukken en samenvatting (Summary).

\section{HOOFDSTUK 1 - INLEIDING}

Her hoofdonderwerp van deze dissertatie is artrose. De gevolgen voor het dagelijks functioneren van artrose staan centraal. In her eerste hoofdstuk van dit proefschrift worden de onderwerpen geïntroduceerd.

De volgende vragen komen aan de orde:

1. War zijn de belangrijkste kenmerken van artrose?

2. Wat zijn de mogelijkheden en beperkingen in de zorg voor mensen met artrose in de huisartsgeneeskunde?

3. Waarom pleiten wij voor een revalidatiegeneeskundige benadering?

4. Wat is de zin en her nut van "zelfmanagement" bij artrose?

5. Wat is een "stepped care approach" en waarom zou het nutrig kunnen zijn bij artrose?

Artrose is een veel voorkomende gewrichrsaandoening. Gewrichtspijn en stijheid zijn de kenmerkende klachten bij artrose. Artrose is een klinisch syndroom. Een syndroom is een complex van verschijnselen, die kenmerkend zijn voor een bepaalde aandoening. Bij artrose is sprake van een complex van veranderingen rond een of meerdere gewrichten mer consequenties voor functie en kwaliteit van leven. De lichamelijke veranderingen treden op in: gewrichtskraakbeen, gewrichtskapsel, bij het gewricht gelegen beenderen en in omliggende spieren. Het gewrichtskraakbeen vertoont bij artrose een verslechtering van kwaliteit in de vorm van defecten en vermindering van de dikte van de kraakbeenlaag. Op röntgenfoto's is dat te zien als versmalling van de gewrichtspleer (de ruimte in het gewricht tussen de botten). De veranderingen in de beenderen bestaan uit veranderingen in de dichrheid van het bot nabij het gewricht (in 
waktermen genaamd subchondrale sclerose: weefselverharding van het bot nabij het kraakbeen). Ook kan bij het gewricht nieuwvorming van bot optreden. Deze nieuwgevormde botstructuren hebben bij enkele gewrichten (bijvoorbeeld knieën en heupen) een kenmerkende vorm en worden osteofyten genoemd. Door de veranderingen van de gewrichtsruimten kan er ruimte ontstaan in de gewrichtskapsels met gevolgen voor de stabiliteit van de betreffende gewrichten.

Artrose komt veel voor en neemt toe met de leeftijd. Zowel de ernst van de afwijkingen neemt toe mer de leeftijd, alsook het aantal mensen met artrose. Uit gegevens, die zijn verzameld in Nederlandse huisartspraktijken, zijn schattingen gemaakt die wijzen op artrose bij 14 mensen per 1000 aan de heup en 23 per 1000 aan de knie. Aangezien de levensverwachting van de Nederlandse populatie nog steeds toeneemt, zal de proportie wan mensen met artrose deze eeuw zeker toenemen.

Artrose kan niet verholpen worden. De behandeling is gericht op het verminderen van. pijn en stijtheid en het verbeteren van het functioneren met artrose. Uit diverse studies is gebleken, dat de kwaliteit van leven door artrose negatief wordt beïnvloed.

Aangezien er geen behandelingen beschikbaar zijn, die alle verschijnselen van artrose kunnen verhelpen, ziet een persoon met artrose zich gesteld voor de opgave de consequenties van pijn, stijtheid en verlies aan functie op te vangen, evenals de consequenties van behandelingen (bijvoorbeeld medicatie, oefeningen, operaties, veranderingen in leefstijl, en dergelijke). Een aantal verschijnselen bij artrose en ook sommige van de voorgeschreven behandelingen beïnvloeden dagelijkse activiteiten zoals werk, gezinsleven en vrijetijdsbesteding aanzienlijk. Mensen met artrose hebben dus niet alleen-zoals wel vaker het geval is bij chronische aandoeningen-te maken met weranderde lichaamsfuncties, maar ook met een veranderd activiteitenpatroon. Een revalidatiegeneeskundige benadering kan hierbij helpen. Zelfmanagement kan daar onderdeel van uitmaken.

Voor toepassing bij gewrichtsaandoeningen heeft Kate Lorig een zelfmanagement programma ontwikkeld en uitgebreid toegepast en onderzocht. Zelfmanagement gaat uir van partnerschap tussen patiënten en gezondheidszorg professionals. De opvattingen en problemen van mensen met chronische aandoeningen staan centraal. 
Van de professionals wordt gevraagd welke kennis voor patiënten nodig is en welke gedragsverandering in verband met hun aandoening. Deze inzichten worden dan gecombineerd tot de inhoud van een zelfmanagementprogramma. Deze programma's zijn bedoeld om het vertrouwen en vermogen van patiënten te vergroten om effectief het leven te leiden dat ze nastreven met de chronische aandoening.

Zelfmanagementprogramma's zijn gebaseerd op inzichten over "self-efficacy". Lorig vat het bondig samen: "In simpele woorden stelt deze theorie, dat mensen, wanneer ze denken dat ze iets kunnen, de kans groter wordt dat ze het voor elkaar krijgen."

Een "stepped care approach" (waarvoor nog geen gangbare Nederlandse vertaling bestaat) is een raamwerk voor de organisatie van hulpverlening gebaseerd op de aard en omvang van behoeften van de pariënt. Het is een beproefde strategie bij andere gezondheidszorgproblemen, zoals hoge bloeddruk, verhoogd gehalte aan cholesterol in het bloed, nicotineverslaving, en lage rugpijn. In een "stepped care approach" wordr gestart met de minst intensieve en vaak minst kostbare behandelvorm in een eerste fase om gezondheidswinst te behalen. Indien nodig wordt overgestapt ("stepped up") naar een intensievere behandeling, meestal complexer en ook kostbaarder. Het voordeel van deze "stepped care approach" is, dat behandelvormen goed aansluiten bij de noden van een individuele pariënt, terwijl onnodige en dure behandelingen veel mensen bespaard worden.

In dit onderzoek zijn de volgende vragen aan de orde geweest:

1. Welke zijn de effecten van een zelfmanagementprogramma op pijn, beperkingen in het functioneren, activiteiten alsook zelfstandigheid bij mensen van middelbare leefrijd met artrose?

2. Welke individuele karakteristieken van de patiënten bepalen de effectiviteit van het aanleren van zelfmanagement bij artrosepatiënten van middelbare leeftijd in een eerstelijnsgezondheidszorgsetting?

3. Wat zijn de effecten van zelfmanagement op gebruik van gezondheidszorgvoorzieningen en indirecte kosten in deze groep artrosepatiënten? 
In het tweede hoofdstuk wordt verslag gedaan van een studie naar de effecten van cen zelfmanagement programma. De diagnose werd gesteld door de huisarts en de behandelingen werden verzorgd door vrijgevestigde fysiotherapeuten.

Het doel van deze studie was de werkzaamheid te bepalen van een zelfmanagement programma in de eerstelijnsgezondheidszorg. De studieopzet was een experiment, waarbij twee behandelvormen met elkar werden vergeleken. De zelfmanagementbehandeling werd vergeleken met gebruikelijke zorg. Het lot bepaalde welke behandeling een deelnemer kreeg. Na de behandeling werden de groepen gedurende 21 maanden gevolgd, waarbij metingen werden verricht met behulp van vragenlijsten en door een fysiotherapeut, die niet op de hoogte was van de behandeling die een persoon had gehad. Aan her onderzoek namen 273 personen deel; hun leefrijd was tussen 40 en 60 jaar. Gelet werd op de veranderingen in pijn en fysiek functioneren. De resultaten tussen 3 en 21 maanden na behandeling werden met elkaar vergeleken. Daaruit bleek, dat de verschillen tussen de twee behandelgroepen bij 21 maanden groter waren dan bij 3 maanden, ten gunste van de zelfmanagement groep. De verschillen in pijn aan de knie en functioneren (gemeten met een vragenlijst: WOMAC) waren statistisch significant. Dat wil zeggen dat de verschillen niet aan toeval kunnen worden toegeschreven, maar hoogstwaarschijnlijk samenhangen met het verschil in behandeling.

\section{Conclusies}

Het zelfmanagement programma heeft een positieve invloed uitgeoefend op de kniepijn en het door de patiënt gerapporteerde niveau van functioneren in deze groep mensen met artrose. Opmerkelijk is de toename van het verschil tussen de groepen op lange termijn ten gunste van de zelfmanagementgroep. 
Het derde hoofdstuk sluit nauw aan bij het tweede en gaat over de vraag of de toepassing van een zelfmanagement programma kosten bespaart. Daartoe werden gegevens verzameld over kosten gemaakt door alle deelnemers aan deze studie.

Ook voor deze vraagstelling was de studieopzet een experimentele waarbij de zelfmanagementbehandeling werd vergeleken met de controlegroep. Dezelfde groep mensen was in de studie betrokken en de analyses werden gecombineerd met verzamelde gegevens over kosten. Kostendagboeken werden bijgehouden gedurende periodes van een maand bij 3, 9, 15 en 21 maanden na de behandelfase. De behandeleffecten waren beter in de zelfmanagementgroep en de kosten verschilden niet tussen beide groepen.

\section{Conclusies}

Het zelfmanagement programma had positieve invloed op de pijn aan de knieën en het functionele niveau zoals dat door de persoon met artrose zelf werd beschreven. De investering van ongeveer 250 euro per persoon was de kostprijs voor de verbetering in deze groep artrosepatiënten tussen 40 en 60 jaar.

\section{HOOFDSTUK 4 - VERANDERINGSBEREIDHEID}

Veranderingsbereidheid staat centraal in hoofdstuk 4. Omdat zelfmanagement alleen effecten kan sorteren, wanneer iemand gedrag verandert, is bereidheid tot gedragsverandering interessant. Recent is een theoretisch model over gedragsverandering in de belangstelling gekomen. In deze theorie worden fasen van veranderingbereidheid beschreven.

Het doel van deze deelstudie was om een vragenlijst te ontwikkelen om de bereidheid tot gedragsverandering bij mensen met artrose te bepalen. Op basis van het theoretische model zijn vragen ontwikkeld en voorgelegd aan alle deelnemers van de studie. Vervolgens is de vragenlijst nader onderzocht. De vragenlijst werd voorgelegd aan de 273 deelnemers aan ons onderzoek. Met behulp van een statistische procedure (een zogenaamde factoranalyse) is onderzocht of de aparte vragen in de lijst met elkaar 
samenhangen op een manier die overeenkomt met de veranderingsfasen zoals beschreven wordt in de theorie. De resultaten waren wat dat betreft bemoedigend. Echter: de factoranalyse is een statistische techniek, die niet aantoont dat de factoren ook overeenkomen met de werkelijkheid. Om dat aan te kunnen tonen is nader onderzoek nodig.

\section{Conclusies}

De ontwikkelde vragenlijst over veranderingsbereidheid bij mensen met artrose laat enkele gunstige "testeigenschappen" zien. Deze bevindingen kunnen aanleiding zijn tot verder onderzoek. De ontwikkelde vragenlijst is interessant voor researchdoeleinden, maar nog niet aan te bevelen voor toepassing in de klinische praktijk.

\section{HOOFDSTUK 5 - INVLOED VAN VREES EN VERMIJOING}

Het dagelijks functioneren van mensen met artrose wordt niet alleen beïnvloed door de ernst van gewrichtspijn en de stijfheid. Uit recent onderzoek bij mensen met langdurige pijnklachten was gebleken, dat vrees voor pijn en letsel kan leiden tor vermijding van activiteiten, wat vervolgens weer kan leiden tot verdere achteruitgang in het functioneren.

In hoofdstuk 5 worden twee studies beschreven die vrees en vermijding bij artrose onderzoeken.

De bedoeling van de onderzoeken in dic hoofdstuk was tweevoudig: (1) allereerst wilden we de testeigenschappen van een veel toegepaste vragenlijst naar vrees voor bewegen nagaan bij artrosepatiënten; (2) tevens wilden we weten of pijngerelateerde vrees van invloed is op het functioneren en in welke mate ten opzichte wan andere factoren, zoals pijn intensiteit of mate van afwijkingen op de röntgenforo's. Uit onderzoeken bij andere aandoeningen van het houdings- en bewegingsapparaat (zoals lage rugpijn en fibromyalgie) was al duidelijk geworden, dar pijngerelateerde vrees een belangrijk verschijnsel is, omdat het functioneren negatief kan beïnvloeden. Bij artrose is nog relatief weinig studie hiernaar gedaan. 
Met de in dit hoofdstuk beschreven studies zijn nieuwe gegevens aan het licht gekomen:

1. De onderzochte vragenlijst laat bij artrose dezelfde twee factoren zien als bij eerder onderzochte groepen (lage rugpijn en fibromyalgie);

2. Uit nadere analyses (zogenaamde regressieanalyses, die we hier niet nader zullen beschrijwen) is een samenhang gebleken tussen pijngerelateerde vrees en functioneren bij artrosepatiënten. Die relatie is negatief; dat wil zeggen dat het functioneren slechter is naarmate de mate van pijngerelateerde vrees hoger uitvalt.

\section{Conclusies:}

Deze bevindingen onderstrepen her belang van de bestudering van pijngerelateerde vrees bij artrosepatiënten. Behandelingen gericht op het verminderen wan pijngerelateerde vrees zijn wellicht ook zinvol bij artrose. Dit dient nader ontwikkeld en onderzocht te worden.

\section{Hoofdstuk 6 - Algemene discussie}

In het laatste hoofdstuk van dit proefschrift worden 3 algemene vragen aan de orde gesteld:

1. Wat is de betekenis van de gepresenteerde studies voor de klinische praktijk?

2. Wat zijn er voor kansen met betrekking tot de toepassing van zelfmanagement programma's?

3. Welke conclusies zijn getrokken betreffende verder te verrichten onderzoek?

Vooral de bevinding, dat de effecten op lange termijn gunstiger waren en de verschillen tussen de zelfmanagementgroep en de controle groep toenamen, is opmerkelijk. Dit pleit voor een bredere toepassing en vergroting van de beschikbaarheid van zelfmanagement programma's. De specifieke kenmerken van een zelfmanagementbenadering worden daarom in het laatste hoofdstuk nog eens uitgewerkt.

Toepassing van zelfmanagement programma's vereist wel nadere scholing van de hulpverleners, die de programma's aanbieden. Opleidingen voor therapeuten zouden deze inzichten kunnen verwerken in scholingsprogramma's. Op dit gebied is nog veel winst te behalen aangezien het om een vernieuwing gaat. 
152 appesudix a 


\section{APPENDIX A:}

The European Definition of General Practice/ Family MEdicine

(WWW.MEDISIN.NTNU.NO/WONCA) 
The European Society of General Practice/Family Medicine has published in 2002 a statement entitled "The European Definition of General Practitioner/Family Physician". The statement was published with the support and co-operation of the WHO Europe Office, Barcelona, Spain.

This consensus statement defines both the discipline of general practice / family medicine, and the professional tasks. It also describes the core competencies required of general practitioners. It delineates the essential elements of the academic discipline and prowides an authoritative view on what family doctors in Europe should be providing in the way of services to patients, in order that patient care is of the highest quality and also cost effecrive. From the definitions within this paper the agendas for education, research, and quality assurance can be derived, to ensure that family medicine will develop to meet the health care needs of the population in the $21 \mathrm{st}$ century.

General practice / family medicine is an academic and scientific discipline, with its own educational content, research, evidence base and clinical activity, and a clinical specialty oriented to primary care.

\section{The characteristics of the discipline of general practice/family medicine are that it:}

a. is normally the point of first medical contact within the health care system, providing open and unlimited access ro its users, dealing with all healch problems regardless of age, sex, or any other characteristic of the person concerned.

b. makes efficient use of health care resources through coordinating care, working with other professionals in the primary care setting, and by managing the interface with other specialties taking an advocacy role for the patient when needed.

c. develops a person-centered approach, orientated to the individual, his/her family, and their community.

d. has a unique consultation process, which establishes a relationship over time, through effective communication between doctor and patient. 
e. is responsible for the provision of longitudinal continuity of care as determined by the needs of the patient.

f. has a specific decision making process determined by the prevalence and incidence of illness in the community.

g. manages simultaneously both acute and chronic health problems of individual parients.

h. manages illness which presents in an undifferentiated way at an early stage in its development, which may require urgent intervention.

i. promotes health and well being both by appropriate and effective intervention.

j. has a specific responsibility for the health of the communiry.

k. deals with health problems in their physical, psychological, social, cultural and existential dimensions.

\section{The specialty of General Practice / Family Medicine}

General practitioners/family doctors are specialist physicians trained in the principles of the discipline. They are personal doctors, primarily responsible for the provision of comprehensive and continuing care to every individual seeking medical care irrespective of age, sex and illness. They care for individuals in the context of their family, their community, and their culture, always respecting the autonomy of their patients. They recognize they will also have a professional responsibility to their communicy. In negotiating management plans with their pacients they integrate physical, psychological, social, cultural and existential factors, wrilising the knowledge and trust engendered by repeated contacts. General pracritioners/family physicians exercise their professional role by promoting health, preventing disease and providing cure, care, or palliation. This is done either directly or through the services of others according to health needs and the resources available within the community they serve, assisting patients where necessary in accessing these services. They must take the 
responsibility for developing and maintaining their skills, personal balance and values as a basis for effective and safe patient care.

\section{The Core Competencies of the General Practitioner / Family Doctor}

A definition of the discipline of general practice/family medicine and of the specialist family doctor must lead directly the core comperencies of the general practitioner/family doctor. Core means essential to the discipline, irrespective of the health care system in which they are applied.

I The eleven central characteristics that define the discipline relate to eleven abilities that every specialist family doctor should master. They can be clustered into six core competencies (with reference to the characteristics in 1.).

1. Primary care management $(\mathrm{a}, \mathrm{b})$

2. Person-centered care $(c, d, e)$

3. Specific problem solving skills $(f, g)$

4. Comprehensive approach (h, i)

5. Community orientation (j)

6. Holistic modeling ( $\mathrm{k})$

II To practice the specialty the competent practitioner implements these competencies in three areas:

1. clinical tasks,

2. communication with patients and

3. management of the practice.

III As a person-centered scientific discipline, three background features should be considered as fundamental:

1. Contextual: using the context of the person, the family, the community and their culture

2. Attitudinal: based on the doctor's professional capabilities, values and ethics

3. Scientific: adopting a critical and research based approach to practice and maintaining this through continuing learning and quality improvement. 
The interrelation of core competencies, implementation areas and fundamental features, characterizes the discipline and underlines the complexity of the specialty.

It is this complex interrelationship of the core competencies that should guide and be reflected in the development of related agenda's for teaching, research and quality improvement. 


\section{DANKWOORD}


Een proefschrift schrijven lukt niet zonder de medewerking van veel mensen. Aangezien ik veel mensen te bedanken heb, verontschuldig me bij voorbaat, als ik ondanks alle aandacht en zorgvuldigheid toch iemand tekort doe. (Ik had verwachr, dat het schrijven van een dankwoord na alle onderzoeksinspanningen "een fluitje van een cent" zou zijn, maar dat pakte anders uit. Waarschijnlijk heeft het ermee te maken, dat ik me realiseer, dat het dankwoord een van de meest gelezen delen wan een proefschrift is.)

Ik zou cen eenvoudig dankwoord willen schrijven en geen autobiografische samenvarting van de onderzoeksperiode. Maar ik realiseer me de onmogelijkheid daarvan en herinner me her volgende citaat van Vladimir Nabokov:

"Zelfs het grofste curriculum vitae kradit en klappert met zijn vleugels op een manier die de ondertekenaar typeert. Ik betwijfel zelfs of iemand zijn telefoonnummer kan opschrijuen zonder iets van zichzelf te verraden."

Voor dit onderzoek ben ik vooral schatplichtig aan Karin Aretz en Marion Drietelaar. Ik heb de samenwerking met hen buitengewoon gewaardeerd.

Marion, jij hebt op voortvarende en elegante wijze veel van de organisatorische aspecten van de trial verzorgd.

Karin, jij hebt me in de beginfase enorm geholpen met het inrichten van de dataset. Na afronding van de dataverzameling kon ik steeds bij je terechr voor analyseklussen. Hopelijk kan ik in de naaste toekomst weer bij je terecht, want de dataset biedt nog veel mogelijkheden voor verder onderzoek.

Verder will ik mijn dankwoord gieten in de vorm van een aftiteling zoals we die kennen in de wereld van de cinema: 


\title{
Promotores \\ Onno van Schayck \\ Rob de Bie \\ Chris van Weel
}

\author{
Inboudelijke ondersteuning \\ Marijke Hopman-Rock \\ Johan Vlaeyen \\ Marielle Goossens \\ Geert-Jan Dinant \\ Arie Dijkstra \\ Carolien Bastiaenen \\ Hubert Schouten \\ Jeffrey Roelofs

\section{Logistieke ondersteuning}

Afdeling huisartsgeneeskunde, Universiteit Maastricht

Linelle Deunk (NMP Nijmegen)

Secretariaat (Hoensbroeck Revalidatiecentrum):

Ine Spinder, Lia van der Pijl, Marijke Scheijen, Coby Scheijen,

Marjo Haagmans en Marlo Cnoops

Pieter Wolcers (werving fysiotherapeuten) 


\section{Met medewerking van}

De 273 deelnemende patiënten.

Hans Rasker, Erik Taal en Marijke Hopman-Rock (inbreng van kennis over zelfmanagement).

De behandelende fysiotherapeuten:

Andries Haan, Olwen Hurkens, Inge Janssen, John Keydener, Jos Kremer, Harry Nijssen, Janine Rosenmöller en Joyce Zuidam.

De fysiotherapeuten, die de nametingen verrichtten: Charlotte en Tom Schambergen, Michel Spanjaard, Hub Dautzenberg en Rex Schreijen.

\section{Huisartsen van:}

RNH (RegistratieNet Huisartsgeneeskunde, UM)

NMP (Nijmeegs Monitoring Project)

CEL (Coördinatie Eerstelijnspraktijken).

Rene Weijers, die de vele röntgenfoto's beschreef en beoordeelde.

Ingrid Schreibers voor de verzorging van de lay-out van het proefschrift.

Joop en Beernd Noordkamp voor de illustratie (kunst met eern hoofdletrer K!). 


\section{Monele onderstewning}

Team Reuma en Pijn van Hoensbroeck Revalidatiecentrum:

Yvonne Flinsenberg, Albere Köke, Amy Heijnen, Ank Kole, Annelies Willen, Annie Janssen, Carla Hoogerworst, Carla Palmen, Claar van den Bosch, Coby Scheijen, Corry Westerhof, Gera Langeslag, Henk Prins, Henriette Byrnes,

Herman Mulder, Hugo van Eek, Ien Ahlers, Monique Hodiamont, Marc op den Camp, Marianne Wolfs, Marie-Joze Meessen, Mario Geilen, Nienke Verkerk, Noël Dortu, Peter Beckers, Peter Kastrop, Petra Smeets,

Ria van de Laar, Rob Coenen, Rob Pelr, Simonetta van Ool, Sonja Janssen en Tonnie Dohmen.

De collega-revalidatieartsen in Hoensbroeck Revalidatiecentrum: Joep Cluitmans, Wip Bakx, Kees Pons, Helma Janssen-Bongers, Bea Hemmen, Anita Tinga, Teun Derks en Martine Moennekens.

De medeopleiders in de opleidingscircuits Limburg en HET (= Hoensbroek-Eindhoven-Tilburg):

Marion Geboers, Minou Hitters, Wim IJspeert, Guido Peusens, Teun Derks, Joop Ruijgrok, Ad Reekers en Evert Schouten.

De managers wan onze afdeling met wie ik de afgelopen 5 jaar beb samengewerkt: Harry Jurjens ( $\dagger$ ), Paul Kurvers, Rene Rademacher en Roger Bastiaens.

\section{Arts-assistenten-in-opleiding tot rewalidatiearts (periode 1996-2005)}

Geerie Winnubst, Julliette Nijlant, Anita Tinga, Onno Bakker, Victor Voerman, Joop Ruijgrok, Bea Hemmen, Jeanine Verbunt, Wim Wetzelaer, Peter Muitjens,

Fred van der Meer, Angeliek Zwinkels, Helma Bongers, Gery Bos, Danielle de Groot-Driessen, Mirto Xanthouli, Monique Müschenich, Kyle Bennett, Judith Reijnen, Nicole Zusterzeel, Maurice Hagedoren, Erik de Klerk, Willem Oudegeest, Roelof Pol, Helma Hijdra, Nanneke van Verseveld en Veronique Moulaert. 
Arts-assistenten-niet-in-opleiding die voor kortere of langere tijd op onze afdeling bebben gewerkt om ervoor te zorgen dat de patiëntenzarg voort kon gaan

Bart Broersma, Slavica Basic, Pieter Struyf, Katrin van Herpe, An Rens, Denise Tillie en Nicole Zusterzeet.

\author{
Bovendien dank aan: \\ Nationaal Reumafonds \\ De successievelijke directeuren van Stichting Revalidatie Limburg: \\ Sjef Peeters \\ Jan Albers \\ Thérèse-Sophie de Wit
}

De directeuren van Hoensbroeck Revalidatiecentrum:

Peter Peters

Joep Cluitmans

Dick van Buren (a.i.)

Mijn opleider:

Kees Pons

Aja Bakker-Boerrigter, Peter Bakker en Henk Goei The, die me de weg wezen naar dit prachtige vak, revalidariegeneeskunde.

Leden van de corona

Joop en Scheltus (vrienden en paranimfen)

Familie en vrienden 
Het warme nest waar ik thuis kom en dat alles de moeite waard maakt:

Mijn lieve ouders, die alles in gang hebben gezet, mij liefdevol de weg hebben gewezen en nu nog steeds hun best doen mij te volgen in de vele activiteiten.

Mijn schoonmoeder, die dit feest helaas niet meer van nabij meemaakt $(\uparrow 2000)$.

Mijn schoonvader, die me gevraagd en ongevraagd adviseert (met veel humor en intelligentie).

Gijs, Jeroen en Bart; onze zonen, die nu 16, 14 en 8 jaar oud zijn. Ik geloof dar ik van die drie jongens nog steeds het allermeeste leer. De zorg voor jullie vind ik het belangrijkste van alles wat ik doe. Het is heerlijk om te zien hoe jullie her maken.

\section{En Carolien?}

Dat is mijn geheim... 
166 asmricultem wirate 


\section{CURRICULUM VITAE}

1960

$1972-1978$

$1978-1984$

$1985-1986$

$1986-1987$

$1987-1991$

$1991-1993$

1993 - heden

$1997-2003$

2003 - heden

1999 - heden

2004 - heden

1987
Geboren te Heer-Maastricht

Gymnasium B, Henric van Veldeke College te Mastricht

Studie Geneeskunde

Universiteit Maastricht:

Arts bij Paulus Stichting

Inrichting voor Verstandelijk Gehandicapten te Sittard

Arts op afdeling rraumatisch hersenletsel

Hoensbroeck Revalidatiecentrum

Opleiding tor Revalidariearts

Stichring Revalidatie Limburg

Revalidatiearts Bio

Kinderrevalidariecentrum en Groot Klimmendaal te Arnhem

Revalidatiearts afdeling Pijn en Reuma

Hoensbroeck Revalidatiecentrum

Plaatsvervangend Opleider Revalidatiegeneeskunde

Opleider Revalidatiegeneestkunde

Lid Wetenschappelijke Commissie VRA (2001 - 2004 sectetaris)

Lid Concilium VRA (sinds 2005 secretaris)

Getrouwd met Carolien Bastiaenen

Vader van Gijs, Jeroen en Bart 


\section{PUBLICATIONS}


Heuts P.H.T.G., de Bie R.A., Drietelaar M., Aretz K., Hopman-Rock M., Bastiaenen C.H.G., Metsemakers J.F.M., van Weel C., van Schayck C.P. Self-management in osteoarthritis of hip or knee: a randomized clinical trial in a primary health care serting. Journal of Rheumatology, 2005;32(3):543-9.

Heuts P.H.T.G., de Bie R.A., Dijkstra A., Aretz K., Vlaeyen J.W.S., Schouten H.J.A., Hopman-Rock M., van Weel C., van Schayck C.P. Assessment of readiness to change in patients with osteoarthritis. Development and application of a new questionnaire. Clinical Rehabilitation 2005;19(3):290-9.

Verbunt J.A., Seelen H.A.M., Vlaeyen J.W.S., Bousema E.J., van der Heijden G.J., Heuts P.H.T.G., Knottnerus J.A.. Pain-related factors contributing to muscle inhibition in parients with chronic low back pain: an experimental investigation based on superimposed electrical stimulation. Clinical Journal of Pain 2005;21(3):232-40.

$2004:$

Heuts P.H.T.G., Vlaeyen J.W.S., Roelofs J., de Bie R.A., Aretz K., van Weel C., van Schayck C.P.. Pain-related fear and daily functioning in patients with osteoarthritis. PAIN 2004; 110:228-235.

Heuts P.H.T.G. Evaluatie van pijnrevalidatie. Revalidata $2004 ; 119: 13-19$.

2003:

Verbunt J.A., Seelen H.A.M., Vlaeyen J.W.S., van der Heijden G.J.M.G., Heuts P.H.T.G., Pons C., Knottnerus J.A.. Disuse and deconditioning in chronic low back pain: concepts and hypotheses on contributing mechanisms. Review. European Journal of Pain 2003; 7:9-21. 
Van den Hout J.H.C., Vlaeyen J.W.S., Heuts P.H.T.G., Zijlema J.H.L., Wijnen J.A.G.. Secondary prevention of work-related disability in non-specific low back pain: Does problem-solving therapy help? A randomized clinical trial. Clinical Journal of Pain 2003;19:87-96.

\section{2:}

Vlaeyen J.W.S., de Jong J., Geilen M., Heuts P.H.T.G., van Breukelen G.. The treatment of fear of movement/(re)injury in chronic low back pain: exposure in vivo versus graded activity. A replicated single-case experimental cross-over design. Clinical Journal of Pain 2002; 18: 251-261.

Vlaeyen ].W.S., de Jong J.R., Heuts P.H.T.G., Crombez G.. Graded exposure in vivo for pain-related fear: The case of chronic musculoskeletal pain. In: Rice, Warfield, Justins \& Eccleston (Eds.). Clinical Pain Management. (2002)

De Jong J.R., Vlaeyen J.W.S., Geilen M., Heuts P.H.T.G. en Crombez G. Graduele exposure in vivo bij pijngerelateerde vrees. Nederlands Tijdschrift voor Fysiotherapie. 2002

\section{$2001:$}

Heuts P.H.T.G.. Revalidatie en chronische pijn. De stand van zaken anno 2001. In: Matti et al (Eds.). Pijn Informatorium (2001), PB0050, 1-15.

Van den Hout J.H.C., Vlaeyen J.W.S., Heuts P.H.T.G., Sillen W.J.T., Willen J.E.H.L.. Functional disability in non-specific low back pain: the role of pain-related fear and problem-solving skills. International Journal of Behavioral Medicine, 2001;8(2):134148. 
Vlaeyen J.W.S., de Jong J., Geilen M., Heuts P.H.T.G., van Breukelen G. Graded exposure in vivo in the treatment of pain-related fear. A replicated single-case experimental design in four patients with chronic low back pain. Behaviour Research and Therapy 2001;39:151-166.

Vlaeyen J.W.S. en Heuts P.H.T.G. Yellow flags als wegwijzers in de behandeling. Preventie van chronische beperkingen wegens aspecifieke rugpijn: mogelijkheden en hindernissen. In: Het medisch jaar 2001. Blz: 89-97. Onder redactie van: van Es J.C., Keeman J.N., de Leeuw P.W., Zitman F.G.. Houten/Diegem; Bohn, Stafleu van Loghum. ISBN: $903133684 \mathrm{X}$

\section{0:}

Heuts P.H.T.G.. Evidence Based Rehabilitation Medicine: van intuïtie via kritische reflectie tor prospectief onderzoek. Een voorbeeld bij artrose-onderzoek. Revalidata 2000; 96:10-15.

Heuts P.H.T.G., namens WPN (Werkgroep Pijnrevalidatie Nederland). Dysfunctie en behandeling bij chronische pijn. WPN-visie. Revalidata 2000; 93:47-49.

Heuts P.H.T.G., Vlaeyen J.W.S.. Richtlijnen en behandelingsstrategieën. In: Vlaeyen J.W.S., Heuts P.H.T.G., editors. Gedragsgeoriënteerde behandelingsstrategieën bij rugpijn. Houten/Diegem: Bohn Stafleu van Loghum; 2000. ISBN: 9031332097

Heuts P.H.T.G., Warmerdam C., Winter F. Pijnrevalidatie: een interdisciplinaire behandeling. In: Kleef Mv, Weber W., Winter F., Zuurmond W., editors. Handboek Pijnbestrijding. Leusden: De Tijdstroom; 2000. ISBN: 9058980073

Heurs P.H.T.G. Boekbespreking van: Hip pain in general practice: Exploration and Classification (dissertatie van dr. S.M.A. Bierma-Zeinstra). Nederlands Tijdschrift voor Fysiotherapie 2000, 2, pag 52 .

Heuts P.H.T.G.. Referaar: osteopathie voor rugpijn. Nederlands Tijdschrift voor Pijn en Pijnbestrijding 2000;1:18. 
De Jong J., Vlaeyen J.W.S., Geilen M. en Heuts P.H.T.G.. Graded exposure in vivo bij vrees voor bewegen/(hernieuwd) letsel. Een single case experiment bij een patient met chronische lage rugpijn. Dth 2000;20:143-161.

Vlaeyen J.W.S., Heuts P.H.T.G. (2000) Gedragsgeoriënteerde behandelingsstrategiën bij lage rugpijn. Cure \& Care; Houten/Diegem: Bohn Stafleu van Loghum;2000. ISBN: 9031332097

Vlaeyen, J.W.S., Heuts, P.H.T.G., Waddell G. (2000) Biopsychosociaal model van rugpijn. In: Vlaeyen J.W.S., Heuts P.H.T.G. Gedragsgeörienteerde behandelingsstrategieèn bij rugpijn. Cure \& Care; Houten/Diegem: Bohn Stafleu van Loghum; 2000. ISBN: 9031332097

\section{9:}

Heuts P.H.T.G. Gedragsgeoriënteerde revalidatie bij chronische pijn: resultaatmering en kwaliteitszorg. Revalidara 1999; 87:4-12.

Heuts P.H.T.G. \& Vlaeyen J.W.S. Chronische pijnproblemen: samenwerking tussen eerstelijns-gezondheidszorg en revalidatiegeneeskunde. In: Jaarboek Fysiotherapie Kinesitherapie 1999. Redactie: J.B. den Dekker et al. Houten, 1999: Bohn, Stafleu van Loghum. ISBN: 9031326186

Crombez G., Vlaeyen J.W.S., Heuts P.H.T.G. \& Lysens R. Pain-related fear is more disabling than pain itself: evidence on the role of pain-related fear in chronic back pain disability. PAIN 1999;80:329-339.

Kole-Snijders A.M.J., Vlaeyen J.W.S., Goossens M.E.J.B., Rutten-van Mölken M.P.M.H., Heuts P.H.T.G., Breukelen van G. \& Eek van H. Chronic low-back pain: What does cognitive coping skills training add to operant behavioral treatment? Results of a randomized clinical trial. Journal of Consulting and Clinical Psychology 1999; $67(6): 931-944$. 
Köke A.J.A., Heuts P.H.T.G., Vlacyen J.W.S. \& Weber W.E.J.. Meetinstrumenten bij chronische pijn. Deel 1: Functionele status. Uitgave van Pijn Kennis Centrum, Academisch Ziekenhuis Maastricht, 1999. ISBN: 9080505412

Vlaeyen J.W.S., Teeken-Gruben N.J.G., Goossens M.E.J.B., Rutten-van Mölken M.P.M.H., Eek van H., Pelt R.A.G.B., Heuts P.H.T.G.. Cognitive-educational treatment of fibromyalgia, a randomized clinical trial. Part I. Clinical effects. Journal of Rheumatology 1999;23:1237-1245.

Vlaeyen J.W.S., van den Hout J.H.C., Kole-Snijders A.M.J., Heuts P.H.T.G.. Eine kognitiv-verhaltenstherapeutische Analyse chronischer muskuloskeletaler Schmerzen. Manuelle Therapie 1999;3, 1-10.

\section{8:}

Heuts P.H.T.G. en Ritzen W.J.M.. De plaats van revalidatiegeneeskunde in het Samenwerkingsprotocol Fibromyalgie Limburg. Revalidata 1998;86:12-17.

Van den Hout J.H.C., Vlaeyen J.W.S., Kole-Snijders A.M.J., Heuts P.H.T.G., Willen J.E.H.L., Sillen W.J.T.. Graded activity and problem solving therapy in sub-acure nonspecific low back pain. Physiotherapy 1998;84: 4, 167.

Vlaeyen J.W.S., Heuts P.H.T.G., Van Akkerveeken P. (1998) Rugpijn. In Passchier et al (Eds.) Psychologie van onbegrepen chronische pijn. Assen: Van Gorcum. ISBN: 90 23232356

\section{7:}

Vlaeyen J.W.S., Van den Hout J.H.C., Kole-Snijders A.M.J., Heuts P.H.T.G. (1997) Het raadsel van de chronische rugpijn. Helpt revalidatie wel of niet? In: De Jong G.A., Knops H.Th. \& Van den Berg H. (Eds.) Nieuwe mogelijkheden in revalidatie en handicap. Assen: Van Gorcum, pp.99-111. ISBN:90 23232801. 
Vlaeyen J.W.S., Nooyen-Haazen I.W.C.J., Goossens M.E.J.B., van Breukelen G., Heuts P.H.T.G., Goei The H. (1997) The role of fear in the cognitive-educational treatment of fibromyalgia. In: T.S. Jensen, J.A. Turner \& Z. Wiesenfield-Hallin (Eds.) Progress in Pain Research and Management. Vol 8. Seattle: IASP Press. ISBN: 0 931092183.

Vlaeyen J.W.S., Kole-Snijders A.M.J., Heuts P.H.T.G., van Eek H. (1997) Behavioral analysis, awoidance learning and fear of movement/(re)injury in chronic low back pain. In: Vleeming A., Mooney V., Snijders C.J., Dorman T.A. en Stoeckart R. (Eds.) Movement, stability and low back pain. The essential role of the pelvis. New York: Churchill Livingstone, pp. 435-444. ISBN 0443055742.

Vlaeyen J.W.S., Van den Hout A., Kole-Snijders A.M.J., Prins H., Heuts P.H.T.G.. Gedragsgeorienteerde revalidarie bij lage rugpijn. Bewegen \& Hulpverlening 1997:14:268-283.

\section{6:}

Heuts P.H.T.G., Vlaeyen J.W.S. \& Ruesink R.. Bewegingswrees bij lage rugpijn. Nederlands Tijdschrift voor Pijn en Pijnbestrijding 1996;4:45-48.

Heuts P.H.T.G.. The standard 'Low back pain' from the Dutch Family Physician Society; viewpoint from neurology. Ned Tijdschr Geneeskd. 1996 Aug 24;140(34):1743.

Ruesink R.W., Vlaeyen J.W.S., Pons C. \& Heuts P.H.T.G.. Bewegingsvrees bij aspecifieke chronische lage rugpijn. Ned Tijdschr Geneeskd 1996;140:2067.

Vlaeyen J.W.S., Kole-Snijders A.M.J., Crombez G. \& Heuts P.H.T.G. (1996) Vrees voor beweging/letsel, vermijding en chronische rugpijn. In: Mattie et al. (Eds.) Pijninformatorium, PB 4600, 1-19. 


\section{5:}

Heurs P.H.T.G. en W.J.T. Sillen. Rugscholing in "Hoensbroeck". In: Rugscholen in Nederland. Red.: L.N.H. Göeken. Lemma BV, Utrecht 1995. ISBN: 905189516 X

Vlaeyen J.W.S., Kole-Snijders A.M.J., Rotteveel A., Ruesink R., Heuts P.H.T.G.. The role of fear of movement/(re)injury in pain disability. Journal of Occupational Rehablilitation; 1995; 5:235-252.

Teeken-Gruben N.J.G., Vlaeyen J.W.S., Goossens M.E.J.B., Rutten-van Mölken M.P.M.H., Eek H. van, Pelt R.A.G.B. \& Heuts P.H.T.G.. Effectiviteit van een cognitief-educatief behandelingsprogramma voor patiënten met het fibromyalgie syndroom. Gedrag \& Gezondheid 1995;23:191-205. 